\title{
The Anatomy, Physiology, Functional Significance and Evolution of Specialized Hearing Organs of Gerbilline Rodents
}

DOUGLAS M. LAY

Museum of Zoology, University of Michigan, Ann Arbor, Michigan 48104

\begin{abstract}
Middle and inner ear anatomy correlates with neurophysiological responses to a wide range of sound frequencies for species of the Gerbillinae representing generalized, intermediate, and specialized anatomical conditions. Neurophysiological data were recorded from 81 specimens of 13 species representing six genera. Anatomical parameters involved in the process of hearing were correlated with the neurophysiological data to assess the effects of different degrees of anatomical specialization on hearing. The 13 species tested in this manner have graphic curves of auditory sensitivity of remarkably similar disposition over the frequencies tested and to those published for Kangaroo Rats. Ears with anatomical specializations show greater auditory
\end{abstract} sensitivity.

The natural history of the Gerbillinae, particularly the kinds of predators, degree of predation, and habitat is reviewed and utilized to interpret the significance of the degree of auditory specialization in the forms studied and to evaluate the prevailing hypothesis that these specializations enhance the ability of these rodents to survive in open desert situations by detecting and evading predators.

The middle ear anatomy of five additional genera and species was also studied. Thus, data on the entire spectrum of gerbilline middle ear morphology provide an evolutionary sequence. Certain anatomical parameters of the organ of Corti show a degree of specialization parallel to that of features of the middle ear. The morphological changes and possible functional roles of these features are considered.

A very high correlation exists for degree of specialization and aridity of habitat, thus specialization increases with increasing aridity. This increased specialization may result from more effective predation in open xeric environments. Auditory acuity for a wide range of low frequency sounds augmented by auditory specialization is hence more advantageous here. There does not appear to be selection for hearing at particular frequencies in this range. The peaks of greatest auditory sensitivity appear to correspond to the resonant frequencies of the different components of the middle ear transformer and cavity.

Rodents of the subfamily Gerbillinae, family Cricetidae have the greatest numbers of species of all mammals that inhabit the Great Palaearctic Desert. Eight genera including at least 46 species are endemic to this broad arid zone. The Dipodidae (jerboas) with 10-11 genera and about 26 species is the only other rodent family which has successfully radiated in this desert. The greatest taxonomic diversity of the Gerbillinae occurs in North Africa, while that of the Dipodidae is in Central Asia. However, both groups occur throughout the Great $\mathrm{Pa}$ laearctic Desert. These two assemblages, which represent evolutionary rodent lines divergent since the Oligocene (Wood, '65), possess a number of similar morphological features that appear to have evolved convergently as adaptations to desert habitats. The ear represents one of these adaptive complexes.

Considerable variation typifies the middle and inner ear of the living gerbillines. Desert dwelling species are specialized relative to those that inhabit the savan- 
nah. The anatomy and physiological responses of ears and the natural history of living species representing generalized, intermediate and specialized conditions were studied to: (1) provide numerical quantification of the anatomical parameters effective in producing auditory responses to sound in air; (2) correlate these anatomical parameters with physiological sensitivity to assess the effects of degree of anatomical specialization on hearing; (3) provide suggestions concerning the evolutionary sequence(s) by which specialized ears may have been derived from generalized ears in the Gerbillinae; (4) evaluate the hypotheses which have been advanced to account for the specialized auditory structures characteristic of many desert rodents.

Earlier studies of rodent ear anatomy have been primarily descriptive. Hyrtl (1845), Doran (1878), Tullberg (1899), van Kampen ('05), Bondy ('08), Cockerell et al. ('14a,b), van der Klaauw (31), Holz (31), Howell ('32), Keen and Grobbelaar ('41), Vial ('62), and Hooper ('68) have described, in varying degrees of detail, the middle ear or the auditory ossicles of a variety of rodents.

Many histologists have examined the inner ear of Rattus rattus (e.g., Iurato, '61, '62), and Cavia cobaya has played an important role in anatomical and modern neurophysiological studies of hearing (e.g., Békésy, '53a,b; Tasaki et al., '52). Studies of inner ear anatomy and/or physiology of rodent ears, other than those species commonly used by neurophysiologists, are limited to those of Legouix et al. ('54), Legouix and Wisner (55), Webster ('60), and Pye ('65).

Middle ear ossicles and/or the auditory bullae of a few species of gerbilline rodents have been described in varying degrees of detail by Cockerell et al. (14b), Turkevich (39), Keen and Grobbelaar ('41), Wassif ('46, '48, '51, '57), and Simkin ('65).

The adaptive or functional significance of hypertrophied middle ears in rodents has been considered in a number of theoretical papers: Howell (32); Heim de Balsac ('36); Zavattari ('38a,b); Petter ('53, '61, '68); Legouix and Wisner ('55); Vial ('62); Simkin ('65); Beecher ('69). Webster ('60, '62) demonstrated experimentally that the hypertrophied bullae of kangaroo rats allow them to detect low intensity sounds produced by the attack strike of owls and snakes. A very high percentage of normal kangaroo rats successfully evaded these attacks.

\section{MATERIALS AND METHODS}

\section{Measurements}

The middle ear bones, tympanum and accessory tympanum were measured with a $10 \times$ or $15 \times$ dissecting microscope fitted with an ocular micrometer with a $10 \mathrm{~mm}$ scale divided into $0.1 \mathrm{~mm}$ units. The ocular micrometer was calibrated against a stage micrometer divided into $0.01 \mathrm{~mm}$ units. Measurements were rounded to the nearest 0.1. All measurements were converted using the determined calibration.

The following measurements were taken:

Footplate of the stapes. The longest diameter and the widest diameter perpendicular to the longest diameter, generally with the stapes in place in the oval window of the cochlea. Occasionally, measurement was of the free intact stapes, the intact oval window, or silicone rubber casts. Casts produce an exact replica of the outline of the stapes footplate, but were only used when both footplate and oval window were damaged.

The malleus. The manubrial lever arm, i.e., the perpendicular from the distal tip of the manubrium to the malleoincudal axis of rotation. This axis of rotation is defined as a straight line passing between the point where the anterior process of the malleus articulates with the tympanic-mastoid fissure and the point where the short process of the incus articulates with the incudal fossa.

The neck of the malleus. The perpendicular from the free tip of the processus brevis of the manubrium to the axis of rotation.

The incus. The incudal lever arm, i.e., the perpendicular distance from the center of the lenticular process of the incus to the malleo-incudal rotational axis.

The tympanum. The longest diameter of the ellipse; the greatest diameter perpendicular to the longest axis (this runs from the superior rim of the tympanum 
to the inferior rim at an angle to the axis of the manubrium that varies slightly from species to species).

The accessory tympanum of Hyrtl. The greatest antero-posterior diameter; the dorso-ventral diameter, i.e., the greatest distance from the superior rim of the tympanic bone to the free tip of the processus brevis of the manubrium.

Cochlear measurements were taken from sections through the midmodiolar axis, but the plane varied somewhat due to slight differences in orientation, and exact point to point comparisons are impossible. Comparisons of variation along the cochlear spiral are based on approximations to the same cochlear level in the various species studied. Measurements were made at $400 \times$ using a Nikon microscope with a calibrated ocular micrometer and rotating stage.

The width of the basilar membrane was measured by the method of Fernandez (52). The greatest height of the Hensen cells was read at right angles to the apical surface of the basilar membrane. The maximum thickness of the hyaline mass was cletermined within the pars pectinata of the basilar membrane.

A casting technique was employed to determine the volume of middle ear cavities. Temporal bones were removed intact from 69 frozen or fresh specimens, two fixed specimens and three cleaned skulls. Dry bullae produce a better cast than moist bullae, therefore bullae removed from fresh, frozen, or fixed specimens were first allowed to air dry at room temperature for 30 minutes to several hours. Cavities were cast in RTV-11, a silicone rubber compound (General Electric Company, Silicone Products Department, Waterford, New York) which is a low viscosity, readily pourable liquid, that after addition of Thermolite-12 curing catalyst, forms a resilient, flexible silicone rubber. This compound plus catalyst was introduced into the external auditory canal against the medially limiting intact tympanic membrane. After the external cast had hardened, the middle ear cavity was force filled by means of a needleless hypodermic syringe placed against a hole drilled through the bullar wall, usually in one of the mastoid chambers. To promote complete filling, pinpoint holes were drilled through the bullar wall at a series of points where internal bony baffles formed blind pockets that tended to trap air.

After the medium had been cured the bone of the bullae was broken away from the cast with a pair of fine tipped forceps under a dissecting microscope. Vacuities detected during this process, were filled while the bullar walls still remained intact. Hardened RTV-11 has a specific gravity of 1.18 (General Electric Technical Data book S-3C). The volume of each cast was determined from its weight. Casts were weighed on a Sartorius electronic scale accurate to 0.001 grams. Bullar volume and tympanum area were determined for 74 adult specimens representing 17 species of nine genera.

The tympanum of the species studied is elliptical, although in a few cases it approaches circularity. The following formula was used to calculate tympanum area, considered as a right elliptical cone:

$$
\pi \mathbf{r} \sqrt{r^{2}+h^{2}} \quad \text { where } \quad r=\sqrt{\frac{a^{2}+b^{2}}{2}}
$$

where $a$ and $b$ are the semiaxes of the ellipse. Wever and Lawrence (54) calculated that the surface area of a human tympanic membrane with diameters of $9.2 \mathrm{~mm}$ and $8.5 \mathrm{~mm}$ and an umbo deflection of $2 \mathrm{~mm}$ is $69 \mathrm{~mm}^{2}$, but did not provide their formula. Inserting these same values into the above formula, I obtained a value of $67.6 \mathrm{~mm}^{2}$, which is $2 \%$ smaller than their value. This difference seems almost inconsequential for the purposes of comparison. The stapedial footplate was measured in the cochlea of these specimens after the silicone cast was removed from the bulla.

Cochlear potentials were recorded and plotted graphically in the standard manner (cf. Wever and Lawrence, '54). These curves indicated that the limit of linearity of the response was reached at approximately $90 \mathrm{db}$ (re. 0.0002 dynes $/ \mathrm{cm}^{2}$ ) for all frequencies and species tested. The degree of the response at $90 \mathrm{db}$ was selected arbitrarily for each of the frequencies recorded and these values were plotted to obtain a curve of overall sensitivity for each species. These data are plotted in figures 10-13. An intensity of $90 \mathrm{db}$ constitutes a very powerful sound and it might be argued that sounds of such 
intensity should not be employed in a study of animals that are apparently undergoing selection for hearing very weak sounds. Because of the linearity of the response up to approximately $90 \mathrm{db}$ (re. 0.0002 dynes $/ \mathrm{cm}^{2}$ ), the use of the $90 \mathrm{db}$ response should not matter because any intensity between 0 and $90 \mathrm{db}$ should produce a curve of very similar disposition to that of $90 \mathrm{db}$ over the frequencies tested. In general, the degree of variation in the cochlear potential response among different specimens of all the species studied was large.

Sound stimuli for measuring cochlear potentials, $\mathrm{CP},(=$ cochlear microphonics $)$ were pure tones generated by a HewlettPackard Model 302 oscillator. The frequencies used varied from $32 \mathrm{~Hz}$ to 16 $\mathrm{KHz}$ in octaves. The $\mathrm{CP}$ responses to the following frequencies were also recorded: $1.2 ; 1.4 ; 1.6 ; 1.8 ; 2.2 ; 2.4 ; 2.6 ; 2.8 ; 3$; $3.5 ; 4.5 ; 10 \mathrm{KHz}$. Stimulus intensity varied from $28.5 \mathrm{db}$ to $123 \mathrm{db}$ SPL. CP amplitudes were measured directly on the oscilloscope and expressed in $\mu \mathrm{V}$ peak to peak. The data obtained for each frequency were plotted on semilog graph paper with intensity in decibels $(\mathrm{db})$ on the abcissa and microvolts $(\mu \mathrm{V})$ on the ordinate. From these graphs the responses at $90 \mathrm{db}$ for all frequencies were determined and graphed separately. Responses at $90 \mathrm{db}$ were selected for comparison, for this point was near the upper limit of the linear response for all frequencies tested.

\section{Histology}

Several specimens of each species studied were sacrificed at the conclusion of auditory tests by perfusion with 300-350 $\mathrm{cm}^{3}$ Heidenhain's Susa fixative. Prior to fixation each animal's circulatory system was flushed with $30-35 \mathrm{~cm}^{3}$ of physiological saline. After perfusion the temporal bones were removed and left in the fixative for 48 hours. Specimens were decalcified with $5 \%$ trichloroacetic acid changed daily. Subsequently each specimen was neutralized in $5 \%$ sodium sulfate solution for 24 hours and then washed in distilled water for 24 hours, dehydrated in graded alcohols and imbedded in $12 \%$ celloidin. Serial sections were cut at $20 \mu$ in the midmodiolar plane and stored in $80 \%$ alcohol until staining with hematoxylin and eosin, dehydration and mounting. Every tenth section of each specimen was stained except for selected specimens of each species in which every second section was stained.

\section{Specimens studied}

The origin, sex, age, details of testing or anatomical utilization, and museum or field number of each specimen is listed in Lay ('68) available from the University of Chicago Library, Chicago, Illinois 60637.

Neurophysiological tests were performed on 45 wild caught, $27 \mathrm{~F}_{1}$ progeny of wild caught stock and seven laboratory stock Meriones unguiculatus. Species with sample sizes were: Tatera indica (5); Gerbillus pyramidum (5); Gerbillus gerbillus (1); Sekeetamys calurus (2); Psammomys obesus (3); Meriones hurrianae (5); M. persicus (6); $M$. tristrami (4); M. vinogradovi (5); M. shawi (15); M. crassus (13); M. unguiculatus (7); M. libycus (7); Pachyuromys duprasi (1). Both ears were tested in 41 specimens while only one was tested in the remaining 38 .

A total of 22 of the specimens studied neurophysiologically were studied histologically. Single specimens were sectioned for all species but $P$. obesus (3), $M$. vinogradovi (3), M. shawi (2), M. crassus (3), and $M$. unguiculatus (2).

The malleus and incus were extracted and measured from wild caught specimens of: Taterillus congicus (1); Tatera indica (8); Gerbillus pyramidum (12); Sekeetamys calurus (6); Psammomys obesus (19); Rhombomys opimus (5); Meriones hurrianae (6); M. persicus (11); M. tristrami (11); M. vinogradovi (7); $M$. shawi (8); M. crassus (17); M. unguiculatus (8); M. libycus (11); Desmodillus auricularis (8).

Volume of the bulla and its component chambers and surface areas of the tympanum and stapedial footplate were determined for: Taterillus congicus (1); Tatera indica (2); Gerbillus pyramidum (3); Sekeetamys calurus (2); Psammomys obesus (10); Rhombomys opimus (2); Meriones hurrianae (8); $M$. persicus (4); $M$. tristrami (4); M. vinogradovi (2); $M$. shawi (10); M. crassus (9); M. unguicu- 


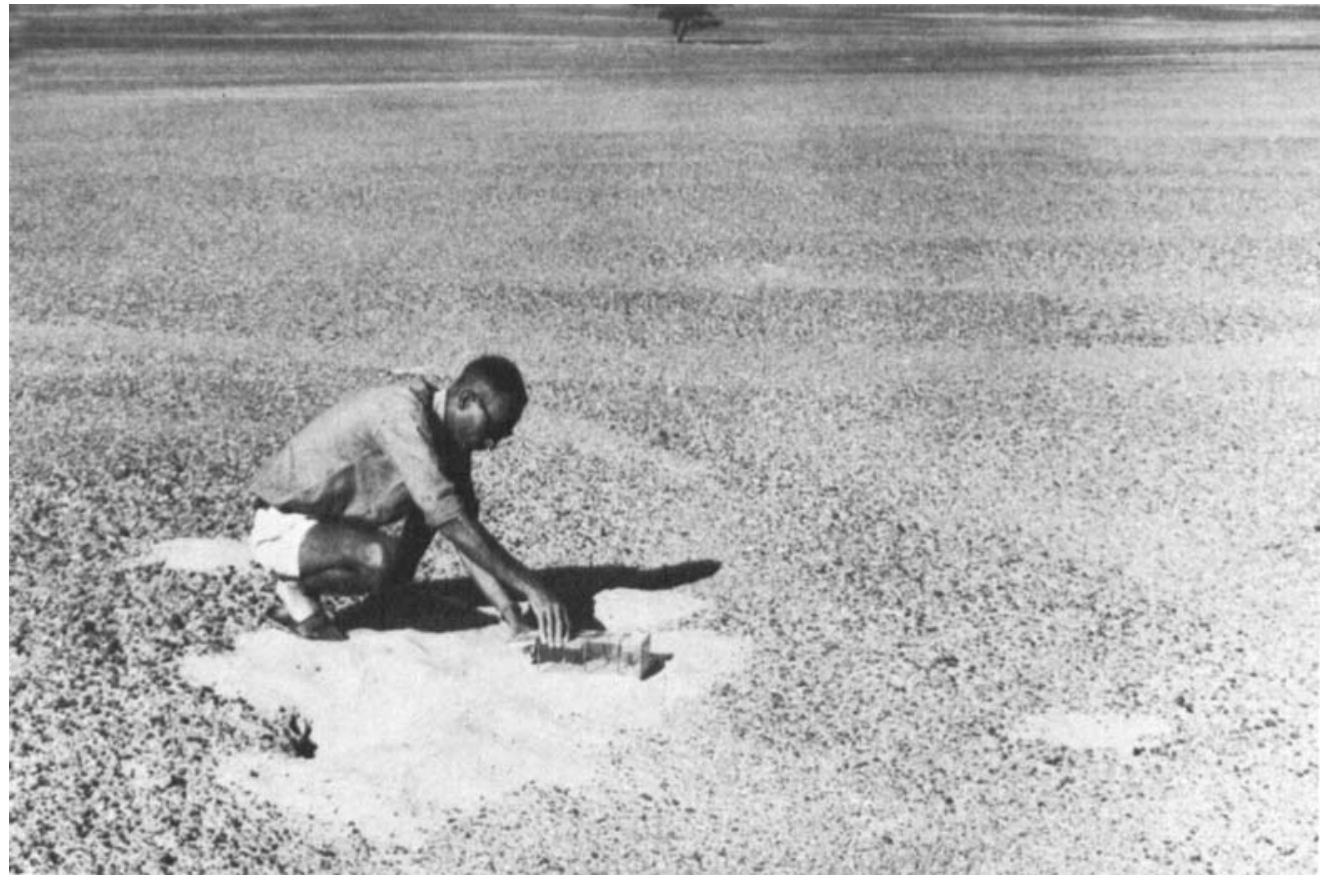

Fig. 1 Burrow of Meriones crassus in Western Desert of Egypt. The acacia tree in the center back-ground constituted the only vegetation in this region. Photograph courtesy of Dr. Dale J. Osborn, USNAMRU-3.

latus (5); M. libycus (7); Desmodillus auricularis (1); Pachyuromys duprasi (3).

\section{Ranges and habits of gerbilline rodents}

It should be emphasized that knowledge of the biology of the Gerbillinae is minimal and generalizations concerning their natural history are at best poor. The majority of the species of the Gerbillinae inhabit open situations varying from true desert to savannah in Africa and Asia. Using annual precipitation, deserts are regions receiving less than ten inches, semi-deserts between 10-20 inches and savannah 10-30 inches. The actual biotic situation is not determined solely by rainfall but by a balance between rainfall and potential evapo-transpiration (Odum, '59; Fay, '65). Most gerbils are nocturnal, though three species - Psammonys obesus, Meriones hurrianae and Rhombomys opimus - seem to be almost totally diurnal. Meriones persicus, vinogradovi, tristrami, shawi, and libycus are primarily nocturnal although each may be active above ground for varying periods during the day. Meriones crassus appears to be completely nocturnal. The other species studied all seem to be predominantly nocturnal but they are occasionally crepuscular (Petter, '61; Golvan and Rioux, '61; Lay, '67; Heptner, '56; Allen, '40; Nurgel'dyev, '69).

All the species studied are almost exclusively herbivorous or granivorous. Desert and semidesert inhabitants survive prolonged periods of drought lasting months or years. The carbohydrates of seeds may be partially metabolized to water by these rodents, allowing maintenance of water balance (Schmidt-Nielson, '64). True deserts, show meager or no plant life except following chance rainstorms, and their inhabitants must seek sustenance in the seeds then produced in great abundance by plants which have adapted to this stringent regime. Peripheral desert areas, only have rains during a brief annual cycle, and virtually all vegetation dies two or three weeks after the last rain (Happold, '67). Small rodents inhabiting such environs must forage on the exposed surface for periods, which vary from several months to years.

All gerbillids seem to live within bur- 


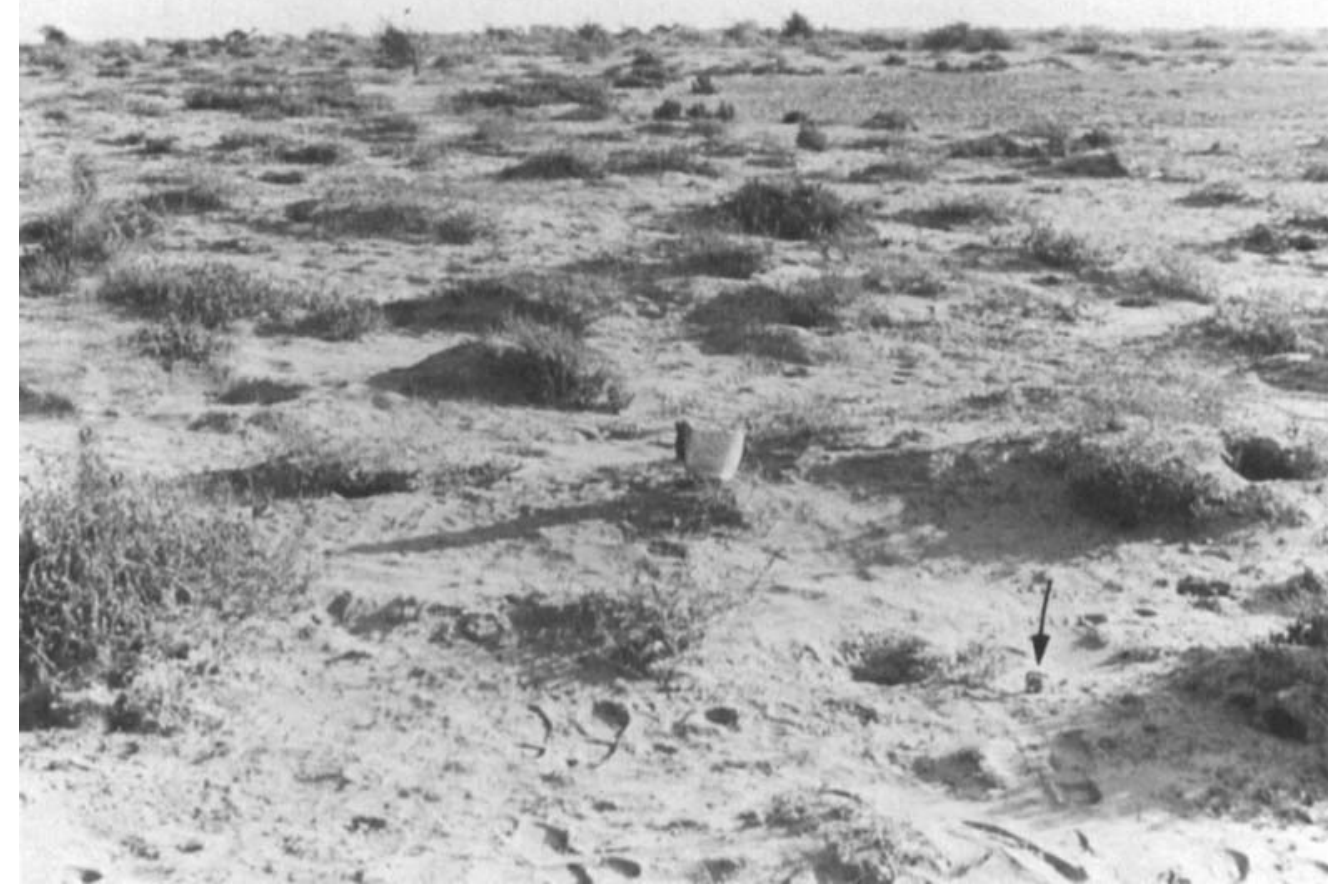

Fig. 2 Habitat of Tatera indica and Meriones hurrianae in December. Numerous burrow openings are visible. Arrow denotes match box positioned for scale. Locality - West Pakistan: $8 \mathrm{~km}$ E Karachi.

rows. Burrows of desert inhabiting species are deep $(2-3 \mathrm{~m})$, intricate and provide a favorable microenvironment in terms of humidity and temperature in contrast with the harsh conditions encountered at ground surface (fig. 1). Nocturnal activity allows these rodents to avoid the least favorable periods of high temperature and low humidity which occur during the day (Petter, '61; Bartholomew and Dawson, '68).

The genus Taterillus ranges across subSaharan Africa from Senegal to the Sudan and south to northwestern Congo, Kenya, and Uganda (Ellerman, '40). Taterillus species primarily inhabit semi-arid steppes or savannahs throughout the range of the genus (Dekeyser, '55; Setzer, '56; Hatt, '40; Bere, '62; St. Leger, '31).

All but one species of Tatera occur in sub-Saharan Africa. $T$. indica exists in Ceylon, the Indian peninsula north to Punjab, west across West Pakistan and southern Afghanistan, the southern half of Iran, southern Iraq and Kuwait thence along the Euphrates River Valley to Syria (Ellerman, '40, '61; Lay, '67; Hatt, '59). $T$. indica occurs in semidesert conditions in that portion of its range west of and including the states of Rajasthan and Gujerat, India (Petter, '61; Lay, '67; fig. 2 ). The remaining species are confined essentially to the grasslands of sub-Saharan Africa but several species inhabit open woodlands and parts of the Kalahari Desert (Dekeyser, '55; Bere, '62; Ansell, '60; Hatt, '40; Shortridge, '34; Davis, '62).

Sekeetamys calurus is endemic to the Sinai Peninsula and the Red Sea Mountains of Egypt where it lives in sparsely vegetated, arid, rocky hill and mountainside situations (Ellerman and MorrisonScott, '51; Hoogstraal, '63) (fig. 3).

Psammomys obesus ranges across the entire Sahara Desert and also occurs in southern Israel and at a single locality in the central part of western Arabia. Its habitat is limited to areas of succulent 


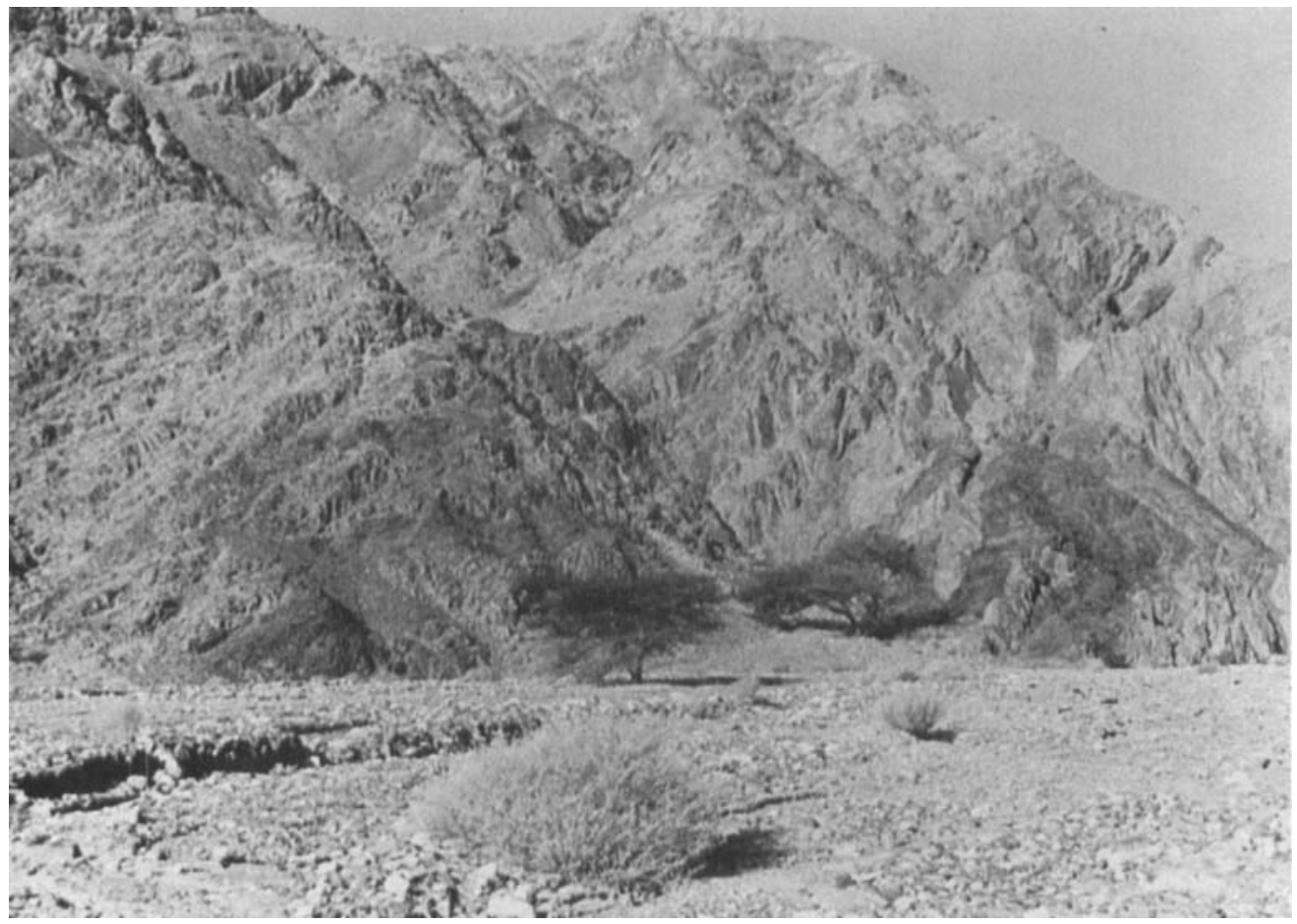

Fig. 3 Sekeetamys calurus inhabits these mountains, which were totally devoid of vegetation in early December at the time this photograph was made. Acacia trees at base of mountains stand about four meters high. Locality - Sinai: ca. $7 \mathrm{~km}$ W Eilat (Israel).

chenopodiaceous plants (Ellerman and Morrison-Scott, '51; Petter, '61; Hoogstraal, '63).

Rhombomys opimus occurs in the desert regions of Soviet Central Asia, northern China and southern Mongolia, eastern Iran and northern Afghanistan. This genus, like Psammomys, appears to be restricted to areas of halophytic vegetation (Ellerman and Morrison-Scott, '51; Gromov et al., '63; Bobrinskii et al., '65; Lay, '67; Allen, '40; Bannikov, '54) (fig. 4).

Gerbillus is composed of $35-55$ species that occur in desert, semidesert and savannah habitat of north and east Africa, the Arabian Peninsula (sensu Harrison, '64) southern Iran, West Pakistan and the states of Rajasthan and Gugerat, India (Ellerman and Morrison-Scott, '51; Dekeyser, '55; Petter, '61; Hatt, '59; Hoogstraal, '63; Zahavi and Wahrman, '57). G. pyramidum occurs primarily in the desert-Nile Valley ecological interface on both sides of the river.
Species of Meriones live primarily in deserts and semideserts but occasionally inhabit near mesic situations in North Africa, the Arabian Peninsula (sensu Harrison, '64), Iran, West Pakistan, Gugerat and Rajasthan states, India, Afghanistan, and the deserts of Central Asia as outlined for Rhombomys (Ellerman and Morrison-Scott, '51; Petter, '61; Hoogstraal, '63; Zahavi and Wahrman, '57; Gromov et al., '63; Bobrinskii et al., '65; Lay, '67; Lewis et al., '67; Bannikov, '54; Allen, '40).

M. persicus inhabits dry, sparsely vegetated, rocky hill and mountainside but has been observed in one instance to inhabit a mesic grassland. This species is confined to the Persian plateau. M. tristrami inhabits semi-arid steppe and cultivated areas from northeastern Iran and Transcaucasia west along the southern edge of the escarpment of the Taurus Mountains of Turkey to Lebanon, thence south to Israel. $M$. vinogradovi is endemic to north- 


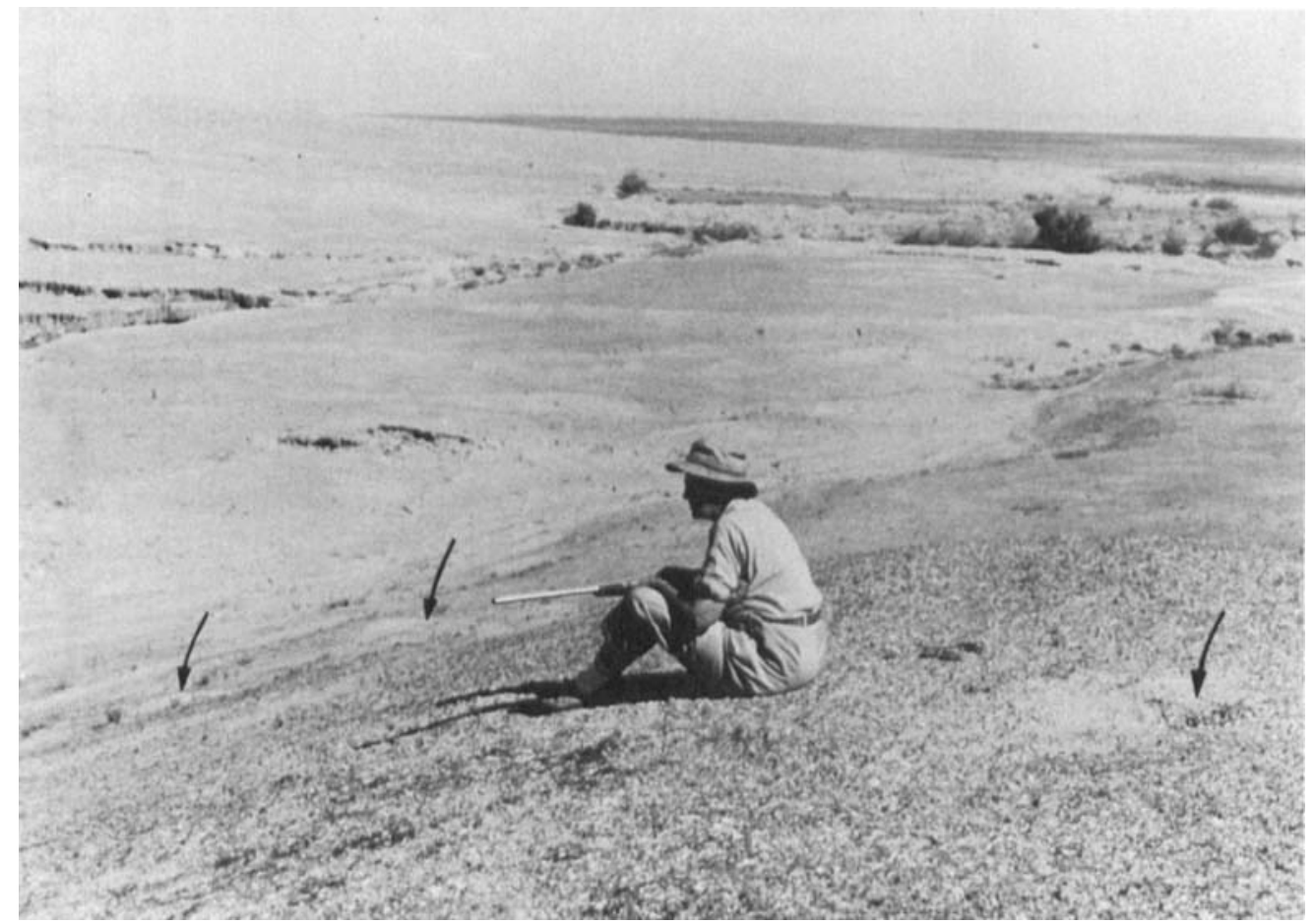

Fig. 4 Large colonies of Rhombomys opimus exist on grey lichen covered hills which support a fairly dense cover of a succulent, Salsola sp., during the wet season. Photograph taken in late October during dry season. Burrows excavated at this time contained large stores of these succulents. Arrows denote burrow openings. Locality - Iran: $40 \mathrm{~km} \mathrm{~N}$ Pahlavi Dezh and ca. $25 \mathrm{~km}$ E of Caspian Sea.

western Iran, adjacent areas of Transcaucasia and southeast Turkey where it inhabits semi-arid valleys. $M$. unguiculatus occurs in arid steppes in northern China, Mongolia, and a very small part of the Soviet Union south of Lake Baikal.

$M$. hurrianae occupies a range within the deserts of Rajasthan and Sind in India and Pakistan and occurs along the southern coast of West Pakistan reaching extreme southeast Iran. It prefers areas of halophytic vegetation, upon which it feeds extensively. $M$. crassus is strictly desert dwelling in its African and Arabian Peninsula range, while on the Iranian plateau it is principally an inhabitant of semi-arid steppe, though it sometimes occurs in desert there (fig. 1). The range of $M$. libycus extends from eastern Morocco across the Sahara, Arabian Desert, Iranian plateau, and the Central Asian deserts to the Western edge of the Gobi Desert in Mongolia. It is a true desert inhabitant in North
Africa and Arabia; it inhabits semi-arid to arid steppe and desert elsewhere. $M$. shawi inhabits the Mediterranean littoral of North Africa from Morocco to Sinai. It occasionally ranges as far inland as the southern limit of the semi-arid steppes $(20-240 \mathrm{~km})$ along the northern edge of the true Sahara but has never been recorded in the desert.

Desmodillus auricularis occurs in the desert and semi-arid regions of the western two-thirds of South Africa throughout Botswana (Bechuanaland) and South West Africa, and penetrates into extreme southwest Angola, where it frequents open sandy desert or dry areas of the Karoo sandstone. However, peripheral populations occur in savannah (Ellerman, Morrison-Scott and Hayman, '53; Shortridge, '34; Davis, '62; Meneses Cabral, '66).

Pachyuromys duprasi is known from 21 localities in and fringing the Sahara Desert ranging from western Algeria to the 
eastern desert province of Egypt (Petter, '61; Hoogstraal, '63; Niethammer, '63; Ranck, '68).

Desmodilliscus braueri is known from less than a dozen places along the southern edge of the Sahara from eastern Senegal to central Sudan, suggesting that it probably occupies the "zone saheliane" and ranges into the southern edge of the Sahara Desert (Dekeyser, '55; Niethammer, '63; Heim de Balsac, '67; Setzer, '69).

Ammodillus imbellis, is known from about 17 specimens from six localities in the semidesert steppes of Somalia and adjacent Ethiopia (Roche and Petter, '68).

\section{The middle ear}

\section{The transformer mechanism}

Sound waves do not pass readily from one medium to another of different acoustic resistance, but are largely reflected at the boundary. Acoustic resistance is determined by the density and elasticity of the medium. The sensory transducers of the ear lie within the fluid filled cochlea, but respond to aerial sound waves. This system has the same transmission properties of an air-seawater interface, so that only one-tenth of $1 \%$ of the energy contained in aerial waves is transmitted. The middle ear transformer system overcomes part of the resistance between these different media (Wever and Lawrence, '54).

The transformer consists of two kinetic units. One part is likened to "a sort of hydraulic principle" due to the surface area differences of the pars tensa of the tympanum relative to the small stapedial footplate. The other produces a lever advantage by the differential force arms of the malleus and the incus and is additive to the effectiveness of the transformer mechanism (Wever and Lawrence, '54). The air within the middle ear cavity resists incursions of the tympanum particularly at lower frequencies; the larger the volume for any given transformer the greater the sensitivity (Legioux and Wisner, '55; Webster, '61). Thus, the total volume of the middle ear air space plays a significant but passive role in the actual transformer efficiency.

Sixty to $72 \%$ of the area of the tympanum vibrates effectively in transmission of airborne sound in man and Felis catus (Bekesy, '60; Wever and Lawrence, '54). Thus, two-thirds of the tympanum area is usually considered to constitute its effective vibratory surface. The area of the stapedial footplate is calculated as an ellipse. The malleus and incus of the ossicle chain act as joined first class levers. The manubrium of the malleus (resistance arm) is longer than the long process of the incus (force arm), hence the perpendicular of these two lever arms from the axis of rotation, establishes the ratio of the incus arm length to that of the malleus. The ratio of the area of the stapedial footplate to the effective area of the tympanum multiplied by the ratio of the length of malleus lever to incus lever provides the transformer ratio (Wever and Lawrence, '54).

The shape of the tympanum is a right circular cone or a right elliptical cone formed by the umbo, the medially indented portion of the tympanum attached to the tip of manubrium. The conical shape of the tympanum provides a mechanism for enlarging the effective receptor area of the pars tensa (Wever and Lawrence, '54). Consequently the higher the umbo, the greater the receptive area of the tympanum, and it is imperative to consider the height of the umbo in calculating the tympanal area. Webster ('60, '61, '62) treated the tympanum of Dipodomys merriami and spectabilis as a right circular cone. Wever and Lawrence considered the human tympanum as a right elliptical cone. Oaks ('67) considered the tympanum as a flat surface.

I have measured the height of the umbo for intact tympani on silicone rubber casts obtained by filling the external auditory meatus. The measurements vary between individuals of the same species and/or bilaterally in individuals. These variations are probably inherent in the study material and methods of preparation (cf. p. 43 text). On drying, the factors determining normal tympanum configuration, such as the tensor tympani muscle, the ligaments that attach to the short process of the incus and the anterior process of the malleus and the structure of the tympanum may have been altered, resulting in deformation from the normal condition. Small variations in any of the constitu- 
ents of the transformer ratio are multiplied by several factors in calculation of this ratio. Dissection of anesthetized specimens or individuals freshly sacrificed would provide the best method for accurate calculation of the area of the tympanic membrane, but such material was unavailable. In spite of the error due to my casting technique, the values provide a fairly reasonable and consistent measure of the tympanum.

Table 2 provides the effective area, calculated as two-thirds of the total area, of the tympanic membrane, the surface area of the stapedial footplate, and the ratio of the former to the latter for the species studied.

It is not possible to measure the malleus and incus of specimens used for casting. Therefore, ossicles were extracted from museum specimens collected from the same areas or near the sources of the specimens studied. For Meriones unguiculatus casts were made from individuals of the laboratory strain (cf. Schwentker, '63) while the ear ossicles were taken from individuals caught wild in Mongolia.

A membrane is located dorsal to the pars tensa in a number of gerbilline and dipodid species. It is separated from the pars tensa by a thin band of connective tissue, the arcus terminalis, between the anterior and posterior spinae tympanicae. Most students of the rodent middle ear (e.g., Van Kampen, '05; Bondy, '08; Van der Klaauw, '31; Oaks, '67) have rejected Hyrtl's (1845) observations and argue that this membrane is an enlarged pars flaccida.

Hyrtl (1845) described a "Membrana tympani accessoria" in Dipus jerboa [sic] $=$ Jaculus orientalis Erxleben, 1777, stating that "owing to its tension it must convey vibrations and compression waves of the air to the upper tympanic cavity (and perhaps also to the middle ear bones), for the bodies of the malleus and the incus lie directly behind it."

The tympanic membrane of the Gerbillinae is composed of a large pars tensa and a small dorsal pars flaccida. Three layers constitute the pars tensa: an outer cuticular layer derived from the skin; a middle fibrous layer composed of superficial radiate and deep circular fibers; a deep mucous layer continuous with the mucous lining of the tympanic cavity. The middle fibrous layer is replaced by loose connective tissue in the pars flaccida.

Bondy ('08) and Van der Klaauw ('31) define the pars flaccida as: "The membrana Shrapnelli lies between (a) the skeletal element that closed the "Tympanicumschenkel' (the hiatus [incisura tympanical lying between the two 'Tympanicumschenkel'), (b) these 'Tympanicumschenkel' [anterior (cranial) and posterior (caudal) legs of the tympanic annulus] themselves and (c) the arcus terminalis; the latter is the band of connective tissue that connects the spinae tympanicae posterior and anterior and lies between the pars tensa of the tympanic membrane and the membrana Shrapnelli." This statement only defines the morphological boundaries of the pars flaccida. Van der Klaauw (31) failed to note that Bondy ('08) distinguished the pars tensa and flaccida histologically by the same features enumerated in the preceding paragraph.

Van Kampen ('05), Bondy ('08), Van der Klaauw ('31), and Oaks ('67), have not studied the histological structure of the accessory tympanic membrane of Jaculus orientalis. Van Kampen ('05) homologized Hyrtl's accessory tympanic membrane with the pars flaccida and the rounded circumference to which the accessory tympanic membrane attaches with the incisura tympanica.

The histological structure of the accessory tympanic membrane is identical with that of the pars tensa in Dipodidae (Salpingotus michaelis, Jaculus jaculus) and Gerbillinae (Meriones unguiculatus, $M$. libycus, Gerbillus pyramidum and Pachyuromys duprasi, fig. 18). This evidence suggests that the architecture of the accessory tympanic membrane of all gerbils and jerboas is the same.

Hyrtl's accessory tympanic membrane is either present or absent. It is large in all species of (Dipodidae) Cardiocranius, ${ }^{\prime}$ Salpingotus, Euchoreutes,' Jaculus, Dipus, ${ }^{1}$ Scirtopoda, ${ }^{1}$ Eremodipus, ${ }^{1}$ Paradipus, ${ }^{1}$ (Gerbillinae) Desmodillus, ${ }^{1}$ Desmodilliscus,' Ammodillus ' ${ }^{1}$ and Pachyuromys.' An accessory tympanic membrane exists

\footnotetext{
1 Monotypic genera.
} 
in some species of Gerbillus and Meriones. In $M$. vinogradovi, the accessory tympanic membrane was found in two specimens, of a sample of 13, bilaterally in one and unilaterally in the other. Size of the accessory tympanic membrane increases in a series of Meriones species from vinogradovi to unguiculatus to zarudnyi to meridianus to libycus reaching maximal development in these last two species and provides suggestions as to the manner in which this membrane may have evolved in the Gerbillinae.

Specimens of $M$. vinogradovi have a rounded opening in the cranial tympanic lamella anterior to the incisura tympanica but the inferior portion of its posterior margin is confluent with the incisura (fig. 20). With enlargement to the size typical of $M$. unguiculatus and libycus its posterior rim obliterates the inferior portion of the incisura, reducing the dorsoventral extent of this latter structure (fig. 21). With further enlargement as in Gerbillus nanus, gerbillus, pyramidum, and cheesmani, Pachyuromys duprasi and Desmodilliscus braueri, the incisura and the lateral wall of the epitympanic recess are almost entirely replaced by the accessory tympanum. The incisura persists as a small, distinct gap in the posterior upper edge of the rim of attachment of the accessory tympanic membrane (figs. 19-23). This posterior relationship is maintained in all the gerbilline rodents studied.

In Desmodillus auricularis the accessory tympanum does not reach the proportions typical of Pachyuromys or Desmodilliscus, and the incisura is bridged by membrane, but its distal edge does not interrupt the rim of attachment of the accessory tympanum (fig. 23).

Study of four species provides data on the origins of an accessory tympanic membrane in Dipodidae. Allactaga elater (Allactaginae) does not process an accessory tympanum. The incisura tympanica is located in the posterior portion of the lateral bony wall of the epitympanic recess (fig. 24). In Jaculus jaculus and blanfordi (Dipodinae) a tympanic incisura persists, but this structure lies entirely posterior to the rounded emargination to which the accessory tympanum is attached (fig. 25). A unique attachment occurs in Salpingotus michaelis (Cardiocraniinae). The out- growth of the anterior leg arcs superiorly and posteriorly over the surface of the mastoid and an incisura exists where the outgrowths of the two legs of the tympanic annulus come into approximation. The major portion of the accessory tympanum appears to attach directly to a rounded concavity of the mastoid but a small postero-ventral portion attaches to the posterior leg of the tympanic annulus, which articulates with the mastoid.

The extension of the anterior leg of the tympanic annulus arcs caudally to a much greater degree than does the posterior leg in the opposite direction. This difference accounts for the posterior displacement of the incisura tympanica in the species discussed above. The anterior process arcs and terminates much further posteriorly in the Dipodidae than in the Gerbillinae.

In gerbils and jerboas that lack an accessory tympanic membrane, a thin plate of bone forms the lateral wall of the epitympanic recess. Two lamellae approximate one another from the posterior and anterior legs of the tympanic annulus and a narrow slit-like opening usually separates them. This incisura is broadest at the lower free edge (distal) and narrows progressively in passing dorsally (fig. 19). A part of the true pars flaccida bridges the incisura. Fusion of the anterior and posterior lamellae may occasionally close the defect. Spinae tympanicae are indistinct in this morphological condition; only in species possessing accessory tympanic membranes do these spinae form discrete pointed processes.

A pars flaccida occupying a position similar to that of Hyrtl's membrane is present in most species of murid rodents (Bondy, '08; Oaks, '67). Sections through both pars tensa and flaccida of Peromyscus leucopus show that the relatively wide, dorsally located pars flaccida, contains loose connective tissue in the middle layer, and is readily distinguishable from the pars tensa. This agrees with the results obtained by Bondy ('08). Thus, the accessory tympanic membrane of Gerbillinae and Dipodidae does not fit the classically accepted criteria characterizing the pars flaccida. Hyrtl's (1845) designation of this structure as an accessory tympanum, though without histological evidence, should be regarded as correct. The error 
in interpretation began with Van Kampen ('05) and has persisted through the papers of those authors that accept his opinion. The different relationships of the accessory tympanum with the incisura tympanica in the Gerbillinae and Dipodidae suggests that this membrane evolved independently in the two groups.

\section{Ossicles}

Middle ear bones of the Gerbillinae have been described or figured as line drawings by Tullberg (1899), Heptner ('40), Cockerell et al. ('14a,b), Keen and Grobbelaar ('41), Wassif ('46, '48), Oaks ('67).

Several aspects of the ossicle chain show features for increasing vibrational sensitivity. The processes forming the rotation axis of the malleus and incus are connected to their respective articulation points by only three ligaments. A medial and lateral ligament holds the tip of the incudal processus brevis in the fossa incudis, and a single ligament connects the pointed tip of the lamina of the malleus to the adjacent tympanic and mastoid bones. Two Dipodomys species show the same condition (Webster, '60). The processus brevis and lamina exhibit a trend toward elongation and terminal attenuation in the morphological series typified by $T$. indica to $M$. shawi to $P$. duprasi. With attenuation, the area of ligament attachment to these processes is reduced. These features probably tend to reduce friction during the rotation of the malleus and the incus.

In all the histological preparations the malleoincudal joint is held together by a capsular ligament. The joint is further rigidified by fine intracapsular ligaments arranged in medial, central (in the center of the sulci) and Iateral bands. Intracapsular ligaments should increase the rigidity, thus reducing energy loss due to mechanical deformation at this articulation.

The manubrium of the malleus extends perpendicular to the axis of rotation in all forms studied, in Dipodomys (Webster, '60, '61) and in many other rodents (Oaks, '67). Oaks ('67) distinguishes this manubrium as a perpendicular type as opposed to a parallel type typical of most murine rodents. The perpendicular type increases the length of the lever arm because the distal tip of the manubrium is further vertically from the axis of rotation.

The neck and manubrium of the malleus of Taterillus emini and Tatera indica extend ventrally, in a uniaxial line, from the body of the malleus. In all the other forms studied, the neck passes laterally from the body, and the manubrium, attached to the distal extent of the neck, angles medially along a different axis at varying angles to the axis of the neck (fig. 26). The processus brevis remains close to the neck in Taterillus but is progressively displaced laterally and ventrally in a morphological series typified by $T$. indica to $M$. tristrami to $P$. duprasi (fig. 26). Other species studied bridge the gaps between these selected types.

A series of remarkable morphological modifications take place in the malleus with the development of an accessory tympanum, including (1) lengthening of the neck, (2) medial rotation of the manubrium, (3) increase in the length of the processus brevis manubrii and (4) the development of a laterally directed ridge on the upper third to half of the neck, to which the accessory tympanum attaches (fig. 18). Table 1 provides the mean and extremes of neck length for 17 species, only five of which possess an accessory tympanum. The average of mean neck length in the group lacking an accessory tympanum is $0.77 \mathrm{~mm}$ compared with $1.37 \mathrm{~mm}$ in the group with an accessory tympanum. Considerable variation exists in each of these groups, particularly since there are large size differences between some of the species and there is some overlap when only neck length is considered. However, the ratio of length of manubrium lever arm to that of neck clearly distinguishes these groups (cf. table 1). Pachyuromys and Desmodilliscus are the most specialized in these respects.

The malleus and incus of all the Gerbillinae have large, well developed heads, the major portions of which lie above the axis of rotation. The caput mallei is two to three times larger than the caput inci. Considerable variation exists in size and morphology of the heads of the malleus and incus among the forms studied and I am unable to discern any trends in this variation. The mass of the malleus and incus is distributed symmetrically about 


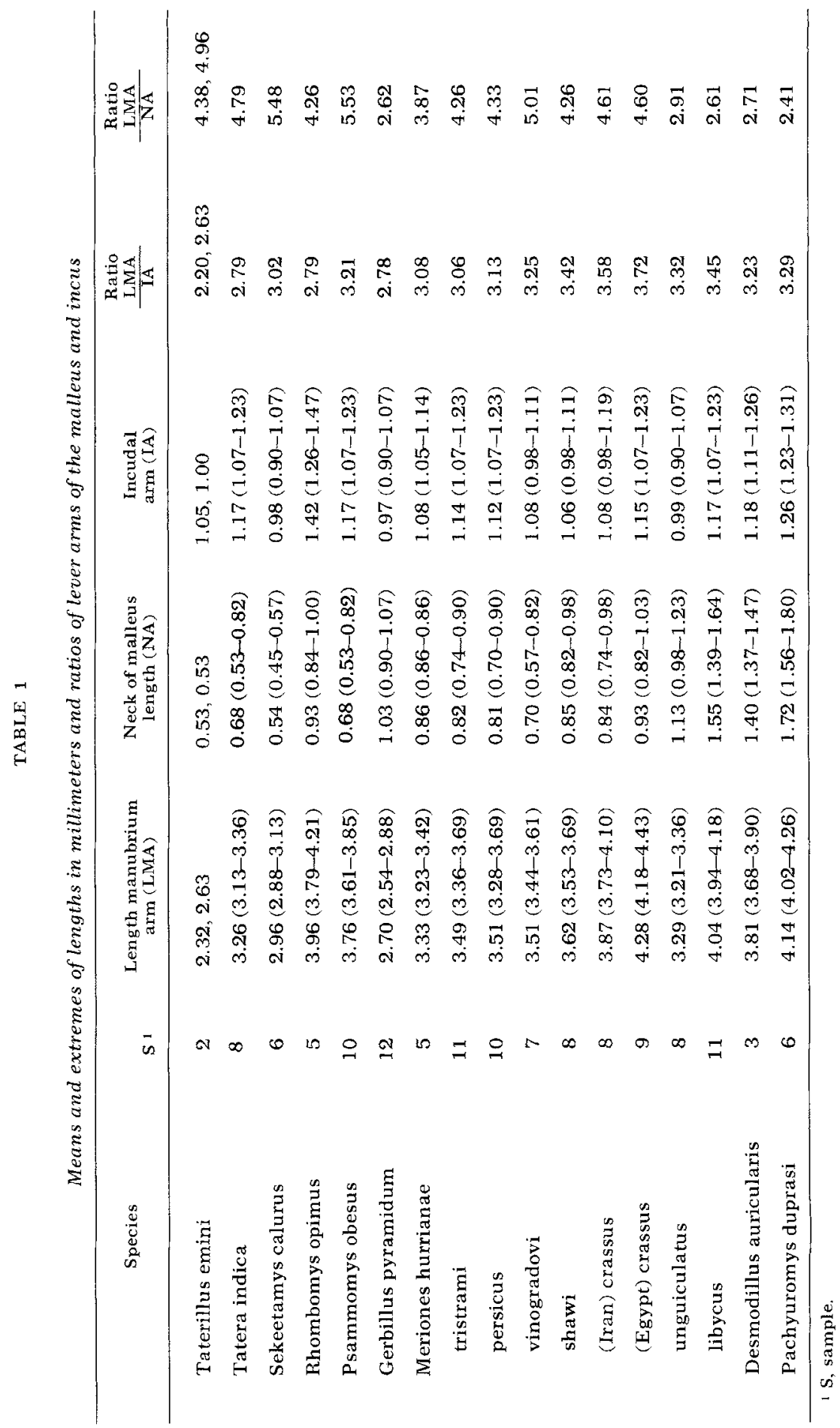




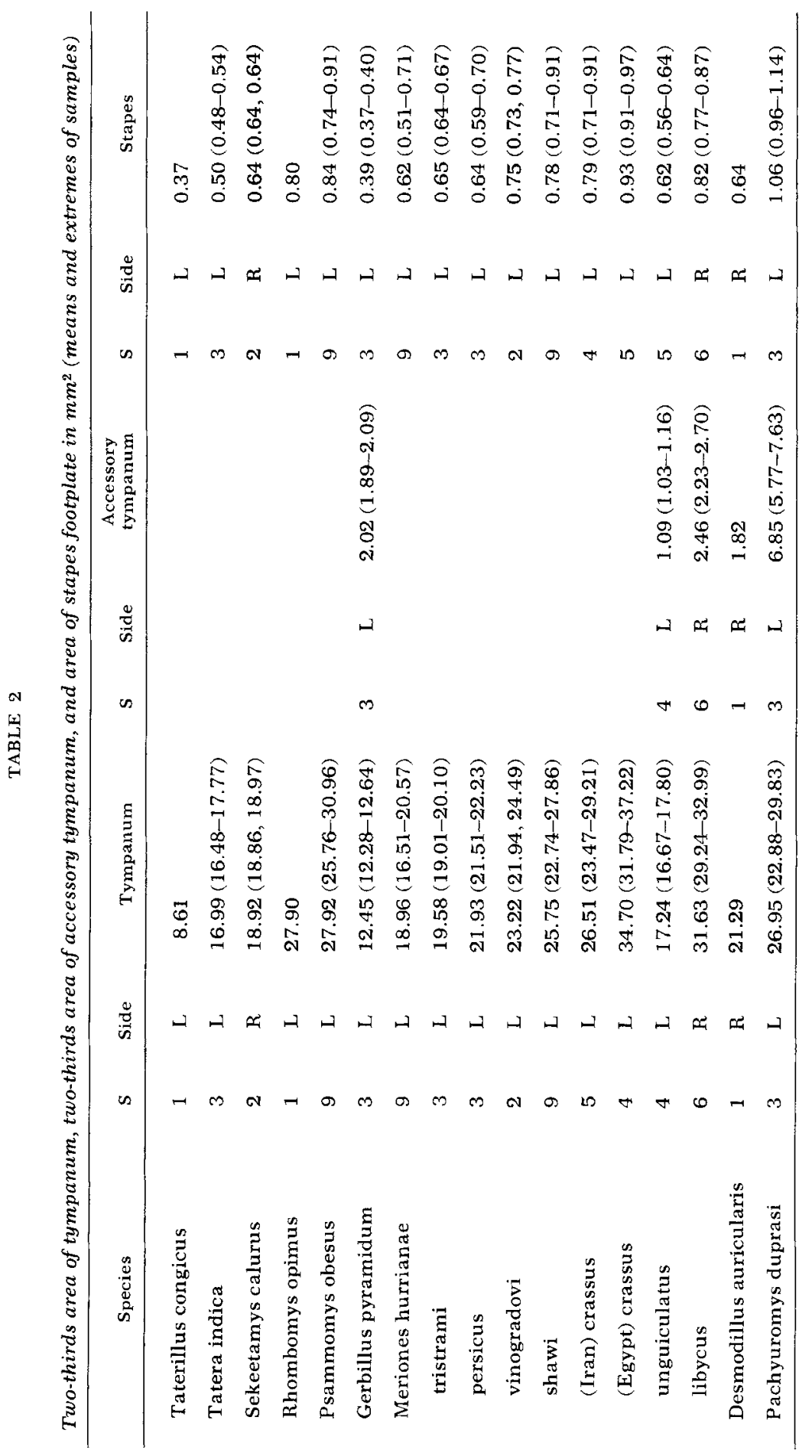


TABIF 3

Transformer ratios

\begin{tabular}{|c|c|c|c|c|}
\hline Species & $\begin{array}{c}2 / 3 \text { area tympanum/ } \\
\text { axea stapes }\end{array}$ & malleus/incus 1 & $\underset{\text { ratio }}{\text { Transformer }}$ & $\begin{array}{c}\text { Transformer } \\
\text { ratio }\end{array}$ \\
\hline Taterillus congicus & 23.14 & 2.61 & $60.40: 1$ & \\
\hline Tatera indica & 33.71 & 2.79 & $94.05: 1$ & \\
\hline Sekeetamys calurus & 29.35 & 3.01 & $88.34: 1$ & \\
\hline Rhombomys opimus & 35.07 & 2.79 & $97.85: 1$ & \\
\hline Psammomys obesus & 33.40 & 3.21 & $107.21: 1$ & \\
\hline Gerbillus pyramidum & 32.01 & 2.79 & $89.31: 1$ & $118.73: 1$ \\
\hline Meriones hurrianae & 30.73 & 3.06 & $94.03: 1$ & 110.13 .1 \\
\hline tristrami & 30.08 & 3.06 & $94.04: 1$ & \\
\hline persicus & 34.00 & 3.12 & $106.08: 1$ & \\
\hline vinogradovi & 31.00 & 3.25 & $100.75: 1$ & \\
\hline shawi & 33.18 & 3.42 & $113.48: 1$ & \\
\hline (Iran) crassus & 33.39 & 3.59 & $119.87: 1$ & \\
\hline (Egypt) crassus & 37.43 & 3.73 & $139.61: 1$ & \\
\hline unguiculatus & 27.63 & 3.32 & $91.73: 1$ & $114.12: 1$ \\
\hline libycus & 38.57 & 3.44 & 132.68: 1 & $200.38: 1$ \\
\hline Desmodillus auricularis & 34.06 & 3.46 & $117.85: 1$ & $145.52: 1$ \\
\hline Pachyuromys duprasi & 25.42 & 3.30 & 83.89:1 & $159.43: 1$ \\
\hline
\end{tabular}

1 Length of manubrial leverarm/length of incudal leverarm.

2 Classical transformer ratio.

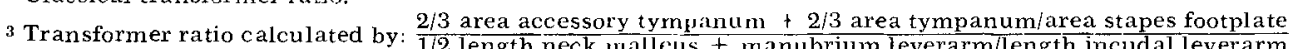

the axis of rotation for a number of mammals (Barany, '38) and this seems to be true of the Gerbillinae. This distribution of the center of gravity of the ossicles coincides with the axis of rotation of the axial ligaments and reduces friction in the system (Bekesy, '60).

The transformer ratio shows a general trend of enlargement from Taterillus congicus to Meriones crassus (Egypt) and $M$. libycus (table 3 , fig. 5). Figure 6 reveals a high degree of correlation among the kinetic transformer components, namely two-thirds area of tympanum, area of stapes footplate, and lengths of malleus and incus lever arms. These components are also correlated with middle ear volume and some features of inner ear anatomy. The transformer may be separated into two parts. Reference to table 1 shows that the length of the malleus lever arm increases more or less progressively from $T$. emini (average $2.48 \mathrm{~mm}$ ) to $M$. crassus (Egypt, $4.28 \mathrm{~mm}$ ), a differential of $42 \%$. In contrast the incus arm is $1.05 \mathrm{~mm}$ and $1.15 \mathrm{~mm}$ respectively in these species, a difference of only $8 \%$. The increase in incus arm length is conservative with respect to that of the malleus. The effective area of the tympanum is smallest in $T$. congicus $\left(8.61 \mathrm{~mm}^{2}\right)$, a species closely related to $T$. emini, and largest in $M$. crassus (Egypt, $34.70 \mathrm{~mm}^{2}$ ). The stapes footplate area is $0.37 \mathrm{~mm}^{2}$ and $0.93 \mathrm{~mm}^{2}$, respectively in these species (cf. table 2). The increase of $86 \%$ in tympanum and $60 \%$ in stapes footplate area between these species represents a net gain of $26 \%$, while the lever difference shows a net increment of $34 \%$. This trend to increase the efficiency of the transformer components is general rather than absolute and the two integral parts enlarge similarly. All parts of the middle ear enlarge with augmentation of the transformer (tables 1,2).

The size of the transformer ratios show good concordance with the habitats of the species studied. A progressive enlargement takes place from savannah to semiarid steppe to desert-inhabiting species. The optimal transformer ratio for any given population of gerbils is determined by environmental, behavioral, locomotor, and reproductive variables. Thus, the optimal transformer ratio for one species may be smaller or larger than that of another species living in similar environmental conditions.

Enlargement of the middle ear volume parallels transformer ratio increase (fig. 5). Pachyuromys duprasi has an inordinately large volume for its classical transformer ratio (fig. 5) but sensitivity of $P$. duprasi exceeds that of $M$. crassus and $M$. libycus for most of the frequencies 


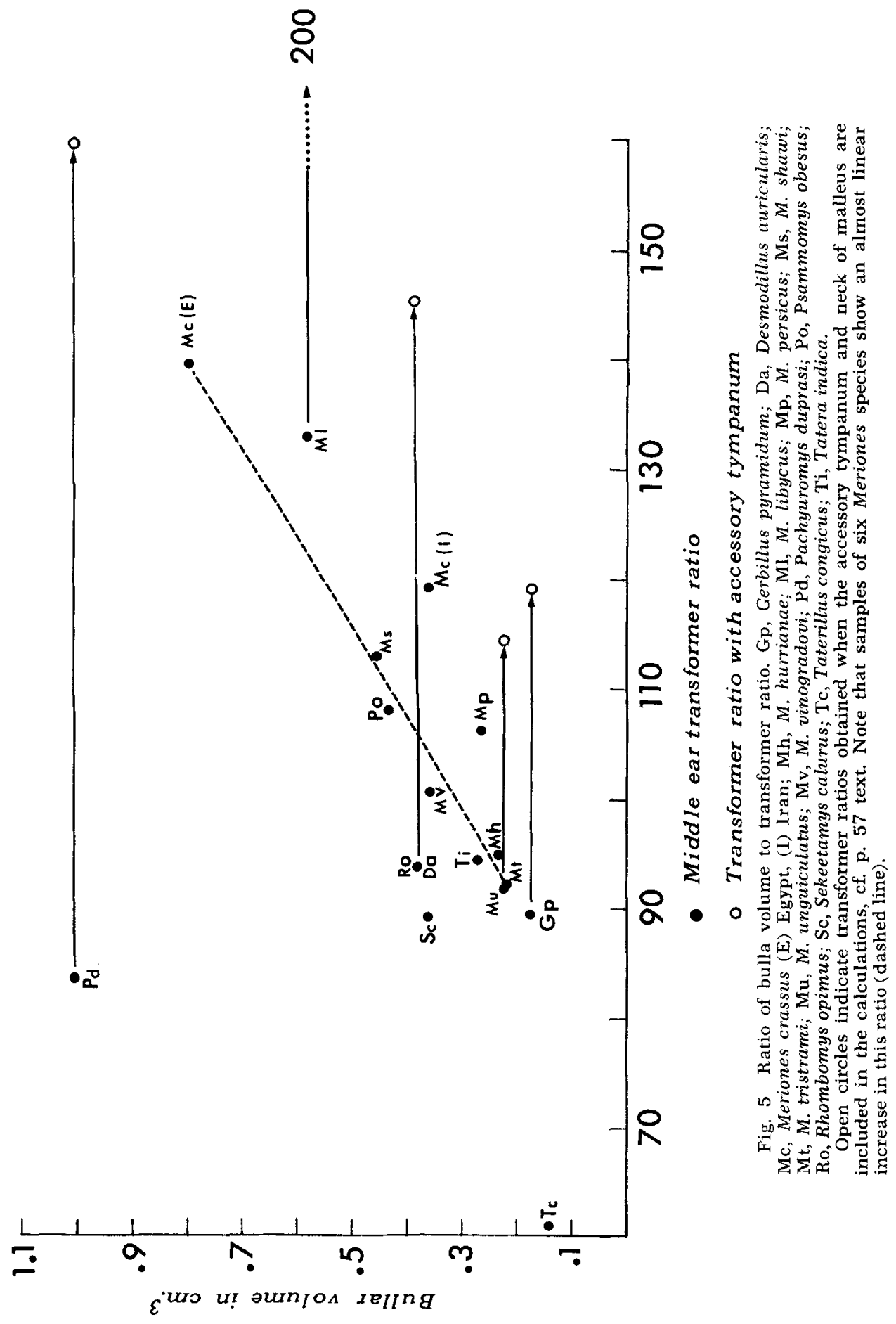


All species $\mathrm{N}=17$

Volume

Two-thirds area tympanum

Malleus arm length

Area stapes footplate

Incus arm length

Area acc. tympanum

Malleus neck length

$\begin{array}{lll}1.00 & & \\ 0.743^{1} & 1.00 & \\ 0.769^{1} & 0.915^{1} & 1.00 \\ 0.868^{1} & 0.898^{1} & 0.904^{1} \\ 0.430^{2} & 0.517^{2} & 0.603^{2} \\ 0.559^{2} & 0.114 & 0.676^{1} \\ 0.564^{2} & 0.228 & 0.920^{2} \\ \text { Vol }^{2} & 2 / 3 \mathrm{AT} & \text { MAL }\end{array}$

1.00

0.743

0.868

0.430

$0.564^{2}$

0.228

$2 / 3 \mathrm{AT}$

\subsection{0 \\ $0.541^{2}$ \\ $0.510^{2}$ \\ 0.973}

ASF
1.00
0.054
0.390

0.390
1.00

0.917

AAT $\quad 1.00$

is, 0.01

Fig. 6 Correlation coefficients of middle ear components for all 17 species studied.

tested (figs. 10-14). Yet, the transformer ratio of the first is only 60 and $63 \%$ as great as of the last two species, and the three species have similar organs of Corti. This suggests that the accessory tympanum functions to augment the middle ear transformer.

The central region of the accessory tympanum attaches to the upper half of the neck and lower-portion of the body of the malleus and to the upper third of the long process and lower part of the body of the incus in living specimens of $G$. pyramidum, $M$. unguiculatus, $M$. libycus and $P$. duprasi. The membrane is stretched taut and is histologically like the tympanum, which suggests that it is capable of vibration in response to airborne sound, and, by virtue of attachment to the malleus and incus, is capable of transmitting vibrations to the ossicle chain.

The manubrium is disposed at nearly right angles to the neck in Pachyuromys (fig. 27). The attachments of the tympanum and accessory tympanum thus lie at sharply different angles and this allows these membranes to function independently by vibrating in different planes but both would displace the neck and manubrium medially. This arrangement seemingly increases the transformer ratio by enlarging the vibratory receptor surface and lengthening the malleus lever arm by a small factor. If the transformer ratio of Pachyuromys is calculated, using the functional area of the tympanum plus twothirds the area of the accessory tympanum and the length of the manubrium lever arm plus one-half the length of the neck, the value obtained (159:1) agrees well with the transformer ratio: volume trend of the other 16 species studied (fig. 5).

The transformer ratio values determined in this manner for the four other species with accessory tympani are disproportionately high relative to volume. If the accessory tympanum functions to enhance the transformer, the system augments the transformer of these four species much less than that of Pachyuromys since the parallel increase of volume and transformer ratio is consistent though nonlinear for all species lacking an accessory tympanum.

The effective area of the tympanum relative to that of the stapedial footplate is much lower in Pachyuromys than in the other species for which the accessory tympanum was measured (table 2). The greater elaboration of its accessory tympanum may compensate for this difference.

The anatomical data concerning the accessory tympanum lend some support to the hypothesis that this structure functions as a part of the transformer. That this membrane characterizes desert inhabiting species and is largest in those inhabiting the most desertic regions seems a good indication that it is an adaptive feature.

\section{Auditory bullae}

The mastoid air cells

Three primary mastoid air chambers occur in the Gerbillinae: anterior; posterior superior; posterior inferior.

Anterior mastoid chamber (fig. 29). The anterior chamber (AM) lies directly above the external auditory meatus. It is usually triangular in dorsal view. A bony partition extends dorsally from the full span of the crista parotica to the superior cover of the bulla and separates the anterior chamber from the superior posterior mastoid cell. The anterior third of the anterior (superior) semicircular canal ex- 
tends into the anterior chamber through the medial edge of this septum. This chamber opens ventrally into the epitympanic recess of the tympanic cavity via a semicircular opening in its inferior wall, the lateral straight border of which is essentially demarcated by the fossa incudis posteriorly and the petrotympanic fissure anteriorly. The posterior half of the semicircle is formed by the crista parotica and the anterior half is demarcated by a bony shelf directed anterolaterally.

Posterior mastoid chambers. There are one or two (the superior posterior SP, and inferior posterior IP) posterior mastoid chambers in most gerbillines. Considerable variation exists in these pneumatizations.

Superior posterior chamber (fig. 29). The SP cavity generally forms a crude pyramid, the base of which can be considered as the posterior limiting bullar capsule while the apex lies just posterior to the anterior junction of the lateral and superior semicircular canals. The lateral canal and the bony shelf that projects posteriorly from this canal to the bullar wall form the ventral border of this chamber. Portions of the petrous and squamous temporal bones constitute its medial boundary. The septum between this chamber and the anterior cavity forms the lateral border of the pyramid, is oriented posterolaterally and inclines toward the occiput. The superior canal penetrates this septum at a right angle. A postero-medially directed shelf of bone projects from that portion of the posterior canal to the posterior border of the bulla, separating a small medial chamber from the remainder of the superior posterior chamber. These are named medial (MSP) and lateral superior posterior (LSP) cells, respectively. The medial connects with the lateral cell through an opening bounded vertically by the posterior canal and dorsally by the lateral canal. The lateral superior posterior chamber opens ventrally into the tympanic cavity by an almost circular orifice bounded posteriorly by the lateral canal and anteriorly by the bony covering of the sacculus.

Inferior posterior chamber (fig. 29). This chamber occurs in most gerbilline rodents and lies immediately ventral to the superior posterior cell. The inferior border of this latter, namely the lateral canal and its bony lamina forms the roof of the inferior posterior chamber. A shelf formed by juxtaposed tympanic and mastoid plates composes the inferior margin, which is inclined postero-ventrally at an angle of about $45^{\circ}$ to the almost horizontal roof. The superior rim of the tympanic and mastoid plate junction forms the ventral limitation. The IP chamber connects dorsally with the SP through an opening bounded by the lateral canal. The tympanic mastoid shelf has a free border anteriorly by means of which the IP is connected to the tympanic chamber.

The posterior auricular branch of the vagus nerve $(\mathrm{X})$ traverses this chamber in the genera Sekeetamys, Gerbillus, Psammomys, Rhombomys, and Meriones. This nerve enters the mastoid cavity via a minute foramen located at the tympanomastoid junction posterior and dorsal to the foramen of the stapedial artery, and then courses either almost straight mediolaterally or parallel to the curvature of the posterior end of the bulla. Laterally it enters the facial canal and emerges with the facial nerve through the stylomastoid foramen. The posterior auricular nerve lies between the overlapping mastoid and tympanic plates (figs. 29, 39). It may lie completely in a bony canal as in Psammomys, Gerbillus pyramidum, G. gerbillus, G. nanus, and Sekeetamys or in a groove in the upper surface of the tympanic plate as in Rhombomys and certain Meriones, where the mastoid plate fails completely to cover the tympanic plate.

This chamber exists as a single cell in many species (cf. table 4) but it may be divided into as many as three compartments. A small medial cell, here named the accessory medial inferior posterior (AMIP), occurs when a bony shelf extends from the ventral portion of the posterior canal to reach the medial bullar wall. This cell, when present, communicates via an opening bounded by the lateral canal dorsally and the posterior canal ventrally with the orifice by which both principal posterior (SP and IP) chambers connect to the tympanic cavity. A dorso-ventrally oriented partition in the lateral third of the compartment may divide the IP chamber 
into lateral inferior posterior (LIP) and medial inferior posterior (MIP) compartments. When such a separation is absent, the single large chamber is termed the common medial inferior posterior (CMIP).

Enlarged auditory bullae are one of the most distinctive features of the Gerbillinae. Two basic components derived from the mastoid and tympanic (= ectotympanic) bones form the auditory bulla (figs. $32,33)$. A trend toward enlargement of the middle ear cavity, the degree of which correlates with the size of the transformer ratio and habitat characterizes the Gerbillinae. Major differences in the component parts of the bulla characterize the groups of species studied and provide some insight into the manner by which the specialized forms may have evolved from a generalized ancestral type.

The mastoid of the gerbilline progenitor was probably somewhat similar to that of Rattus rattus. In this species the mastoid faces postero-laterally and lies primarily posterior to the tympanic bulla (fig. 34). The anterior end of the mastoid roofs the epitympanic recess and only at this point does the mastoid make contact with the tympanic. The subarcuate fossa, which houses the petrosal lobe of the cerebellar paraflocculus, forms the most significant feature of the mastoid in Rattus. The subarcuate fossa, which is connected to the brain cavity through the arch of the anterior semicircular canal, is formed by a thin layer of lamellate bone that balloons out into the mastoid lateral to the plane of the canal arc. Small unconnected air cells are present within a thin layer of cancellous bone interposed between the wall of the fossa and the external lamellate wall of the mastoid. A very small, hollow anterior mastoid cell exists but has connection neither with the epitympanic recess nor with the small cells surrounding the subarcuate fossa (figs. 34, 35).

The mastoid of Taterillus is approximately the same size as in Rattus. In $T$. emini and congicus the AM cell, 0.003 $\mathrm{cm}^{3}$ in volume, is four or five times more capacious than that of Rattus and opens ventrally into the epitympanic recess by an aperture which is completely surrounded by mastoid elements. The floor of the AM in Rattus is very thin and trans- lucent to light at several places; this condition might be considered as adumbrating the development of the connection between the tympanic and AM chambers. The nature of the posterior region in $T$. emini is not unlike that described for Rattus. However, T. congicus has developed a small $\left(0.002 \mathrm{~cm}^{3}\right)$ chamber in the posterior mastoid, above the level of the lateral canal between the wall of the subarcuate fossa and outer mastoid wall. No connection exists between it and the AM because the lateral wall immediately posterior to the anterior chamber adheres to the border of the subarcuate fossa.

The anterior and posterior mastoid chambers of Tatera indica are each ten times larger than the respective cells of $T$. congicus. This enlargement has been accomplished by reduction of the subarcuate fossa, lengthening the mastoid antero-posteriorly, displacement of the lateral mastoid wall laterally, and pneumatization of the cancellous bone between these boundaries. The small segment of mastoid which extends inferior to the plane of the lateral canal is composed of inner and outer layers of lamellar bone between which is a thin layer of cancellous bone containing minute air cells.

The AM and PM cell morphology of Gerbillurus paeba does not differ in any important respects from that of Tatera. The mastoid below the plane of the lateral canal, however, is considerably larger than that found in either Tatera or Taterillus due to expansion dorso-ventrally. The cancellous bone between the inner and outer walls has been replaced by a single narrow chevron-shaped chamber which extends around the posterior angle of the mastoid (figs. 36, 37). This chamber does not connect with either the tympanic cavity or the posterior superior cell, but because of its relations this cavity probably represents the initial stage of development of a posterior inferior cell typical of most of the more specialized Gerbillinae discussed below.

Taterillus, Tatera, and Gerbillurus are characterized by the most generalized mastoid morphology among the extant Gerbillinae. The mastoid of all other genera is highly pneumatized and these segregate into two groups on the basis of 


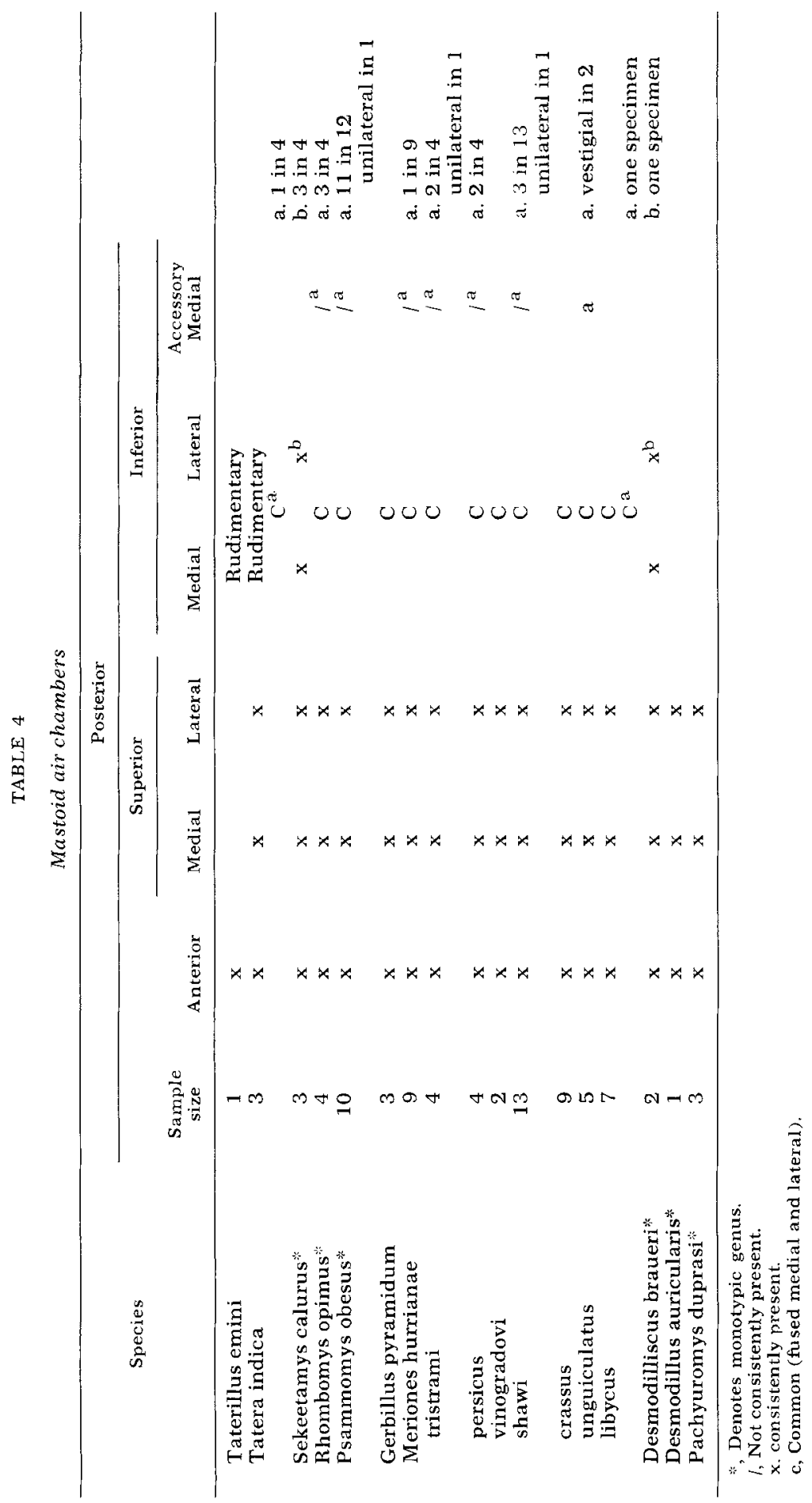


morphology. The presence of only a PS chamber in Ammodillus, Desmodillus and Pachyuromys differentiates these from all the other genera, which are characterized by both SP and IP cells (cf. table 4 ).

Considerable variation in posterior mastoid morphology characterizes this last group with regard to the number of chambers present and the volumes of each (tables 4,5 ).

Because the inferior chamber is absent or rudimentary in Tatera, Taterillus and Gerbillurus, while the superior cell is relatively well developed, I believe that the former cell probably arose after the latter. However, the alternative that those forms with SP and IP chambers may represent a distinct evolutionary line cannot be ruled out. Further, it seems that inferior cells of small volume may be indicative of degree of specialization when considered with other parameters suggesting varying degrees of auditory specialization. The inferior chamber is smaller than the superior in 9 of 13 species studied. Of these, $S$. calurus seems to be least specialized and the inferior chamber is partitioned into three parts in three specimens and two parts in a fourth. The medial and lateral inferior chambers have fused to form a single common inferior cavity in this fourth specimen, the condition typical of the other 12 species of this group. Vestiges of the bony partition that originally divided this chamber occur commonly in $M$. shawi as a raised ridge oriented dorsoventrally along the middle of the posterior wall of the cell; the same condition exists in Desmodilliscus. A minute accessory medial cavity is present in all specimens of Sekeetamys studied, a large proportion of Rhombomys and Psammomys and a smaller percentage of four species of Meriones. This cell is present unilaterally in single specimens of $M$. tristrami and $M$. shawi and vestigial in $M$. unguiculatus (table 4). The AMIP cell is incorporated into the medial inferior cell when the wall formed by the horizontal lamina of the lateral canal fails to develop. The general trend of change in the inferior cell is toward fusion of the two or three small cells into a single large unit concomitant with expansion of this chamber. The fenestration connecting the IP with the tympanic cavity is smallest in Sekee- tamys calurus, among all 13 species, by a factor of at least five. Among the other 12 species, the size of this opening seems to be closely correlated with the magnitude of the transformer ratio. This connection is smallest in Meriones hurrianae, persicus and tristrami and largest in $M$. cras sus and libycus (figs. 39, 40).

The superior chamber is highly pneumatized in all the Gerbillinae but Taterillus, Tatera, and Gerbillurus paeba and is always divided into a small medial compartment that varies much less in size than does a large lateral chamber (tables $5,6)$. In the generalized condition of $T a$ tera and Gerbillurus the superior chamber connects only with the anterior cell. In all other forms studied the SP opens ventrally either directly into the tympanic cavity (Desmodillus and Pachyuromys) or into the inferior chamber directly above the opening of this chamber into the tympanic cavity. The arc of the lateral canal and the sacculus form the limits of this opening in all species but Desmodillus auricularis and Sekeetamys calurus. Though no measurements have been made to verify this, the opening is remarkably uniform in size, except in Pachyuromys duprasi in which the diameter of the arc of the lateral canal is about twice that of any of the other species examined.

The subarcuate fossa extends into the medial side of the superior chamber where it completely fills the inside of the lateral canal arc in Tatera indica and Gerbillurus paeba. However, in all other forms, it is reduced relative to this condition and is progressively eliminated from the SP chamber with increasing pneumatization. It persists as a small nodule in most species but is absent in $M$. crassus, $M$. libycus, and $P$. duprasi (figs. 41, 42).

The morphology of Desmodillus and Sekeetamys provides indications as to how this mastoid tympanic connection may have developed. The superior chamber of Desmodillus connects with the anterior cell as in Tatera and Gerbillurus. The subarcuate fossa is virtually absent and a sheet of thin bone fills the arc enclosed by the lateral canal and its connection with the utriculus. A very small semicircular opening adjacent to the utriculus perforates this sheet, thus joining the SP with the tympanic cavity. This connection 


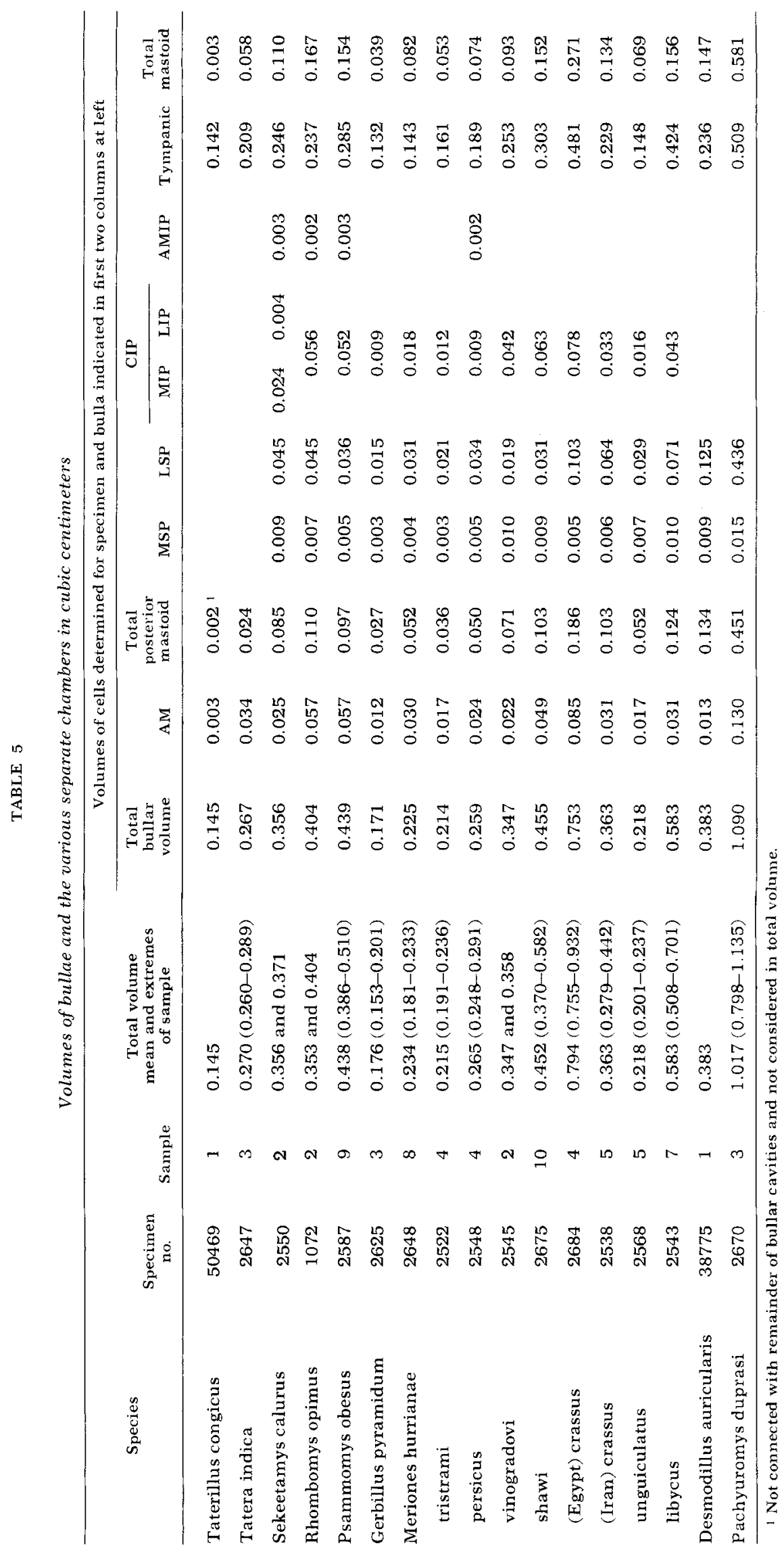




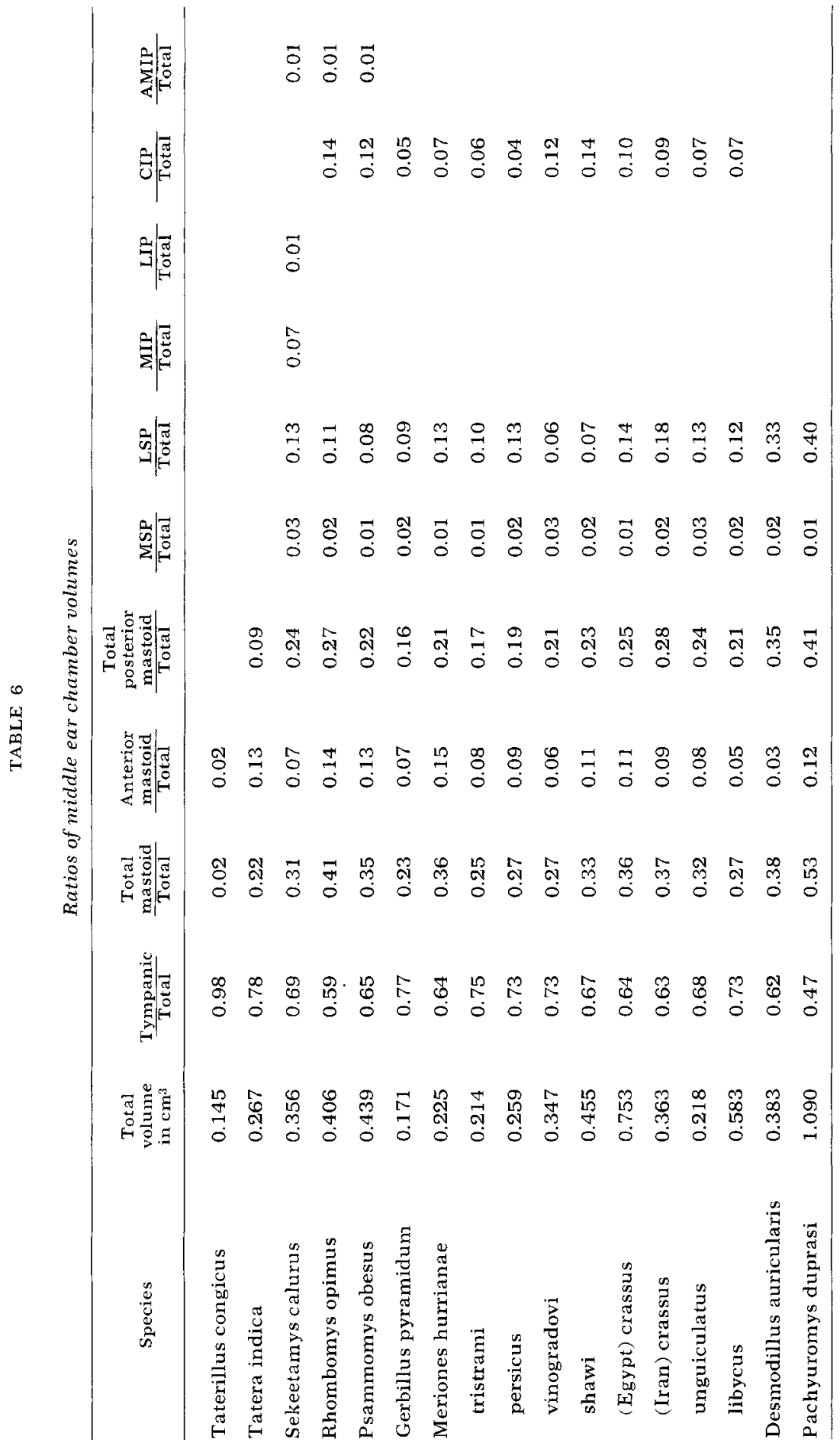


has enlarged in Sekeetamys to encompass two-thirds the area enclosed by the lateral canal, but a thin bony partition still fills the lateral one-third of the arc. However, a partition separates the posterior superior and anterior cells in this species and in Pachyuromys, which is the closest related form of all Gerbillinae to Desmodillus. The septum between the anterior and superior cells, characteristic of all the species with greatly pneumatized mastoids with the exception of Desmodillus, may have developed as an internal buttress for the following reasons. The entire outer layer of mastoid is composed of thick lamellar bone in Tatera. The outer layer is much thinner than in Tatera in all forms with pneumatized mastoids. The anterior cell of Desmodillus is small in volume and the ratio to total bullar volume is the smallest of all specialized forms (tables 5, 6). Desmodillus, however, possesses what appears to represent initial stages in the development of a partition between the anterior and superior chambers. A small sickle-shaped buttress extends ventrally from the roof at the juncture of the anterior and posterior superior cells. The thicker medial portion of this brace attaches to the anterior canal at a point slightly posterior to the anteriormost extent of this canal. A larger wedge-shaped plate arises from the entire length of the crista facialis lateral to the point from which this ridge emerges from the lateral canal, is oriented dorso-ventrally and is highest laterally where it fuses to the lateral wall of the mastoid. The upper free edge of this plate and the lateral extent of the upper buttress meet to form a slightly raised ridge along the lateral roof between the anterior and posterior superior cells. This incomplete septum lies at the boundary of these two cells (cf. p. 58 text) and is in good accord with the boundaries of the complete partition of other specialized species (fig. 38).

A number of muscles insert entirely or partly into the mastoid along the outside boundary between the anterior and posterior superior cells. These are the cleidomastoid, occipitoscapularis, splenius capitis, longissimus capitis, and temporalis. The partition between the anterior and posterior cells rests upon a beam formed by the laterally directed anterior part of the lateral canal superimposed on the facial canal and the thick crista facialis lateral to the point where these two canals diverge. Pneumatization of the anterior cell produces concentric expansion and thinning of the bony roof. It seems that under these conditions a vertical, truncated, triangular partition would reduce compressile forces on the broad thin mastoid roof and provide a stable insertion for these muscles. If such is the case, then a connection of the posterior superior chamber with the tympanic or posterior inferior cells is required in order to achieve maximum bullar volume.

The evidence suggests that the anterior cell developed first and was followed by pneumatization of the posterior mastoid. It is not clear when the division of this latter region into superior and inferior chambers first occurred or if this event may have occurred independently in one or several lines. If the double chambered posterior mastoid line is derived from a Tatera-like ancestor then the evidence available suggests that the inferior chamber evolved subsequent to the superior cell.

The tympanic portion of the bulla is conservative in the degree of change observed between generalized and specialized forms relative to the degree of mastoid modifications described above. This cell composed 47 to $98 \%$ (mean $69.1 \%$ of the total middle ear volume among the forms studied) (table 6).

This chamber constitutes $18 \%$ of total middle ear volume in Dipodomys merriami and spectabilis (Webster, '61). Although I have made no volumetric determinations, study of the auditory bullae of specimens of the heteromyids Microdipodops pallidus and $M$. megacephalus suggests that a similar size relationship holds for these specialized forms. Likewise, examination of specimens of the specialized Dipodidae, Jaculus jaculus and blanfordi and Salpingotus michaelis suggests that the tympanic volume constitutes considerably less than half of total bullar volume and probably less than $25 \%$. Illustrations of the skulls of Eremodipus and Cardiocranius (Vinogradov, '37; Gromov et al., '63; Ognev, '48) indicate that the same rela- 
tionship holds for these specialized forms. Specimens of Ctenodactylus and Massouteria (Ctenodactylidae), inhabitants of the rocky highlands of the Sahara region, also show the tendency of greater pneumatization of the mastoid cells relative to the tympanic. The middle ear structure of Heteromys and Perognathus is less specialized than that of Dipodomys and $M i$ crodipodops. As the ears become specialized the mastoid component enlarges much more than does the tympanic component (Howell, '32).

Specimens of Allactaga, Alactagulus, Dipus and Scirtopoda and illustrations of Pygerethymus, Scarturus, Paradipus, and Euchoreutes (Vinogradov, '37) show a trend in the enlargement of the middle ear cavity very similar to that which appears to have occurred among the Heteromyidae described above. The middle ears of these dipodids show virtually every intermediate stage between the most generalized and most specialized conditions. In this trend the mastoid component expands at a much greater rate than the tympanic. No generalized ctenodactylids are known.

In the Gerbillinae the mastoid volume increases from $2 \%$ of total bullar volume in the generalized Taterillus to $53 \%$ in the highly specialized Pachyuromys (mean of forms studied $30 \%$ ) (table 6).

Any discussion of evolutionary trends in the gerbilline ear must regard this organ as a unit composed of the middle and inner ears, which function together to convert airborne sound to neural responses. Enlargement of the tympanic cavity has in general followed two directions. The most obvious pathway is that of overall increase in volume by expansion in all directions. Table 6 illustrates the overall changes in tympanic size among the species studied.

Dissections of bullae and/or examination of endobullar casts reveal that pneumatization of the tympanic bone around the anterior edge of the external auditory meatus is achieved by a partitioning of the tympanic wall. The tympanic wall in this region is formed of a single lamina in generalized forms (e.g., Taterillus, Tatera, Meriones persicus) but separates into medial and lateral plates in intermediate and specialized forms. The medial lamina then forms the anterior wall of the external auditory meatus and helps support the tympanic annulus. The lateral wall becomes continuous with the lateral bullar wall.

The space between these plates is pneumatized in different ways in the gerbillines studied. Volume has been added to the middle ear cavity by expanding this space so that the anteroventral part becomes confluent with the tympanic chamber as in Meriones crassus, sacramenti and libycus (fig. 46). The tympanic may also separate into dorsal and ventral sheets just anterior to the superior extent of the external auditory meatus. This cavity when formed is purely tympanic in origin, but in most cases opens into the lateral side of the anterior mastoid chamber. This condition occurs in Desmodillus, Pachyuromys, Psammomys, Rhombomys, and Meriones shawi, hurrianae, and crassus. Both pathways of pneumatization of this region occur in a number of these same forms. The inferior enlargement predominates in Psammomys, $M$. shawi and $M$. crassus, the superior enlargement characterizes Desmodillus and $M$. hurrianae and superior and inferior cavities are nearly equal in Pachyuromys (figs. 43-46). Five casts of Meriones crassus from Iran show that both centers have enlarged and are in virtual contact, separated by a single bony lamina. Three of four casts of $M$. crassus from Egypt show that the internal lamina separating these centers has been lost and that the two chambers are continuous but a pronounced external groove demarcates the former point of division.

The tympanic anterior to the external auditory meatus is pneumatized in a unique manner in the two specimens of Desmodilliscus braueri studied. The tympanic wall has been inflated to a degree equal or similar to that found in Pachy. uromys, $M$. crassus and libycus. However, this cell opens into the tympanic chamber via a small fenestra $0.63 \mathrm{~mm} \times$ $0.32 \mathrm{~mm}$ ) just below the point of articulation of the anterior process of the malleus with the tympanic. In these other mentioned forms this cell is not cut off from the tympanic chamber but consti- 
tutes a direct unconstricted continuation of it.

\section{The tympanic annulus}

The tympanic annulus supports the tympanum. In the adult condition it lies within the tympanic cavity. The annulus does not form a complete ring. Approximately the upper one-third to one-fourth of the ellipse remains open as the dorsal arms never meet. The ventral portion extends considerably further medially than the dorsal part so that the ring rests at a rather sharp angle to the vertical. This angle varies among the forms studied but has not been quantified.

The attachment of the tympanic annulus to the lateral bullar wall (tympanic) has been modified in all of the Gerbillinae, but exists as a raised ridge on the medial surface of the lateral tympanic wall in the Dipodidae and Heteromyidae.

In the Gerbillinae the tympanic annulus retains connection to the rest of the tympanic, but the bulla has been extensively remodelled in this region. The attachment of the free ends of the annulus to the tympanic at the dorsal edge of the external auditory meatus constitutes what is essentially the primitive condition or the condition as occurs in Taterillus, Tatera, Sekeetamys, Rhombomys, and the less specialized species of Gerbillus and Meriones. The points of attachment here represent raised ridges on the inside of the lateral bullar wall. In the more specialized species of Gerbillus and Meriones, Desmodillus, Psammomys, Desmodilliscus and Pachyuromys the condition remains essentially the same but is obscured by the pneumatizations of the tympanic anterior and dorsal to the external auditory meatus and/or by the development of the accessory tympanic membrane. Distal to the points of attachment of the free ends of the annulus the situation changes strikingly. The diameter of the external part of the auditory canal is approximately one-half that of the tympanic annulus. Thus, the canal widens in its medial extent. The cylindrical canal opens opposite the upper two-thirds of the tympanum and its upper margin is flush with the superior portion of the annulus. Because the inferior extent of the tympanum inclines sharply medially and its diameter is greater than that of the canal, a bellshaped lamella of bone joins these two. The meatal cylinder and bell-shaped support of the annulus are connected to the lateral bullar wall by a series of buttresses (figs. 47, 48). These braces run essentially perpendicularly between the auditory canal and the lateral wall. With increase of bullar volume these buttresses lengthen and at the points of attachment to the lateral wall, each principle strut branches dendritically into smaller braces forming elaborate patterns. Dissection of the lateral wall reveals that in spite of rather complicated peripheral patterns a primary arrangement exists. There are three primary braces which form a modified $T$, the arms of which form a well-opened chevron. The base of the $T$ passes ventrally while the arms of the chevron are directed anteriorly and posteriorly, respectively (figs. $47,48)$.

This morphological arrangement allows the tympanic air space to expand into the area lateral to the tympanum. The great expansion of this area that is obvious by comparison of Taterillus or Tatera with Pachyuromys, Meriones crassus or several other forms suggests that the tympanic bulla has enlarged in this manner. The buttress system between the truncated cone and lateral wall probably functions to stabilize the tympanic annulus but also may act to maintain the integrity of the bulla by resisting compressile forces which might be produced by contractions of the posterior belly of the digastric, stylohyoid, stylopharyngeus, and styloglossus, which either originate on or pass over the inferior surface of the tympanic bulla. The buttress appears appropriately shaped to direct compressile forces upward along the various axes to the more stable region at the base of the external auditory meatus. These forces would likely be dissipated along this route and if not totally damped on reaching this point, the $\mathrm{V}$ shaped floor of the external auditory meatus would seem ideally situated to transmit any excess forces to the structurally stable region at the tympanic mastoid junction above the meatus. These factors would most likely be functional in those species possessing greatly inflated bullae (e.g., Pachyuromys, $M$. crassus).

The internal relocation of the tympanic 
annulus seems to be one, if not the key factor that has allowed pneumatization of the tympanic cavity of the Gerbillinae. By elaborating this modification a large volume has been incorporated into the middle ear chamber of these rodents. This volume probably represents between 30 and $40 \%$ of the total air space of the tympanic cavity in the species with greatest hypertrophy ( $M$. crassus, $M$. libycus and P. duprasi).

Two other lines of evidence support the observation that the auditory bullae have expanded concentrically.

In Tatera indica the posterior auricular branch of the vagus nerve passes around the outer edge of the bulla in a groove along the tympanic-mastoid juncture and, on the lateral side of the bulla just posterior to the stylomastoid foramen, enters a bony canal which joins the facial canal anteriorly. The posterior auricular and facial nerves (VII) exit via the stylomastoid foramen.

In all the gerbillids possessing inflated mastoid cells the posterior auricular nerve passes through the posterior mastoid cells as discussed above (p. 58 text). Examination of an ontogenetic series of Meriones shawi and Pachyuromys duprasi confirms that the adult posterior mastoid and posterior portion of the tympanic expand posteriorly and laterally. It seems likely that with the increased pneumatization of the mastoid cells the posterior auricular nerve was surrounded and its course came to lie between the laminae of the tympanic and mastoid bones within the middle ear.

In Dipodomys and Jaculus this phenomenon does not occur, apparently because the mastoid cells expand to a much greater degree than the tympanic bullae. Due to this differential enlargement in the specialized heteromyids and dipodids the original course of the posterior auricular nerve outside the bulla is altered only little or not at all.

With great inflation of the anterior and superior mastoid cells as in $M$. crassus, Desmodilliscus and Pachyuromys the paraoccipitals, parietal, and interparietal bones have been extensively remodelled and are reduced in width. Hypertrophy of the tympanic results in a great reduction in width of the basioccipital and basisphenoid. An- terior expansion of the tympanic modifies the squamosal and alisphenoid extensively. These changes are relative to the generalized condition typical of Taterillus, Tatera, and Gerbillurus. The species other than the forms mentioned above display virtually all degrees of transition between the extremes of generalization and specialization.

The functional significance of hypertrophied bullae was referred to brieffy above (p. 49 text). Impedance of the ear drum at low frequencies is greatly influenced by the cushion of the middle ear cavity (Békésy, '60). Increase of air pressure within the middle ear reduces cochlear potential responses to low frequency tones more than for high frequency tones (Wever and Lawrence, '54). Cochlear potentials were greatly diminished relative to normal Dipodomys and Meriones crassus when bullar volume was reduced (Webster, '61; Legouix and Wisner, '55). This difference is attributed to increased resistance to incursions of the tympanum. Effective tympanum area and middle ear volume increase concomitantly (tables 2, 5 ). The species studied neurophysiologically are most sensitive to sounds in the low frequency range of $500-2800 \mathrm{~Hz}$ (figs. 10-13). Species showing greatest sensitivity to these sounds are characterized by larger transformer ratios as discussed above, and this increase has resulted in part by enlargement of the tympanum. A larger tympanum will compress a middle ear air cushion of given volume proportionately more than will a small tympanum. Low frequency sounds produce greater displacements of the tympanum than high frequencies. The characteristic hypertrophy of the middle ear volume of the specialized Gerbillinae has probably evolved as a means for reducing friction due to enlargement of the tympanum coupled with the auditory specializations for hearing low frequency sounds. Bullar hypertrophy, within the two chambered mastoid gerbils ( 8 genera, ca. 75 species) has resulted in a great deal of experimentation upon a single architectural plan.

A correlation matrix of the mean values of the six kinetic components of the gerbilline transformer ratio and the volume of the middle ear cavity for 17 species is 
presented in figure 6. A high degree of correlation exists among all of these factors. Only five combinations are not well correlated at the 0.05 or $0.01 \%$ levels. Three components, two-thirds the area of the accessory tympanum, the length of the neck of the malleus, and the length of the incus lever arm, seem to account for these low values. The first two of these components are involved in an acquired system characteristic of only five of the 17 species. Both of these factors are ostensibly least correlated with length of incus arm and the functional area of the tympanum, while each is highly correlated with the other four components and with each other.

It seems that the gerbilline middle ear represents a highly integrated organ, the components of which have evolved at very similar rates.

\section{The inner ear}

In the following discussion I have used the standard anatomical nomenclature for reference to inner ear anatomy (Bloom and Fawcett, '68). Details of what is known concerning the manner in which the organ of Corti functions to transduce mechanical stimuli to neural responses are presented by Békésy ('53a,b, '54, '56, '60), Davis ('54, '59, '61), Wever and Lawrence ('54), and Wever ('66).

The basilar membrane is stiffer near the stapes than at the helicotrema, located at the opposite end of the cochlea (Békésy, '56). For man and most other mammals studied, this stiffness is about 100 times greater near the stapes than near the helicotrema. At very low frequencies the movement of the vibrating system is independent of mass, and the displacement of the various parts of the membrane is determined solely by their elasticity. Damping by the cochlear fluids affects movement of the basilar membrane. Traveling waves, observed along the basilar membrane, display a flat maximum that shifts its location along the membrane with change in frequency. In summary, these observations show that structurally the basilar membrane is adaptive for responding to different frequencies in different regions and that this phenomenon actually occurs. Thus, high frequencies are "received" by the stiff membrane of the basal turn, and lower frequencies by the more flexible area away from the basal turn.

The organ of Corti acts as a mechanical impedance-matching device complementing that of the middle ear. Békésy shows that "a pressure on an elastic membrane can be transformed not only into a pull but also into a shearing force." Where a part of an elastic plate is covered with a thin layer of stiff material, then bending of the elastic plate will produce shearing forces under the stiff layer that may be large compared to the pressure forces acting to bend the plate (Békésy, '53a).

As the basilar membrane bulges "upward" or "downward" the stiff reticular lamina tends to rock on the support of the rods of Corti around an axis where the basilar membrane attaches to the osseous spiral lamina. In turn, the tectorial membrane swings on its attachment to the limbus spiralis. In characterizing the movements of these two structures, Békésy ('53a) has shown that the tectorial membrane is quite stiff and resistant to vibrations due to its small elastic forces and large friction forces, whereas the opposite holds for the basilar membrane. The result of these two movements is a shearing force between the reticular lamina and the tectorial membrane (cf. figs. 11 and 12 in Davis, '59). The "hairs" extend from the hair cell cuticular plates, which are firmly attached within the reticular lamina, to the undersurface of the tectorial membrane to which they are firmly attached. Therefore, as the basilar membrane bends, the "hairs" are also bent due to different axes and characteristics of movement of the tectorial and basilar membranes. The remaining events in the auditory stimulation sequence are electrical.

Legouix and Wisner's (55) brief description of the inner ear of Meriones crassus provides the only published information on the anatomy of the inner ear of the Gerbillinae.

The structure of the organ of Corti of the 14 species examined in this study, while somewhat modified in certain respects, is typical of the basic pattern described for Felis catus, Rattus rattus, Cavia cobaya, and Homo sapiens. 
The cochlea contains two and one-half to three turns or six to seven half-turns respectively, in the six genera and 14 species studied histologically. While a seventh half-turn is present in a few species (e.g., $T$. indica, $M$. tristrami, $M$. libycus), the organ of Corti diminishes in size rapidly beyond the sixth half-turn. Legouix and Wisner ('55) reported two and one-half turns in the cochlea of $M$. crassus. Data concerning cochlear anatomy are available for several species of desert inhabiting heteromyid rodents, that show anatomical convergence to the Gerbillinae in a number of middle and inner ear characters. Webster ('61) states that four and one-fourth turns are present in the cochlea of Dipodomys merriami and spectabilis. Three full turns or seven half-turns are present in the cochlea of Dipodomys agilis and nitratoides, Microdipodops pallidus, and Perognathus californicus (Pye, '65). Only Pye ('65) provided an illustration from which the number of cochlear turns could be discerned. I have studied sections of $D$. (cf. merriami) and find three turns. Webster ('61) lists eight half-turns and another fraction of a turn for the cochlea of $\mathrm{Di}$ podomys. In actuality three half-turns as viewed in midmodiolar section, the method Webster used, constitute a single complete turn. Thus, there are only three and onehalf turns in the cochlea of the two species of Dipodomys studied by Webster, which is in much better agreement with the number of turns found by Pye (loc. cit.) and that presented here. The cochlea of this specimen is somewhat longer in midmodiolar axis than in any of the gerbilline species studied. However, the diameter of this Dipodomys cochlea is considerably narrower than that of the gerbilline species. The three scalae appear on gross examination to be more voluminous in all turns in the gerbilline species than in Dipodomys but these differences were not measured. The cochlea of Salpingotus michaelis, a desert inhabiting jerboa of the family Dipodidae, has two complete turns and is similar in diameter to the Gerbillinae.

The organ of Corti displays several specializations in the majority of the Gerbillinae. Legouix and Wisner ('55) were the first to note that the Hensen cells are much more hypertrophied than in the guinea pig and that a hyaline mass lies within the basilar membrane.

The basilar membrane is narrowest in the basal turn and widens progressively to the fifth half-turn, then narrows somewhat in the sixth half-turn for all the forms studied (fig. 7). This pattern seems to be typical of most mammals in which the basilar membrane has been measured (Guild, '27; Wever, '38; Fernandez, '52; Webster, '61; Pye, '65). Within the Gerbillinae the width of basilar membrane increases progressively along the cochlea as does increasing middle and inner ear specialization (fig. 7). Throughout the cochlear coil, the narrowest width was found in the two species of Gerbillus studied, and the widest in Pachyuromys duprasi.

The presence of a hyaline mass within the basilar membrane was first mentioned, but without detailed description, by Wisner et al. (54). This was the first discovery of any such structure in any vertebrate. A similar mass occurs in Dipodomys (Webster, '61). The hyaline mass is contained within the zona pectinata of the basilar membrane; the fibrous components of the basilar membrane "splits" into two sheets which encompass the hyaline mass (fig. 49). Wisner et al. ('54) refer to it in Meriones as "sub basilar," but, their figure 7 clearly shows that this mass is contained between the dorsal and ventral fibrous lamellae of the pars pectinata. A hyaline mass within the pars pectinata has been noted for two species of Dipodomys, Microdipodops pallidus, Perognathus californicus, and Heteromys anomalus (Pye, '65), but not in Liomys pictus.

A similar structure has been reported and measured within the zona pectinata of a variety of bats (Griffin, '58; Pye, '66a,b, '67), and odontocete whales (Reysenbach de Haan, '56), where it is confined to the basal turn.

In 11 of 12 species of Gerbillinae studied, a hyaline mass is present in the organ of Corti and is confined to the pars pectinata of the basilar membrane. Two fibrous strata are present in the pars pectinata. These two strata unite to form a single sheet in the pars tecta of the basilar membrane and at the junction with the spiral ligament. Comparison of the 


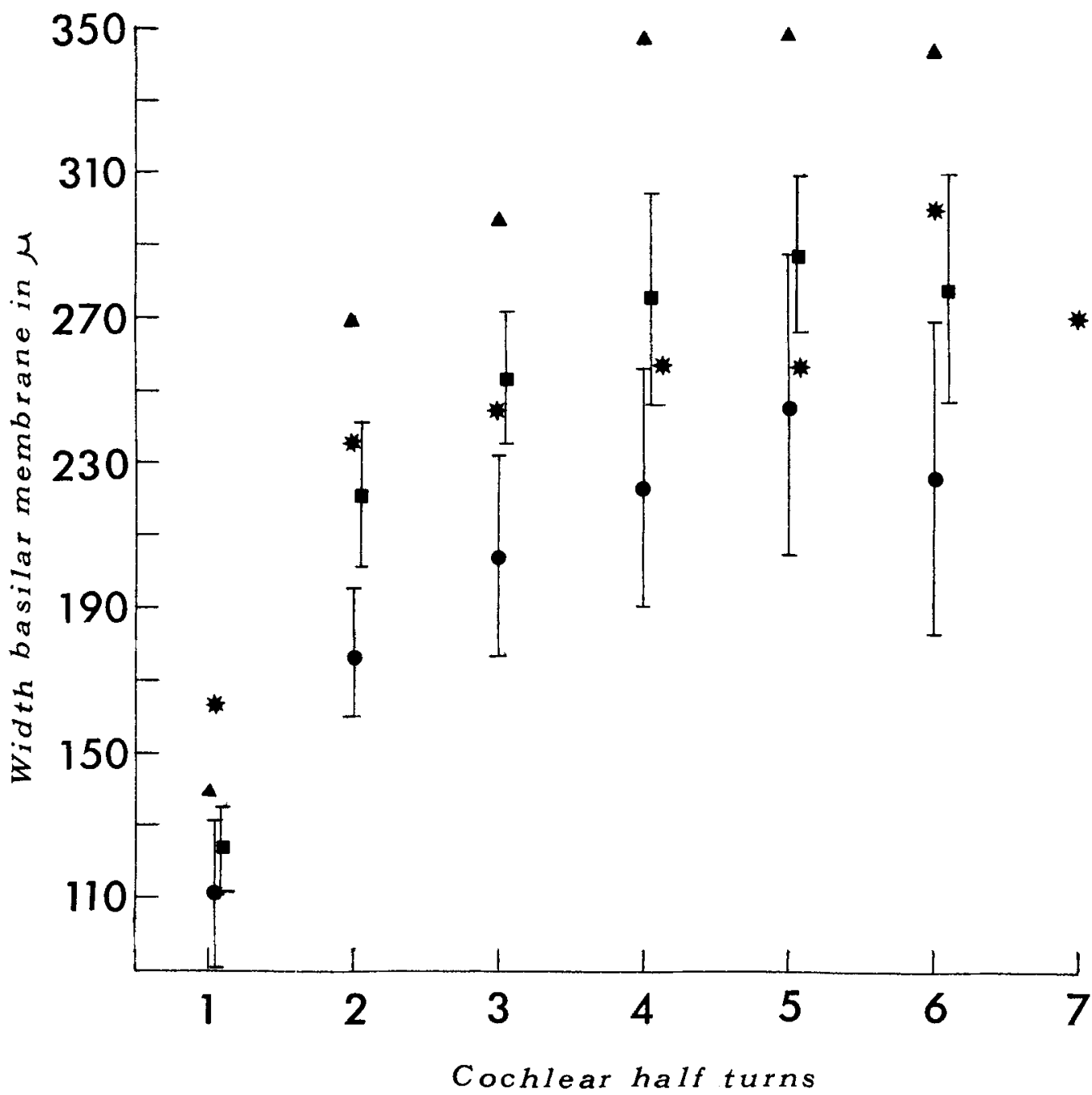

Fig. 7 Variation in basilar membrane width along the cochlear coil. Circles, Tatera indica, Gerbillus gerbillus, G. pyramidum, Sekeetamys calurus. Squares, Psammomys obesus, Meriones persicus, M. tristrami, M. shawi, M. crassus, M. libycus. Triangles, Pachyuromys duprasi. Asterisks, Dipodomys cf. merriami. Vertical lines with bars indicate one standard deviation.

variation of this structure along the cochlear coil among the forms studied reveals several interesting trends.

Tatera indica lacks a hyaline mass. The species of Gerbillus and Sekeetamys studied, possess a hyaline mass that is only slightly elaborated. Meriones, Psammomys, and Pachyuromys have greatly enlarged the hyaline mass beyond the condition of the previous two genera but the mass reaches greatest proportions in Psammomys. Figure 8 provides graphic representation of the variation in the thickness of the hyaline mass of these groups along the cochlear spiral. Hyaline tissue is first encountered in the apical part of the basal half-turn. Because of the differences in specimen orientation no measurements of the hyaline tissue were recorded from the basal half-turn. Maximum thickness is reached in halfturns three, four, and five in each group, and declines in the apical half-turn or is absent, as in the specimen of Sekeetamys examined. However, figure 8 does not reveal the relative position of the hya- 


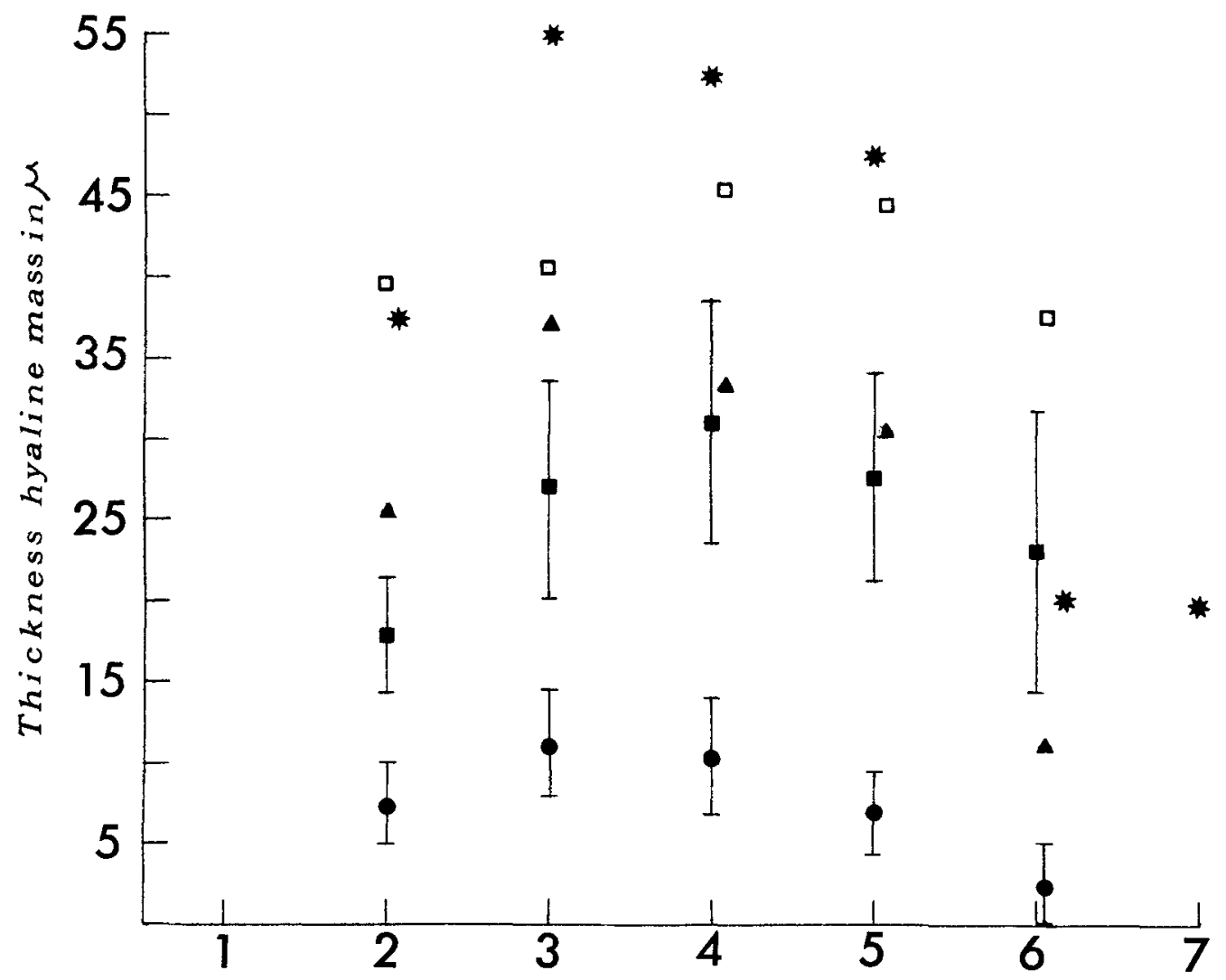

\section{Cochleat half turns}

Fig. 8 Variation in thickness of hyaline mass along the cochlear coil. Circles, Gerbillus gerbillus, G. pyramidum, Sekeetamys calurus. Closed squares, Meriones persicus, $M$. tristrami, $M$. shawi, $M$. libycus and $M$. crassus. Open squares, Psammomys obesus. Other symbols as in figure 7 . Vertical lines with bars indicate one standard deviation.

line mass in the basilar membrane and may thus be somewhat misleading, because positioning of this mass probably affects the characteristics of vibration of any given segment of the membrane. The position of the hyaline mass varies considerably along the cochlear turn. It may be located centrally, beneath the organ of Corti or take a more peripheral position toward the spiral ligament (figs. 50-56). In all species studied, the mass was most centrally located in half-turns three and four. In general, it was displaced towards the spiral ligament in half-turns two, five and six. In the two apical half-turns the tendency for positioning towards the spiral ligament begins, with the exception of Pachyuromys, in half-turn five and reaches an extreme in half-turn six. Although a hyaline mass has been noted (supra cit.) in a number of mammals, I am unaware of any attempt at explanation of its origin. The submicroscopic basilar membrane of $R$. rattus figured by Iurato ('62) appears to be extremely similar in structure to that of Tatera indica. The pars pectinata is formed by the following components: (1) two anhistous fibrous layers; (2) anhistous "cottony" ground substance; (3) basilar membrane cells. These components present a most interesting arrangement in $R$. rattus. A thin fibrous layer formed of medium-sized radially aligned fibers runs in a straight line beneath the organ of Corti from which it is separated by a $200 \AA$ mem- 
brane. A layer of "cottony" ground substance intervenes between this thin fibrous layer and a second thicker fibrous layer composed of large size fibers, which do not run parallel to the first fibrous layer, but curve slightly, with the concave side toward the cochlear duct. A second layer of "cottony ground substance" occurs between the second fibrous stratum and the single layer of basilar membrane cells that cover the scala tympani surface of the membrane. The two fibrous strata unite, forming a single layer in the zona tecta and at the attachment of the basilar membrane to the spiral ligament. The pars pectinata is about twice as thick in the "middle cochlear whorl" than in the basal and apical whorls due to a greater amount of "cottony ground substance" (Iurato, '62).

Iurato's study offers a number of implications for consideration regarding the origin of the hyaline mass. It seems possible that the hyaline mass of the pars pectinata of the Gerbillinae may represent different degrees of elaboration of the "cottony ground substance" between the two fibrous strata. The presence and morphological disposition of the two fibrous strata of the pars pectinata are certainly similar to the fibrous strata found in those Gerbillinae having a hyaline mass in the pars pectinata. Knowledge of the ultrastructural organization of the basilar membrane of the Gerbillinae might provide a basis for a better understanding of the manner in which the hyaline mass has developed in this subfamily and in elucidating its functional significance.

The Hensen cells of the organ of Corti show considerable hypertrophy in the Gerbillinae in comparison to the condition in Rattus rattus, Cavia cobaya and Felis catus. Considerable variation in degree of hypertrophy exists among the species studied and along the cochlear coil in each species (fig. 9). In general, these cells are of minimal height in the basal half-turn and increase progressively in the apical direction reaching a maximum in the third or fourth half-turn, and decline beyond this point; however, height at the sixth half-turn considerably exceeds that of the first half-turn. Tatera and Sekeetamys represent exceptions to this generalization.
The Hensen cells of Tatera indica show an unbroken increase in height from the basal to the apical half-turn, reaching a maximum in the sixth half-turn. The graphic curve of Hensen cell height for Sekeetamys is bimodal, where height increases from one-half turn one to one-half turn two, decreases by $150 \mu$ in one-half turn three, then increases to maximum in one-half turn four, decreases by $165 \mu$ in one-half turn five, and increases slightly in one-half turn six.

The relatively distinct groups into which the various species segregate, on the basis of middle ear anatomy and the morphology of the hyaline mass, are much less apparent if only Hensen cell hypertrophy is considered; the means of these groups, however, indicate differences.

In summary, all of the species studied demonstrate good concordance in the disposition of the curve for Hensen cell height along the cochlear spiral. The amount of variation in cell height along the cochlear coil is considerably less among all the species studied than that found for thickness of the hyaline mass.

Because specialized forms of the Heteromyidae and Gerbillinae show convergence in a number of features of ear structure, it seems appropriate to consider here the available data regarding certain characteristics of the organ of Corti of the Heteromyidae.

A group of unusual supporting cells in the organ of Corti of Dipodomys have been described as Hensen cells (Webster, '61). They are flask-shaped with long apical cytoplasmic processes, and do not rest upon the basilar membrane but upon a layer of supporting cells which rest on the basilar membrane. Pye ('65) described these cells in Perognathus, Microdipodops and two other species of Dipodomys, but referred to Heteromys, which lacked these unusual cells, as being of "conventional form." In Heteromys, all Gerbillinae studied, and numerous other mammalian species (Pritchard, 1881), only the Deiters' cells stain darkly (basophilic) while those of Claudius and Henson stain lightly (acidophilic).

My sections of Dipodomys and the plates of Webster and Pye reveal that the Hensen cells (sensu Webster) are distinctly basophilic, in sharp contrast to all other sup- 


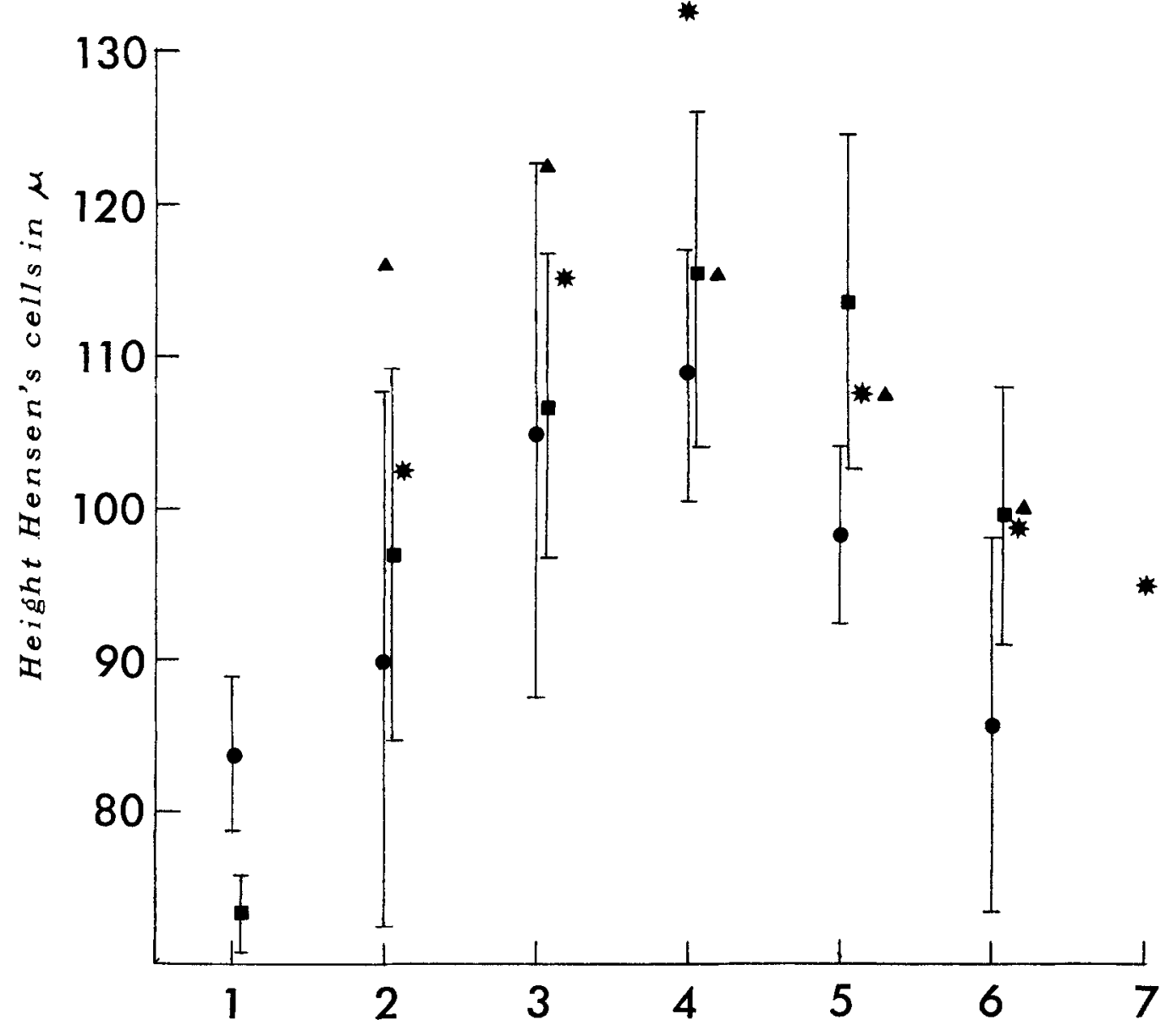

Cochlear half turns

Fig. 9 Variation of Henson cell height along the cochlear coil. Symbols as in figure 7. Vertical lines with bars indicate one standard deviation.

porting cells, except Deiters' and those of Boetcher. Of the supporting cells in the organ of Corti, only the Deiters' and pillar cells contain a considerable quantity of oriented fibrous material (Iurato, '61, '67). The Hensen cells (sensu Webster) of my specimen of Dipodomys show birefringence (anisotrophy) in the axis, from base to tip, of the "cytoplasmic process," the same axis in which Deiters' cells show birefringence. This indicates the presence of an oriented arrangement of intracellular material in these cells. Birefringence was seen only in Deiters' and pillar cells. In the Gerbillinae only the Deiters' and pillar cells showed birefringence. These unusual cells of the specialized heteromyids may not be Hensen cells because their structure differs from classical Hensen cell morphology. They cannot be defined without more extensive study. A number of features of their internal morphology (oriented fibrous? material) and external (long apical processes in contact with the reticular lamina) are quite reminiscent of Deiters' cells. The Deiters' cells farthest from the modiolus abut against the Hensen cells nearest the modiolus; the phalanx bearing necks of the former run close along the modiolar face of the first row of Hensen cells. Thus, the Deiters' cells are in close proximity to the 
Hensen cells in the generalized ears of Rattus and Cavia (Engstrom and Wersall, '58; Iurato, '61).

Specialized structures generally originate as modifications of preexisting structures. The possibility that Deiters' cells have proliferated and now rest upon the Hensen cells in the Heteromyidae should be investigated. The cochlea of the desert and semidesert inhabiting species of Liomys and Perognathus should obviously be studied. The supporting cells upon which these unique cells rest have been identified as "cup cells of Claudius" by Webster (61). I believe that these "Claudius" cells probably represent the Hensen cells of other mammal species. The supporting cells of the organ of Corti of the specialized Heteromyidae appear to be unique among the mammals in which these structures have been studied.

\section{Auditory sensitivity}

Examination of figures 10-14 reveals a striking similarity in the disposition of the overall curves of sensitivity of the species studied electrophysiologically. With respect to all the species studied, the peak of maximum sensitivity occurs between 2200 and $3000 \mathrm{~Hz}$. A second major peak, usually of slightly less magnitude, exists between 1200 and $1800 \mathrm{~Hz}$. These two peaks are separated by a pronounced drop in sensitivity at either 2000 or $2200 \mathrm{~Hz}$. The peak between 1200 and $1800 \mathrm{~Hz}$ does not seem to be present for Tatera indica, Meriones persicus, or $M$. hurrianae. $T$. indica shows a minor peak at $2000 \mathrm{~Hz}$ followed by a drop at $2200 \mathrm{~Hz}$, but both persicus and hurrianae display a graded rise in responses from 1200 to $2200 \mathrm{~Hz}$. At least three additional peaks occur, one at 4000 or $4500 \mathrm{~Hz}$, a second at $8000 \mathrm{~Hz}$ (in all species but $T$. indica and $M$. hurrianae), and the third usually at $800 \mathrm{~Hz}$, but at $1000 \mathrm{~Hz}$ in $M$. hurrianae and $u n$ guiculatus. This last peak does not appear for $T$. indica and $S$. calurus. A minor peak occurs at $500 \mathrm{~Hz}$ in a few species. The major impression obtained from plotting the sensitivity curves of all species on a single graph is that increasing anatomical specialization in the inner and middle ear, results in a concomitant increase in the cochlear potential response (or sen- sitivity) over the range of frequencies tested (fig. 14).

The exact details of the manner by which the mechanical energy of the fluids of the inner ear is imparted to the organ of Corti to produce neural sensation are unknown. It is widely acknowledged that bending of the "hairs" of the hair cells is critical for eliciting a neural response. The only direct observations in vivo of the vibrations of the cochlear partition, in response to sound have been provided by Békésy ('53a,b, '54). Békésy ('53a) states:

\begin{abstract}
". . that a fair description of the movements of the organ of Corti would be obtained by taking the movements of the basilar membrane as the primary given movement. To this movement are joined in a passive way the reticular membrane through the pillars of Corti and the Hensen cells. To the reticular membrane is loosely connected the stiff tectorial membrane damping the vibrations of the reticular membrane. The Reissner's membrane has the loosest coupling of the vibrations of the basilar membrane, but by observing the stained nuclei of the cells in the Reissner's membrane it is easy to see that the longitudinal and radial displacements of the Hensen cells are transmitted even to the Reissner's membrane. . . near the place of maximal transverse vibrations on the basilar membrane. On the side of the stapes the ends of the hair cells under the tectorial membrane and the Hensen cells perform vibrations in a direction which is close to the direction [radial] of the fibers of the tectorial membrane. . . the movements of the Hensen cells are always larger than the movements of the outer hair cells ... in the case of the longitudinal vibrations the tips of the hair cells under the tectorial membrane are so much damped that it seems to be correct to assume that the Hensen cells are moved by the longitudinal bending of the basilar membrane, and they in turn transmit their movements to the outer and inner hair cells. By separating the hair cells from the edge of the reticular membrane the longitudinal vibrations of the outer hair cells decrease their amplitude $1: 4$. Therefore, the Hensen cells contribute to originating the longitudinal vibrations of the hair cells."
\end{abstract}

The process of transducing mechanical energy to neural responses in the cochlea is extremely complex and incompletely understood in many respects. In this study it is possible only to infer cochlear function from a combined study of cochlear potential responses and histological sections of the ears of the species examined. The techniques which I have employed, 

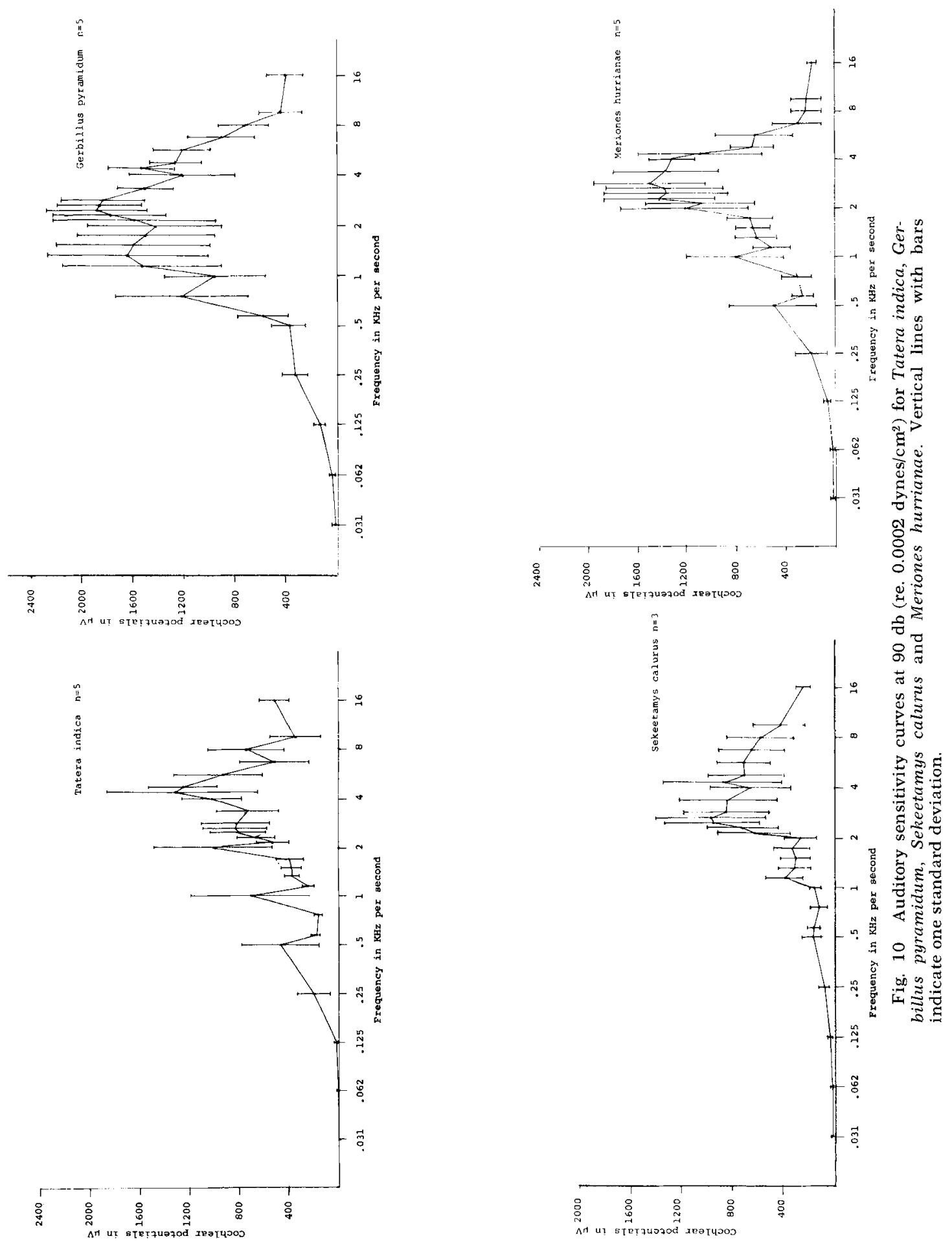


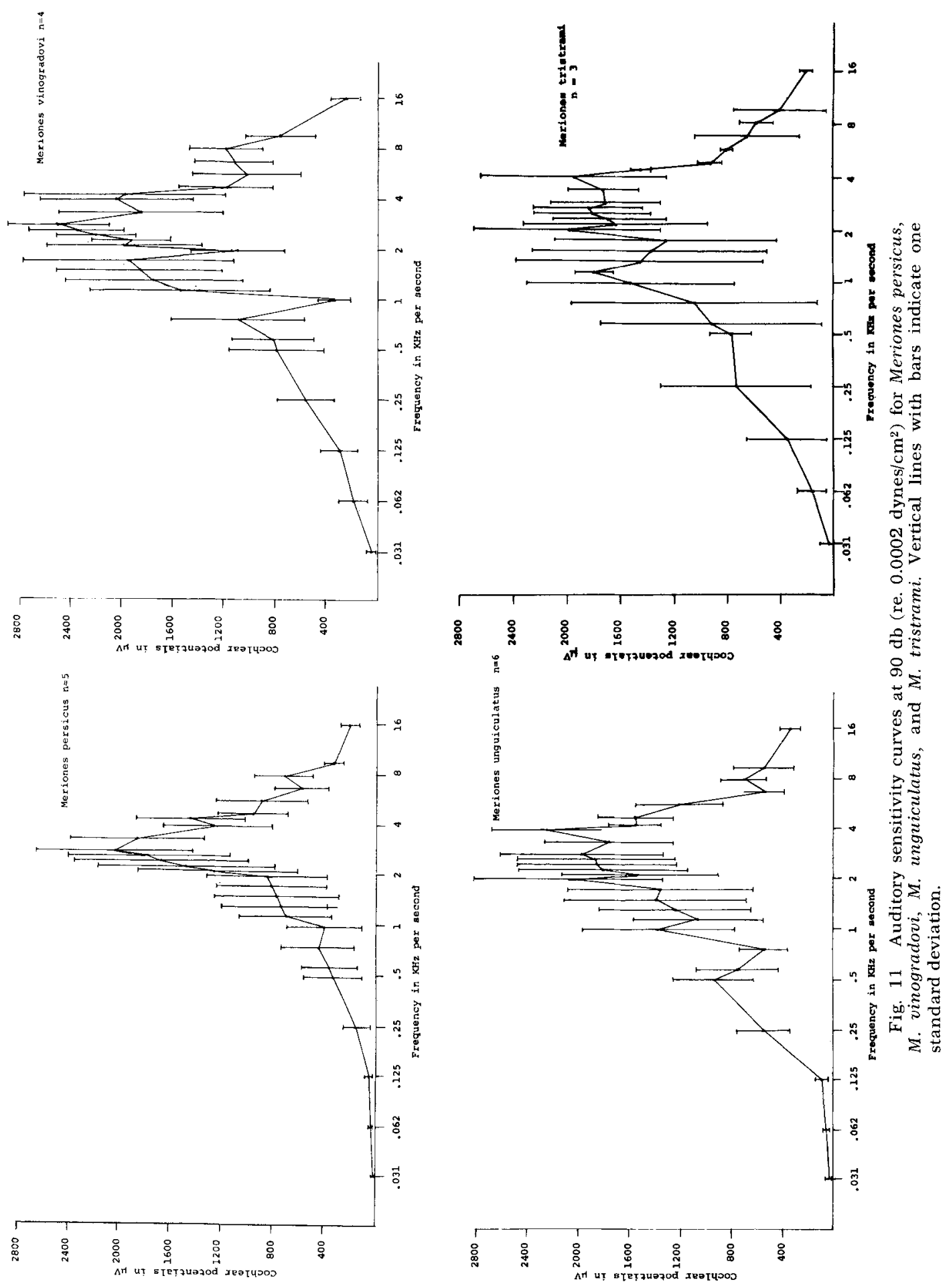




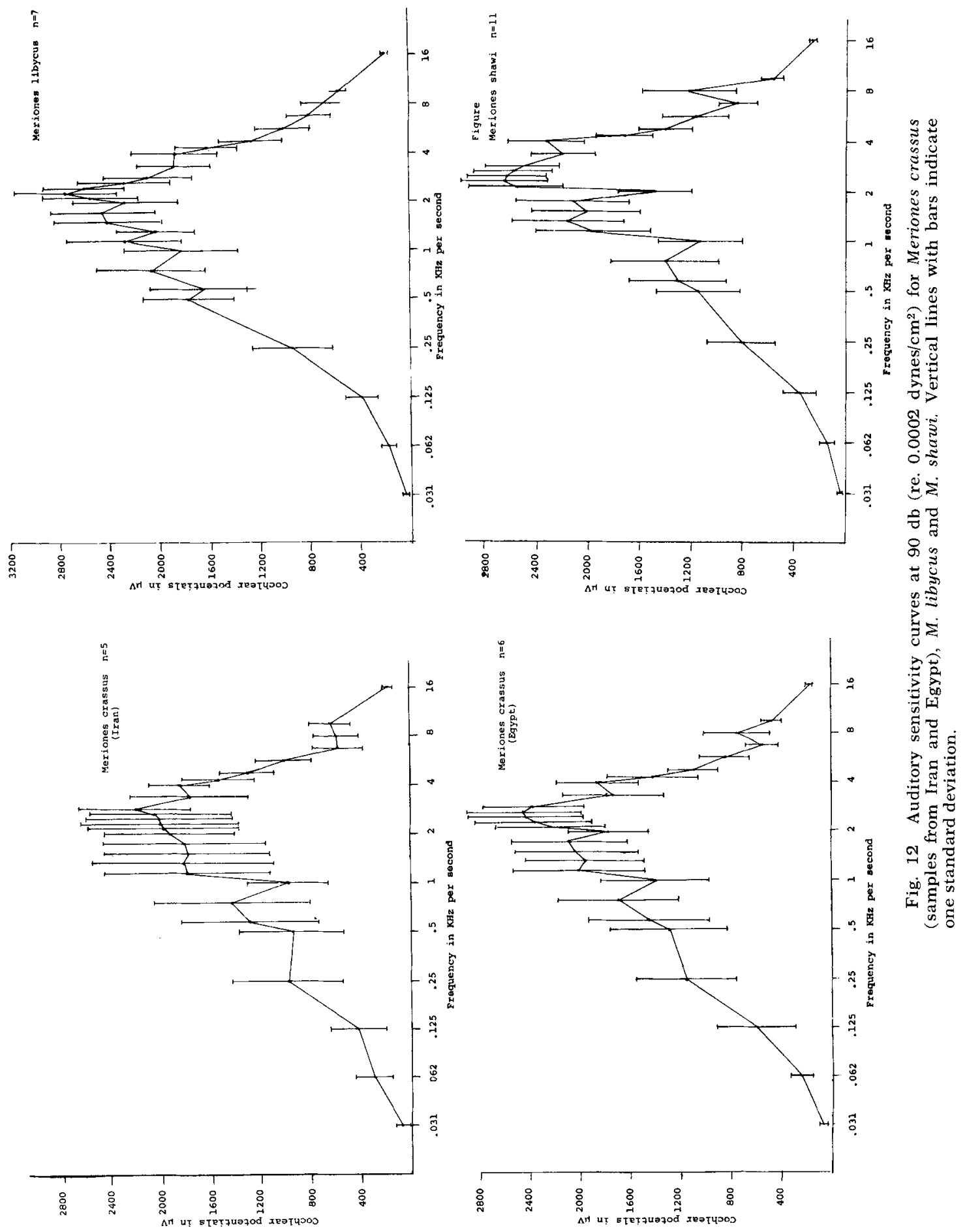



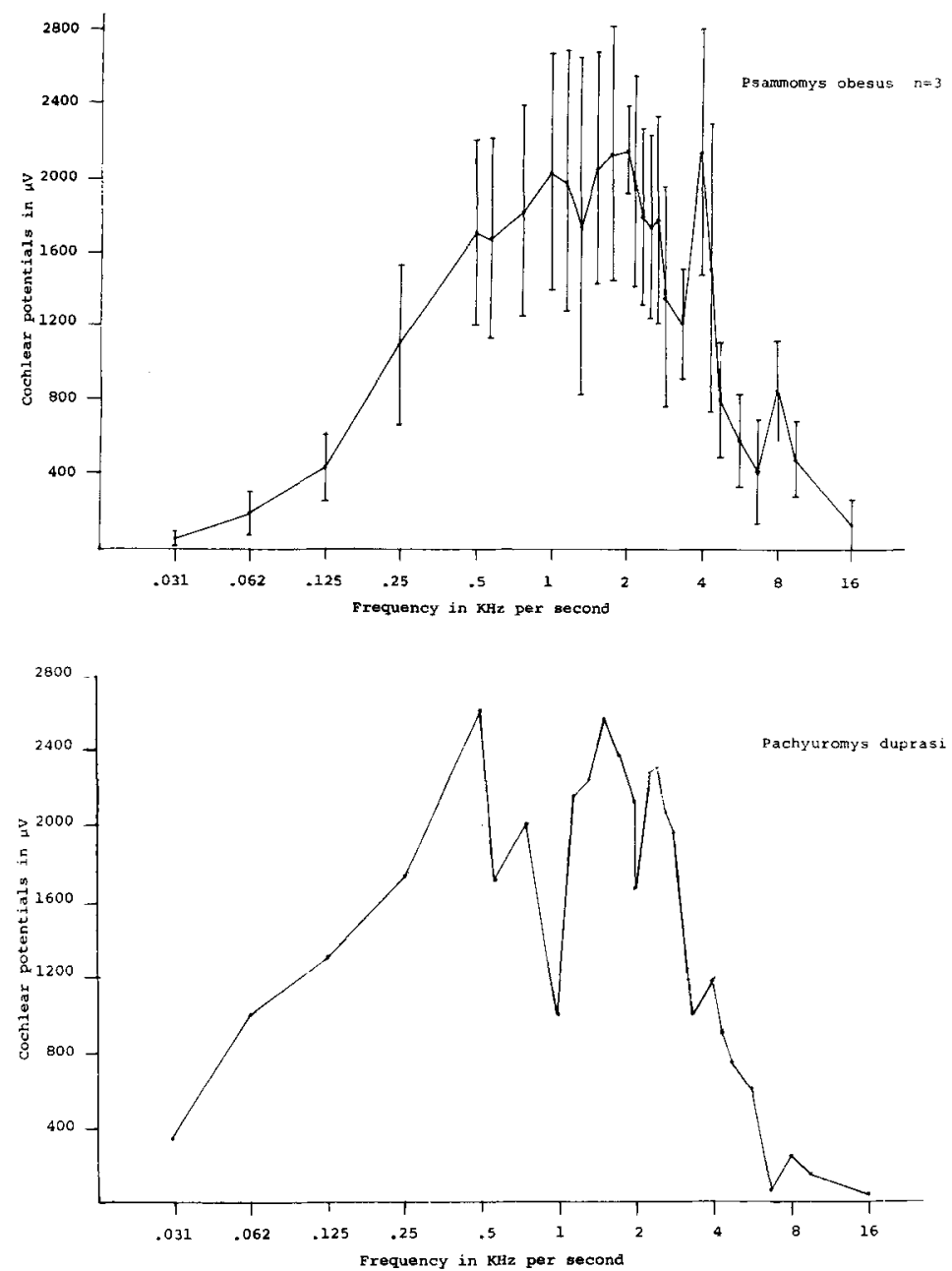

Fig. 13 Auditory sensitivity curves at $90 \mathrm{db}$ (re. 0.0002 dynes $/ \mathrm{cm}^{2}$ ) for Psammomys obesus and Pachyuromys duprasi $(\mathrm{n}=1)$. Vertical lines with bars indicate one standard deviation.

while admittedly limited, do permit one to make some fairly reasonable postulations regarding cochlear function.

There appears to be a general correlation between the height of the Hensen cells and the thickness of the hyaline mass along the cochlear coil with the frequencies of maximum sensitivity determined by cochlear potentials. The amplitudes of motion of the basilar membrane in cochleae of fresh human cadavers showed that the central portion of the cochlea responds to frequencies around $2000 \mathrm{~Hz}$ (Békésy, '44). Frequency localization was mapped along the basilar membrane for cats which were behaviorally conditioned for pure tone threshold and pitch discrimination. Correlation of conditioned responses with the localization of cochlear lesions showed that $500 \mathrm{~Hz}$, $1000 \mathrm{~Hz}, 2000 \mathrm{~Hz}$, and $4000 \mathrm{~Hz}$ were localized respectively at $81 \%, 70.5 \%$, $58.2 \%$, and $45.9 \%$ of the length of the basilar membrane from the basal end (Schuknecht, '60). Other techniques have produced similar results for the guinea pig (Tasaki et al., '52). As shown above, maximum cochlear potentials for the Gerbillinae occur in the range of 1200-3000 $\mathrm{Hz}$ and maximal development of the Hen- 


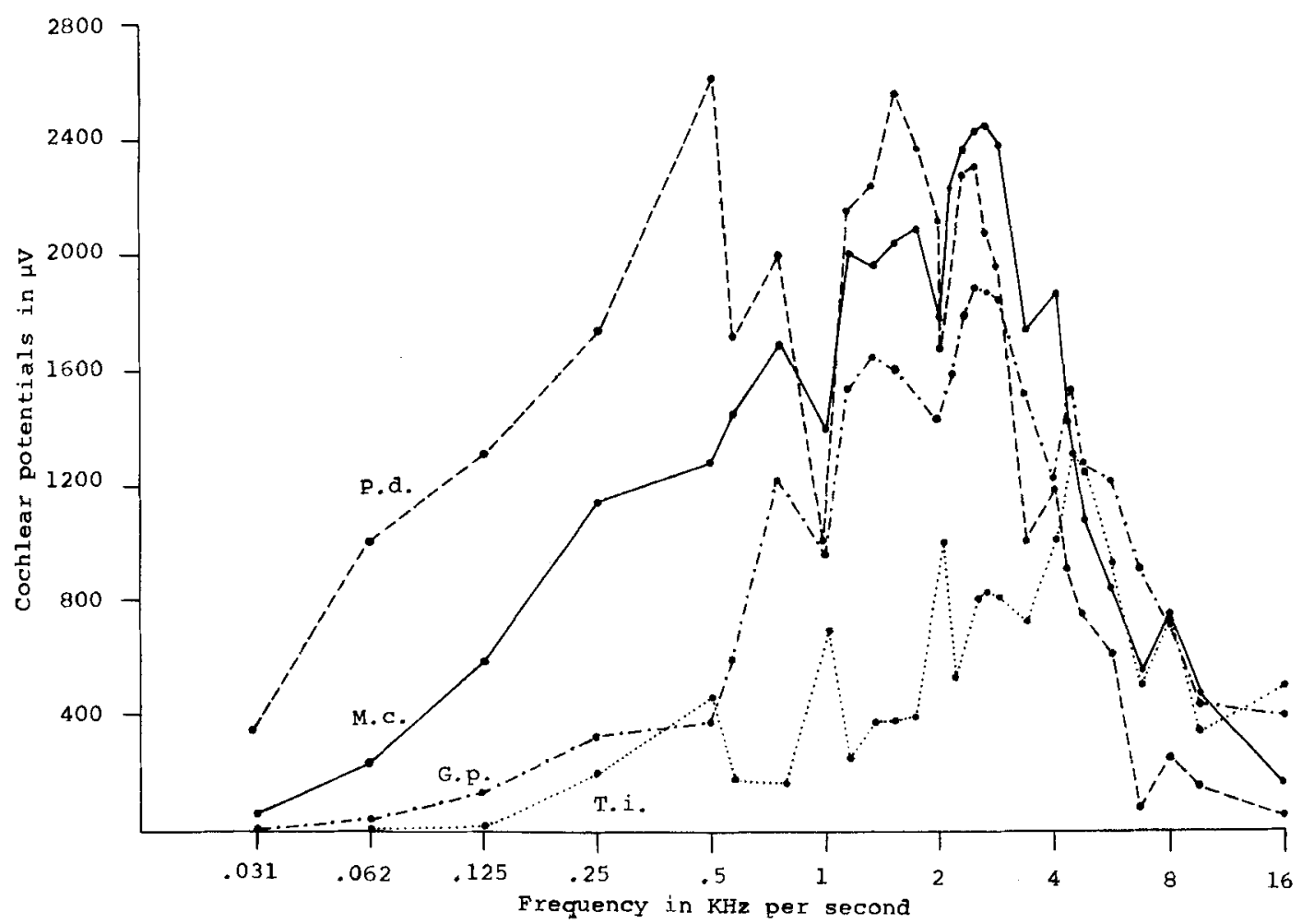

Fig. 14 Composite of mean auditory sensitivity curves at $90 \mathrm{db}$ (re. $0.0002 \mathrm{dynes} / \mathrm{cm}^{2}$ ) of four species representing generalized to specialized ears. T.i., Tatera indica (generalized). G.p., Gerbillus pyramidum (intermediate). M.c., Meriones crassus (specialized). P.d., Pachyuromys duprasi (specialized).

sen cells and hyaline mass exists in the central three half-turns of the cochlea. Assuming that the frequency analysis of the gerbilline cochlea is similar to that found for other mammals, it appears that the modifications of the organ of Corti are in some way related to increased auditory sensitivity. $T$. indica and $M$. hurrianae have similar transformer ratio/middle ear volume ratios but markedly different cochlear potential responses over all frequencies (cf. figs. 5, 10). This strongly implies that the pronounced differences in anatomy of the organ of Corti of these species may be responsible for these differential sensitivities rather than the slight difference in middle ear structure, which theoretically favors greater sensitivity for $T$. indica.

The size of the shearing forces relative to the bending pressure on the surface of the membrane increases with the thickness of the elastic layer (Békésy, '53a).
The shearing forces to which Békésy refers develop between the reticular lamina and the tectorial membrane. Békésy stated "It may be that the thickness of the layer between the reticular membrane and the basilar membrane is important in this respect."

While it is not possible to explain the functional significance of the specializations of the gerbilline organ of Corti because of the incompletely known physiology of this structure, certain hypotheses may be drawn regarding these modifications.

The Hensen cells contribute to the longitudinal bending of the basilar membrane, and, because the reticular membrane is attached to the Hensen cells, this membrane is displayed proportionally according to the length of the movement arc of the Hensen cells. The length of the arc of a circle for an arc of $\theta$ degrees increases in direct proportion to the length 
of the radius. In this case the height of the Hensen cells constitutes radius length. Displacement of the reticular membrane and the hair cells should be directly proportional to Hensen cell height if mechanical impedence is similar for Corti organs of differing mass. It follows that the greater the height of the Hensen cells, the greater will be the displacement of the reticular membrane for any given amplitude. If this mechanism should prove operative in the Gerbillinae, the hypertrophy of the Hensen cells is obviously an important factor for producing shearing forces between the reticular lamina and tectorial membrane; seemingly a weaker stimulus would provide sufficient shear to produce a response than would be required for animals with unhypertrophied Hensen cells. The histological and physiological data seem to support this interpretation.

The nature of the function of the hyaline mass is more obscure. It may simply add mass to the system in addition to that added by hypertrophy of the Hensen cells, which would tend to increase force if acceleration remained constant. An increase in mass might tend to damp movements of the cochlear partition and a larger hydraulic force would seemingly be required to achieve a displacement of the same magnitude as produced in an organ of Corti of smaller mass. Even if displacement is diminished, there should be no reduction in the shearing forces produced because the increase in mass does not produce a proportional decrease in acceleration. Indeed, the added mass probably improves responses to low frequency sound under appropriate conditions as discussed below.

The large diameters of the scala vestibuli and tympani should reduce friction to the displacements of the cochlear fluids. The diameter of these scalae is larger in the Gerbillinae than in Cavia cobaya (Legouix and Wisner, '55) and Dipodomys ?merriami. It is possible that larger cochlear scalae have evolved to reduce friction in compensation for the increased mass of the cochlear partition. Indeed, the stimulus for increase of middle ear transformer ratio and volume might be the increased friction resulting from specialization of the organ of Corti. Pneu- matization of the mastoid did not occur in the species lacking a hyaline mass.

The weighting of the basilar membrane by the addition of a hyaline mass might serve to alter the vibratory characteristics of the cochlear partition. Weighting the center of circular diaphragms in water effectively narrows the resonance frequency but does not decrease sensitivity. Indeed increase in sensitivity is governed by the effective mass of the diaphragm, while the factors tending to damp the diaphragm are relatively insignificant. Maximum sensitivity of center loaded diaphragms was achieved when the load was equal to the effective mass of the diaphragm (Powell, '24; Powell and Roberts, '23). Though the basilar membrane is not circular, it vibrates in a sinusoidal manner as does a diaphragm. The center loading of the hyaline mass increases with increase in organ of Corti mass. It is possible that there may be some analogy between these two systems and loading the basilar membrane with a hyaline mass constitutes a means of increasing the vibrational sensitivity of the organ of Corti.

The possibility exists that a hyaline mass might modify the vibratory characteristics of the basilar membrane for the frequencies to which it will respond maximally. More data are needed concerning both the morphology of the hyaline mass and neurophysiology of the organ of Corti. In animals, under selection for hearing weak sounds in a particular frequency range, it seems possible that selective forces might work to augment either or both of these alternatives. The hyaline mass has been acquired independently in a number of mammalian families. In each it is present in that part of the basilar membrane known from neurophysiological data to respond to those sound frequencies for which these animals are most sensitive. Audition of these sounds plays an important biological role in Chiroptera (Griffin, '58), odontocete whales (Norris et al., '61) and, seemingly, in a number of desert-inhabiting rodents.

\section{Functional significance of auditory specialization}

The very large middle ear cavities of desert rodents have attracted the attention of a number of investigators since 
Lataste $(1882,1888)$ who noted mammals inhabiting the Sahara desert possessed much larger middle ears than closely related North African species extralimital to the desert proper. Several explanations of the significance of hypertrophy have been offered. Howell ('32) concluded that the great inflations of Dipodomys, Jaculus and Dipus are developed as resonating apparatus. He also suggested that the accessory tympanum in the latter two forms might act as an independent "sounding board." Hatt ('32) suggested that bullar hypertrophy might shift the center of gravity of the skull posteriorly and thus facilitate ricochetal locomotion, a hypothesis later shown to be invalid (Webster, '62). Orr ('40) invariably found among the wide ranging hares and rabbits of California, that those of the southern deserts possessed larger pinnae, and tympanic bullae than did conspecifics inhabiting less arid regions. He suggested that increase in size was correlated with greater auditory sensitivity, since (1) predators are more numerous in deserts, thus necessitating better hearing for predator evasion; and (2) sound reception is more difficult in deserts.

Knudsen ('31, '35) demonstrated that sound transmission is considerably reduced for frequencies above $1000 \mathrm{~Hz}$ in air characterized by low humidity or high temperature or both. The absorption of sound in air is greatest at relative humidities of $10-20 \%$ for frequencies of 1500 $10,000 \mathrm{~Hz}$. Absorption of 1500 and 3000 $\mathrm{Hz}$ was found to be considerably less than that of 6000 and $10,000 \mathrm{~Hz}$. Decreased absorption was determined to be a function of water vapor concentration. Absorption of the frequencies 3000,6000 and $10,000 \mathrm{~Hz}$ at $20^{\circ} \mathrm{C}$ was almost doubled when the temperature was raised to $55^{\circ} \mathrm{C}$. The higher the frequency the greater the absorption (Knudsen, '31, '33). High temperatures and low humidities characterize the Great Palaearctic Desert for prolonged durations, lengths of which are dependent on geographical location. Such conditions probably favor airborne and wide ranging mammalian predators by minimizing sounds produced by their locomotion. This represents a factor for which prey species must compensate if predators are to be avoided.
Heim de Balsac ('36), studied the ears of Saharan mammals and noted a high correlation between bullar volume and environmental desiccation. Because he failed to understand ear physiology, his functional explanations are obsolete. Equally outdated hypotheses were proffered by Zavatarri ('38a,b).

Petter ('53, '61), Legouix et al. ('54), Wisner et al. ('54) and Legouix and Wisner ('55) noted that bulla volume and population density in the Sahara are inversely proportional and suggested that the hypertrophied "tympanic bullae" augment auditory sensitivity, especially for lower frequencies by decreasing middle ear impedance. This was supposed to enable individuals to hear at great distances so that they may find mates. The premise of low population density in marginal portions of the range was not documented, nor was variation of bullar volume within populations inhabiting marginal and optimal range determined for any species. Table 5 shows that bullar volume varies considerably within all populations including those of $M$. crassus and Pachyuromys, upon which a large part of Petter's hypothesis is based. It was stated that the cry of these animals "seems to correspond to the same narrow band of frequencies lof greatest sensitivity = $2000 \mathrm{~Hz}$ ], "but the only frequencies which they reported for these cries were 25-35 $\mathrm{KHz}$.

Two species of Dipodomys which show convergence in many respects of middle and inner ear anatomy to the condition of Meriones have been studied by Webster ('61). Webster ('62) recorded a sensitivity curve with four major peaks; maximum between $1800-2400 \mathrm{~Hz}$; another at 2600 $2800 \mathrm{~Hz}$ only slightly smaller than the maximum; a tertiary at $1200 \mathrm{~Hz}$; a quaternary at $3500-4000 \mathrm{~Hz}$, which was very similar to that which Legouix et al. (54) recorded for Meriones. Kangaroo rats with middle ears of normal and reduced volume (volume was reduced in a manner similar to that employed by Legouix and Wisner, '55) were exposed to predation by owls, Otus asio, and rattlesnakes, Crotalus cerastes. All specimens with reduced volume were quickly caught by these predators in contrast to a very small percentage of the normals. Tape recordings revealed 
that the owl's attack flight produced frequencies up to $1200 \mathrm{~Hz}$ and that each time a rattlesnake struck, a weak burst of sound was produced containing frequencies up to $2200 \mathrm{~Hz}$. Webster suggests that auditory and locomotor specializations aid kangaroo rats in avoiding snakes or owls in the dark and have an important adaptive value. The only vocalizations he was able to record from these animals were chirps containing frequencies of $5000-7500 \mathrm{~Hz}$, well above the range of greatest sensitivity.

Analysis of vocalizations of three gerbil species by Oaks ('67) may be summarized as follows:

Psammomys. (1) A trilled squeak when annoyed or hurt contained frequencies between $2-5.5 \mathrm{KHz}$, with most of the components between 3-4 Khz. (2) One untrilled distress squeak consisted of two short sounds which ranged between 8$15 \mathrm{KHz}$. (3) Several annoyance squeaks carried "loud" components over $20 \mathrm{Khz}$.

$M$. crassus. (1) Squeaks made by unreceptive females embodied frequencies from $13 \mathrm{KHz}$ to more than $15 \mathrm{KHz}$ with some components over $20 \mathrm{KHz}$. (2) Two or more individuals fighting emitted sounds in the range of $4-15 \mathrm{KHz}$, the major frequencies of which were $13-15 \mathrm{KHz}$, but some components up to $20 \mathrm{KHz}$ were also present. (3) Distress calls made by very young newborn contained "a loud fundamental which ranges in frequency from 2000-3000 cps, with several loud overtones in the audible range."

Pachyuromys. (1) Unreceptive females emitted "loud, trilled or raspy squeaks" between $2-10 \mathrm{KHz}$ "mostly in the range between 3000 and 6000 cps." (2) The mating chirps of an estrous female embodied frequencies between 4-15 KHz, mostly from 10-15 KHz. (3) The squeaks of distressed or abandoned babies contained a "loud" fundamental "of about 1500 to 3000 cps and several loud overtones."

Oaks concluded, that "the most significant sounds for gerbils are probably those made by predators or by other individuals of the same species in warning of predators. Sounds made by other individuals of the same species in connection with mating are probably less important except at short distances."
Oaks believes that high frequency sounds in the $10-20 \mathrm{KHz}$ range are the most important means of vocal interspecific communication in the Gerbillinae. Nevertheless, she recorded a number of vocalizations in the 2 to $5 \mathrm{KHz}$ range produced by young $(1500-3000 \mathrm{KHz})$ or by annoyed or fighting individuals $(2000-5000 \mathrm{KHz})$. Certainly, parts of these sounds fall within the range of maximum auditory sensitivity that I have found for the Gerbillinae. I do not believe that important adaptive significance can be attached to hearing these frequencies in these situations because: (1) fighting or annoyed individuals are usually in close, often direct, contact with their antagonist and thus should be able to hear these sounds without difficulty: (2) reproduction is usually seasonal in wild Gerbillinae (Heptner, '56; Bodenheimer, '48; Kim, '60); the female usually drives the male away from the nest and cares for the young until these become independent at about four weeks of age in most of the species I have observed in captivity. It is doubtful that sounds produced by abandoned newborn could be heard on the surface of the ground outside the deep and intricate burrow. My observations of females of Pachyuromys duprasi, Meriones crassus, shawi, libycus, unguiculatus and hurrianae, Tatera indica and Gerbillus pyramidum with newborn litters indicate that the mother spends most of her time in the nest box with the litter, leaving occasionally at night to feed or exercise, until the young begin to feed independently at age 17-21 days. Thus, it seems that it is important that she be able to hear young within the burrow during this period. However, because of the confined nature of the burrow and the nature of the cries of the distressed young (audible at 10 to 20 feet in the laboratory) and the seasonal nature of the reproductive period, it does not seem that specialization of the ear to the degree characteristic of the desert species can be attributed to selection for hearing newborn better. Further, males which do not care for the young hear as well as females.

Recordings and analyses of 42 vocalizations elicited from seven specimens of $M$. unguiculatus revealed three major amplitudinal peaks in the spectrograms, a 
first order peak in the region of $4-6 \mathrm{KHz}$, second order peak around $10 \mathrm{KHz}$, and third order peak about $15 \mathrm{KHz}$ (Finck and Goehl, '68). The auditory sensitivity as determined by cochlear potentials in the present study agrees well with the values obtained by Finck and Sofouglu ('66) for this species. That no vocalizations were recorded in the range of $1-4 \mathrm{KHz}$ in spite of very good auditory sensitivity in this range suggests that more data regarding predator prey interactions in natural situations be obtained before assigning major adaptive significance to vocal communications in these rodents.

Beecher ('69) postulates that the enlarged bullae of ricochetal rodents function as motion detectors. This hypothesis is based upon a belief that the inertia of acceleration of rapid locomotion produces air movements within the auditory bullae. These air movements are said to impinge upon "air vanes" (anterior process and buttress of the manubrium of the malleus) situated at right angles to one another and are then transmitted via the ossicular chain to the cochlea where they elicit a response which somehow produces an appropriate postural response through connections in the central nervous system. The following objections apply: (1) The surface areas of the "vanes" are minute and it is unlikely that air impinging upon these would provide sufficient thrust to overcome resistance of the mass of the ossicular chain and attached tympanum. (2) The "vane" of the manubrium is smaller than that of the anterior process and lies at right angles to the malleoincudal axis of rotation, and is firmly attached to the tympanum. Even if the small forces that might strike it were capable of displacing it, only slight distortion would result because it is mechanically impossible to transmit forces in this plane to the stapes. (3) The largest bullae of desert rodents contain slightly more than $1 \mathrm{~cm}^{3}$ of air, only fractions of which would be capable of impinging upon the vanes because of bony baffles. Even then these air movements would not likely contain the energy of sinusoidal sound waves. (4) The "vanes" of richochetal rodents are characteristic of many other non-ricochetal small-bullae rodents that were not considered. (5) Surely the vestibular system of these animals is sufficient to provide them with a motion sense far superior to that proposed. Selection would certainly favor the cheapest means of improving motion sensitivity and rather than impose the already complex auditory system with additional new functions, selection should seemingly favor elaboration of the vestibular system.

This hypothesis is so weakly founded that it does not deserve further consideration or testing. None of the above cited papers have provided information regarding predators or degree of predation in the natural environment of any of the species studied. Considerable information is available concerning this aspect of gerbilline biology.

\section{Relationship to owls}

Gerbil remains have been found in owl pellets from: South Africa (Davis, '58; Nel and Holte, '65; Coetzee, '63; Niethammer, '68); Malawi (Hanney, '65); Mali (Heim de Balsac and Lamotte, '54); Morocco (Brosset, '60); Algeria (Niethammer, '63); Israel (Dor, '47); Iran (Misonne, '59; Lay, '67); Afghanistan (Niethammer, '65); USSR: Kazakhstan; Uzbekistan; Turkmenistan (Dunaeva and Kucheruk, '38; Mironov, '49; Gromov and Parfenova, '50; Petrovskaya, '51; Gusev and Chueva, '51; Dement'ev and Gladkov, '51; Dement'ev et al., '53; Pavlov, '62); Mongolia (Kowalski, '68).

These studies establish that at least five owl species of large (Bufo bubo), intermediate (Tyto alba, Asio otus, A. flammeus) and small size (Athene noctua) feed on at least 22 species of nine genera of Gerbillinae.

Certain Russian studies have correlated feeding habits with time of year or with specific localities in Central Asia. These, exemplified by Gusev and Chueva ('51) and Dement'ev et al. ('53), show: (1) Prey items vary qualitatively and quantitatively among different ecological situations but are largely comprised of small mammals, especially rodents (usually $80 \%$ or more of total diet). (2) During the spring, summer and fall a significant proportion of invertebrates, reptiles and birds is taken 
in addition to rodents. (3) During the winter the prey is almost exclusively comprised of nonhibernating rodents, among which Gerbillinae and Murinae are the most abundant.

The data from only one study ( $\mathrm{Nel}$ and Holte, '65) suggest that in areas where the two types occur sympatrically, owls may capture rodents with generalized ears more frequently than those with specialized ears. A sample of 1396 rodents recovered from owl pellets collected in KalahariGemsbok Park, South Africa contained three species with generalized ears (Gerbillurus paeba, Tatera schinzi, T. brantsi) in a 10:1 ratio to the single species having specialized ears, Desmodillus auricularis, but the authors state only that simultaneous trapping data indicated that population density of $D$. auricularis was considerably higher than indicated by the owl pellet data.

\section{Relationship to snakes}

There is limited information concerning predation of snakes on Gerbillinae. Golvan and Rioux ('61) report catching several dozen snakes during the course of excavating Meriones burrows in Kurdistan Province, Iran, one of which had an adult $M$. vinogradovi in its stomach.

Remains of Gerbillinae have been found in the digestive tracts of snakes from desert or semidesert areas of southern Uzbekistan SSR as follows: Coluber ravergieri $-M$. libycus; Coluber tyria $-M$. libycus (1 of 2 specimens containing this species had eaten three young $M$. libycus); Naja oxiana - M. libycus (Bogdanov, '64). Agkistrodon halys feeds to some extent on Rhombomys and $M$. meridianus in northern Kazakhstan, but hibernates from October to April (Bogdanov, '70). This pattern is probably typical, with minor variations, for other snakes in Central Asia. Therefore, snakes are effective predators only during the warm parts of the year. Bogdanov also found that small snakes consume small prey items (mostly invertebrates, birds and young rodents) and individuals $60 \mathrm{~cm}$ or longer feed almost entirely on adult rodents. Darevsky ('66) notes that an adult viper, Vipera xanthina, consumes no fewer than 100 small rodents (Microtus) per season in Armenia.

These data suggest that snakes prey significantly on small rodents. Their effectiveness as predators on Gerbillinae remains to be evaluated.

\section{Relationship to carnivores}

Felis margarita, the barkhan cat, feeds primarily on $M$. meridianus and $R$. opimus in the Kyzylkum desert of Uzbekistan. Remains of these rodent species were recovered from feces of this cat, which is said to be totally dependent on its prey for water (Andrushko, '48).

In the Turkmen SSR F. margarita is a nocturnal predator during the hottest parts of the year, and primarily diurnal during the remainder. Analysis of 182 stomachs and fecal remains revealed that $65 \%$ of the diet was rodents comprising $R$. opimus (34\%) and $M$. meridianus $(19 \%)$. The remainder of the diet consisted of birds, reptiles, and arthropods (Sapozhenkov, '61a). A sample of 94 stomachs and scats of Felis catus libyca in the eastern Karakum Desert of Turkmenia SSR contained $78 \%$ mammalian remains, and $22 \%$ birds, birds' eggs $(11 \%)$ and reptiles. Gerbils accounted for the major portion of the mammal diet (Rhombomys $38 \%, M$. meridianus 19\%) (Sapozhenkov, '61b). The Caracal, Lynx caracal, (102 stomachs and scats) diet contained $85 \%$ mammal remains. The major food elements were hares (Lepus) $-41 \%$, Rhombomys $-16 \%$, and jerboas $-11 \%$ (Sapozhenkov, '62).

Mambetzhumaev and Palvaniyazov ('68) found that the Felis libyca inhabiting the Kyzylkum desert and the dry Ust-Urt plateau had an entirely different dietary regimen than the population of the Amu Darya River delta. The steppe-desert animals fed largely on Rhombomys and $M$. meridianus and to a small degree on birds and jerboas, while the Amu Darya delta population fed on a much wider variety of foods, which were available due to the less stringent climatic conditions of this area. Felis chaus, distribution of which is confined to watered areas of the Amu Darya delta, showed a highly variable diet. Analysis of 157 stomachs and scats 
revealed that rodents comprised $77 \%$ of the contents of 130. M. tamariscincus, accounted for $75 \%$ of the remains in 126 of the specimens studied. Felis margarita, which occurred only in the Kyzylkum and Ust-Urt plateau preyed extensively on rodents $(88 \%$ of the diet in 53 of the 61 specimens studied). Birds, reptiles, and insects formed the remainder. Among the rodent remains, Rhombomys was the most common species encountered while jerboas were consumed to a lesser degree.

Vulpes vulpes feces collected in September in Kurdistan, Iran contained $80 \%$ Meriones, $6 \%$ other rodents, $7 \%$ plants, $7 \%$ insects and grain. In October, foxes of the same region fed almost exclusively on grapes (Misonne, '59). Stomach contents of $25 \mathrm{~V}$. vulpes collected from diverse localities in Iran contained only three rodents, none of which can be considered as desert inhabitants and the stomach of one $V$. ruppelli collected in arid steppe contained a jerboa, lizard, and centipede (Lay, '67). Lewis et al. ('68) found remains of $M$. tristrami in the stomachs of $V$. vulpes collected in Lebanon.

In summary, details concerning predators of and degree of predation on the Gerbillinae, especially in the Great Palaearctic Desert, are scarce and the role of predation in the biology of these rodents is at best only suggestive. Very little is known concerning mammalian and reptilian predators of these rodents and information presently available indicates that owls prey extensively on them. Reports of owl predation virtually cover the range of the Gerbillinae, but none provide the information necessary to evaluate critically the degree to which owls prey on gerbils, especially in open desert situations. The data provide some tantalizing bits of information, which are suggestive that gerbilline ear specializations may be important with respect to predator avoidance, but we need documentation by simultaneous assays of rodent population densities and owl pellet contents from the same localities.

Data suggests that the variety of available food resources of owls is greatly reduced in the deserts of Central Asia in winter (Dunaeva and Kucheruk, '38; Petrovskaya, '51). Of the vertebrates that occur in the Kyzylkum desert of Uzbekistan and Kazakhstan SSR, 16 of 40 mammal, 15 of 251 bird, and none of 24 reptile and amphibian species are present or active the year round (Zakhidov, '58). All invertebrates are also said to be inactive in the winter months. Such seasonal fluctuations probably result in considerable alterations of predator-prey relations. Essentially, the mammals active during the winter are rodents and carnivores, and at least $30 \%$ of the bird species are raptors. Because gerbilline rodents constitute the major non-hibernating prey component of this fauna, they would likely incur greater pressure from owls, and other active predators such as cats and foxes during this period. Certainly mammals, such as cats, are important predators on gerbils in the deserts of Central Asia.

A number of the owl species reported to prey on Gerbillinae occur throughout most of the Great Palaearctic Desert, e.g., Bubo bubo, Athene noctua and essentially Tyto alba. Both $F$. catus libyca and $F$. margarita also have a similar distribution. $V$. ruppelli occurs in this desert from Morocco east to India. This species is replaced in Central Asian deserts by $V$. corsac. Colubrid snakes occur throughout the Great Palaearctic Desert.

It seems valid to assume that owls, cats, foxes, and snakes are likely to display similar feeding habits throughout the Great Palaearctic Desert and that rodents probably provide the primary prey, at least for the first three of these groups.

The seasonal changes in the faunal composition are less in the Saharo-Sindien portion of the Great Palaearctic Desert and for this reason there will probably be considerable differences in the predatorprey relationships from those seen in the Central Asian desert. Indeed, the distribution of the more generalized ear forms, Gerbillus and Tatera, only extends to about $32^{\circ} \mathrm{N}$ in eastern Iran and southern Afghanistan, which corresponds to the southern extent of the frost line (Misonne, '59). No physiographic barriers exist to prevent northward dispersal. Species with specialized ears, $R$. opimus, $M$. libycus and $M$. meridianus occur on both sides of this line. It seems possible that one of the factors limiting northward extension 
of Tatera and Gerbillus might be attributable to their inability to cope with the increased predation during the winter, assuming that these forms could tolerate the colder climate. Any differences in selective forces acting upon both predator and prey species in these two regions can only by evaluated by further field studies.

Webster ('62) did not consider mammals as important predators upon Dipodomys even though he reported ('60) that bobcats, Lynx rufus, and coyotes, Canis latrans, proved extremely efficient in catching kangaroo rats in spite of the latter's rapid leaps. The role of mammalian predators in the desert ecosystem demands study, before generalizations regarding the factors responsible for the evolution of specialized ear anatomy of desert rodents are accepted.

Nevertheless, a number of owls prey extensively on gerbilline rodents. The data of Nel and Holte ('65) provide the best indication that species with more specialized ears have a selective advantage over species with more generalized ears in avoiding owl predation. All other information in this regard (supra cit.) is only suggestive that this phenomenon may occur. The auditory sensitivity curves show that, concomitant with anatomical specialization, there is an increase in overall sensitivity, which includes an incrementation in the 1200-1800 Hz peak (fig. 14). The attack flight of the single owl species considered by Webster ('61) contained frequencies up to $1100 \mathrm{~Hz}$. Of the known owl predators on gerbils, Athene noctua is a small species, similar in size to Asio otus, the species Webster ('61) studied. Tyto alba and Otus asio are middle-sized species while Bubo bubo is large. It is possible that the flight of different owls produces different frequencies. The 1200$1800 \mathrm{~Hz}$ peak of the gerbils may represent the $1100 \mathrm{~Hz}$ peak which Webster found for Dipodomys. The components of the human middle ear have different resonant frequencies (Onchi, '61). These are: stapes, 3500-4000 Hz; malleo-incudal body, $1500-1700 \mathrm{~Hz}$; mastoid antrum, $2250 \mathrm{~Hz}$. The middle ear transformer was shown to produce a maximum pressure gain of $25 \mathrm{db}$ at 1000 and $2000 \mathrm{~Hz}$. The antrum and mastoid air cells increased displace- ment of the tympanum below $1000 \mathrm{~Hz}$ and decreased it in the range of 1000-3000 $\mathrm{Hz}$. However, this effect was within $10 \mathrm{db}$.

These data correspond well with the peaks of maximum sensitivity for gerbils and kangaroo rats and suggest that natural selection has favored increased sensitivity in the lower frequencies among the Gerbillinae, but not to particular frequencies in this range. The peaks in the sensitivity curves of these rodents are likely due to the vibrational characteristics of the components of the middle ear transformer. Increased sensitivity correlates well with the degree of anatomical specialization of the species. Specializations of the organ of Corti occur by a regular transition over most of the length of this organ and are not confined to narrow regions which would be expected if adaptation to particular frequencies occurred.

The evidence indicates strongly that the auditory specializations of the desertinhabiting Gerbillinae have probably evolved primarily in response to increased predation incurred when this open environment was inhabited.

\section{Considerations concerning the evolution of the specialized Gerbillinae}

The Gerbillinae of the Great Palaearctic Desert are characterized as either herbivores, represented by three species, Rhombomys opimus, Psammomys obesus, and Meriones hurrianae, or granivores, comprising the remainder of this subfamily (Petter, '61). These two groups also are distinct in basic activity patterns. Almost all the herbivores are active diurnally, while the granivores are almost completely nocturnal. The herbivores, all of which are allopatric, feed almost exclusively on halophytic vegetation of the family Chenopodiaceae, which grows year round and is confined to soils characterized by rather high salinity. These plants provide a stable localized food supply.

These three species are members of the gerbilline group characterized by the most specialized ears. This mode of life is a specialization, for it is dependent on a restricted variety of plants limited geographically to salt pans and only a few gerbils have succeeded in utilizing it. 
Psammomys, Rhombomys and $M$. hurrianae have evolved dental specializations for this type of diet. These three species probably adapted to this alimentary regime after attaining auditory specializations and their patterns of diurnal activity developed subsequent to this dietary change.

Because the great majority of the Gerbillinae are primarily granivorous, including the less specialized desert-inhabiting forms, characterized by Gerbillus, this probably represents the primitive modus vivendi. Desert perennials are seasonal or have rapid growth and reproductive cycles which begin whenever rain falls. In many parts of the Great Palaearctic Desert, water requirements for stimulating growth and fruiting of perennials may not be available for periods of several years. As a response to such environmental extremes, these plants produce an inordinately high seed yield which enhances survival over periods of prolonged drought. While these plants occur over extensive areas, they probably do not provide the stable localized food supply or cover furnished by saltworts. With the progressive invasion of deserts the Gerbillinae probably encountered increasingly stringent conditions characterized by diminishing plant densities. Survival in such conditions would more likely require greater movement over larger, more exposed areas to secure sufficient quantities of seeds. Predators would constitute a greater threat to survival in these more open situations than in places with sufficient ground cover. Thus for the prey species to survive in this environment, natural selection would favor any means by which these animals could better balance the effects of predation. The ear of modern desertinhabiting Gerbillinae has probably evolved in response to this mode of life.

Joleaud (38) and Moreau (55) have shown that the formation of the Sahara has been characterized by at least three major climatic fluctuations, roughly corresponding to the Pleistocene pluvials and interpluvials, which have resulted in successive expansions and contractions of the desert proper. Similar cyclic climatic instability has probably prevailed in the Sahara since middle Pliocene time (Butzer, pers. comm.). Climatic fluctuations have also characterized the western part of the Iranian plateau during the late Quaternary (Megard, '67).

Stebbins (52) considered unstable desert environment and plant evolution and provides three reasons why evolution might be expected to be relatively rapid in arid or semi-arid regions: (1) Local diversity in topography, soil, and other factors will have a much greater effect on the character of the vegetation than in regions where moisture is adequate. (2) The population structure of the component species is likely to be particularly favorable to promote rapid evolution. (3) Plants can evolve a number of different specialized structures as adaptations to dry conditions.

Only the first two of these need concern this discussion. As Stebbins points out "regional diversity of species and genera in arid or semi-arid regions has two important effects on evolution . . . the frequent geographic or spatial isolation provides many situations favorable to the origin of reproductive isolating mechanisms . . . climatic fluctuations will cause frequent merging of previously isolated and differentiated races or species, and hence give many opportunities for the increase of genetic diversity through hybridization and introgression, as suggested by Anderson ("49)." Wright (40) demonstrated that the most favorable situation for rapid evolution exists when a large or medium sized population is divided into many subunits which are largely isolated from each other, but can interchange genes through occasional migrations between these subunits. This kind of population structure permits new gene combinations to become established in different subunits by natural selection and/or chance fixation, without the swamping effect that occurs in large continuous populations. Migrations between subunits prevent stagnation within these and, at the same time, allow the population as a whole to draw upon a large pool of genes. Stebbins ('52) states "in arid or semi-arid regions, with their regional diversity, this type of population structure may be expected much more frequently than in areas with abundant moisture." Stebbins be- 
lieves that divergent evolution will not necessarily be limited to adaptations toward xerophytism in semi-arid regions. He found evidence of readaptation of xerophytes to more mesic conditions in regions where climate was becoming progressively moister.

Details of past climatic regimes are sketchy for most of the Great Palaearctic Desert. In the Saharan region west of a line between Tripoli, Libya and Khartoum, Sudan there is considerable evidence of Pleistocene climatic amelioration roughly correlated with the glacial maxima of Europe, while the area northeast of this line appears to have remained desertic throughout this period (Moreau, '63). These climatic oscillations undoubtedly produced ecological and faunal fluctuations over a vast region of a type favoring speciation among the fauna and flora.

The desert-adapted Gerbillinae show much diversity in ear anatomy, tooth structure, and locomotor apparatus (hind-limb and tail). On the basis of dentition and ear structure Rhombomys, Psammomys, and Brachiones are all closely related to Meriones. These closely related genera form a group which I shall refer to as the Meriones-group. Only two genera Meriones and Gerbillus, of the desert-inhabiting gerbils are polytypic, the former with 15 species, the latter with about 55 species. These two genera are characterized by ears representing different levels of specialization, yet within each group there appears to have been considerable experimentation with ear structure. All 15 species of Meriones inhabit semi-arid or desert situations. Most differ considerably in the degree and manner of bullar hypertrophy. Five have evolved an accessory tympanum with its associated modification of the malleus. Initial stages in the development of an accessory tympanum have been found in two of 13 specimens of $M$. vinogradovi. The accessory tympanum has been evolved at least twice and possibly three times in Meriones. Eleven of 14 species of Gerbillus, ranges of which are confined to the Sahara or the deserts of the Middle East, have evolved an accessory tympanum and the concomitant modifications of the malleus. Though only one has been studied in detail., consider- able variation in size of accessory tympanum appears to exist among these suggesting that this structure may have evolved more than once in this genus. Only one of four East African species of Gerbillus studied has an accessory tympanum. The accessory tympanum characterizes three other genera, none of which appears to be closely related to either the Meriones-group or Gerbillus. Pachyuromys and Desmodillus are closely related and probably represent an independent evolutionary line characterized by a single-chambered posterior mastoid cell and other morphological features (Lay, unpublished data) and each possesses an accessory tympanum. Desmodilliscus, having a double-chambered posterior mastoid differs strikingly from the Meriones-group in dentition and locomotor features, yet possesses an accessory tympanum. Pachyuromys, Desmodilliscus, and Desmodillus are the only forms in which a laterally. directed protuberance has been developed on the neck of the malleus for the attachment of the accessory tympanum, which reaches greatest relative proportions in the former two genera. Petter ('61), Ranck (68) and Osborn (pers. comm.) have called attention to the isolated and fluctuating nature of gerbil populations within different regions of the Sahara and Bannikov ('54) states that great fluctuations in density characterize $M$. unguiculatus in Mongolia and Transbaikalia SSR. My own cursory observations indicate that such populations may also typify the gerbilline species inhabiting Iran. While a great deal of documentation is required for evaluation of these population characteristics, these observations are suggestive that populations of widespread Saharan species of Gerbillinae are composed of many small isolated subunits of the type that Wright ('40) thinks are most conducive to rapid evolution. Adaptation of small populations of gerbils to factors associated with environmental fluctuations has doubtlessly played a significant role in the development of the genetic diversity responsible for the auditory specializations and the origin of features in parallel, as exemplified by the accessory tympanum, which characterize this group of rodents.

A posterior mastoid morphology like 
that of any of the more specialized Gerbillinae does not characterize any of the generalized savannah-inhabiting forms of Taterillus, Gerbillurus or Tatera. The similarities between these two groups suggest that the specialized gerbillines were derived from an ancestral gerbilline(s) not greatly unlike the modern generalized group.

The Gerbillinae are represented very poorly in the early fossil record but late Pleistocene remains of Meriones and Gerbillus are fairly common in Israeli and USSR collections. Schaub ('34) described Pseudomeriones abbrevictus from "Pliocene" deposits in Mongolia. Bogachev ('38) described bones of Gerbillus sp. from Late Pliocene beds in Armenia. It is impossible to determine any details concerning the ear anatomy from the descriptions provided by these authors. Tedford (pers. comm.) has collected Plio-Pleistocene specimens of Tatera cf. indica in Afghanistan. From such scanty information it is impossible to attempt reconstruction of the evolutionary events in the radiation of the Gerbillinae with certainty. It is possible to state from a study of the middle ears of modern forms that a generalized ancestor(s) gave rise to at least two modern lines. One line is characterized by a single-chambered posterior mastoid cavity and represented by three living monotypic genera, Pachyuromys, Desmodillus and Ammodillus. The first two share considerable specializations not only in ear anatomy but in many other respects. The other linage contains the remainder of the living Gerbillinae, all of which possess a twochambered posterior mastoid cell. Study of living forms does not provide indications of whether or not this group constitutes a monophyletic or polyphyletic assemblage.

It seems likely that the ancestor of the specialized Gerbillinae was probably a savannah inhabitant somewhere in the region that became the Great Palaearctic Desert. I suspect that these rodents originated in Africa because of the major dis tribution and speciation of all recent forms but the Meriones-group occurs on this continent. However, the less likely possibility that the African Gerbillinae may have been derived from immigrants cannot be ruled out. Greatest species di- versity in the Meriones-group occurs in Asia. The geographical center where the greatest number of species exist is on the Iranian plateau.

Evidence exists that much of the region presently known as the Sahara desert was largely savannah in late Pliocene times and in parts of the Pleistocene (Moreau, '63). Similar conditions seem to have existed in the asiatic parts of the modern Great Palaearctic Desert. All subpolar deserts grade into grassland peripherally where climatic factors become less extreme. These savannahs usually provide stable food and water sources for rodent inhabitants. The location of grasslands along an ecological gradient provides opportunities for adaptive experimentation within progressively arid situations. It seems possible that the intermittent late Plio-Pleistocene climatic fluctuations culminating in the present dessication may have provided the conditions which produced the modern desert-inhabiting species from an ancestral savannah form not greatly different from modern Tatera. That the group of generalized species which occur at the climatically more stable southern periphery of the arid zone have maintained, with relatively slight modification, their generalized nature lends considerable support to this hypothesis.

\section{ACKNOWLEDGMENTS}

This paper derives from a $\mathrm{PhD}$ thesis in Anatomy at the University of Chicago. I am greatly indebted to many who helped, particularly to Drs. Caesar Fernandez and Ronald Singer, who generously made their laboratories available and provided much valuable counsel and assistance. Drs. Harry Hoogstraal, Mahmoud Bahmanyar, George Rabb and Mr. Jerry Anderson provided live animals. Miss Mary Cernius and Mrs. Addye Brown rendered assistance with the histology. Drs. Karel Liem, Richard Van Gelder, Henry Setzer and Joseph Moore allowed me to dissect or study specimens in their care.

Dr. David Wake provided much sound counsel and the use of facilities of his laboratory. Mr. Leslie Siemens and Louis Martonyi assisted with the plates and 
figures. Last, but by no means least, my wife Nelda has given me moral support above and beyond the call of duty.

Financial assistance for this study was received from the U.S. Public Health Service (NIH grant AI 07384), the Wallace C. and Clara A. Abbott Memorial Fund of the University of Chicago and the National Science Foundation (grant GB 6190).

\section{LITERATURE CITED}

Allen, G. M. 1940 The mammals of China and Mongolia. Natural History of Central Asia, Part 2. Amer. Mus. Nat. Hist., New York, pp. $621-1350$

Anderson, E. 1949 Introgressive hybridization. 109 pp., Wiley, New York.

Andrushko, A. M. 1948 K rasprostraneniyu biologii barkhannogo kota. Priroda. 1948 (10): 81-82.

Ansell, W. F. H. 1960 Mammals of Northern Rhodesia. 155 pp., 19 figs., 17 range maps. Govt. Printer. Lusaka.

Bannikov, A. G. 1954 Mlekopitayushchie Mongol'skoi Narodnoi Respubliki. Izd. Akad. Nauk SSR, no. 53, 669 pp.. 44 tab., 54 maps. 99 figs.

Barany, E. 1938 A contribution to the physiol ogy of bone conduction. Acta Oto-laryngol. Suppl. 26, 223 pp. 57 figs

Bartholomew, G. A., and W. R. Dawson 1968 Temperature regulation in desert mammals. In: Desert Biology. Vol. 1. Brown, ed. Academic Press, New York, pp. 395-421.

Beecher, W. J. 1969 Possible motion detection in the vertebrate middle car. Bull. Chicago Acad. Sci., 11: 155-210.

Békésy, G. von 1944 Uber die Frequenzauflosung in der menschlichen Schnecke. Acta Oto laryngol., 32: 60-84

_ 1953a Description of some mechanical properties of the organ of Corti. $\mathbf{J}$. Acoust. Soc. America. 25: 770-785.

$1953 \mathrm{~b}$ Shearing microphonics produced by vibrations near the inner and outer hair cells J. Acoust. Soc. America. 25: 786-790.

1954 Some electro-mechanical properties of the organ of Corti. Ann. Otol., Rhinol. Laryngol., 63: 448468

1956 Current status of theories on hearing. Science, 123: 770-783.

1960 Experiments in hearing. $x+745$ pp., 691 figs. McGraw Hill. New York

Bere, R. M. 1962 The wild mammals of Ugan da. 148 pp., Longmans. London.

Bloom, W., and D. Fawcett 1968 A textbook of histology. Saunders, Philadelphia. 720 pp.

Bobrinskii, N. A.. B. A. Kuznetzov and A. P. Kuz yakin 1965 Opredelitel Mlekopitayushchikh SSSR, Izd. "Prososhchenae" Moscow. 2nd ed., 382 pp., 129 figs., 111 distribution maps.

Bodenheimer, F. S. 1948 Ecological and phys iological studies on some rodents. Physiol. Comp. et Oecol., 1: 376-389.

Bogachev, V. V. 1938 Paleontologicheskie za metki, Tr. Azerb. AN SSSR, Geol. Ser., 9(39): 1-96.
Bogdanov, O. P. (ed.) 1964 Pozvonochnye zhivotnye yuga Uzbekistana: Ekologiya i khozyaist. vennoe znachenis pozvonochnykh zhivotnykh yuga Uzbekistana Bassein Surkhandarvi). Akad. Nauk Uzbekskoi SSSR, Inst. Zool. and Parisitol. Izd. "Nauka" Uzbekskoi SSSR, Tashkent. $158 \mathrm{pp}$.

- 1970 Pitanie obykhovennogo shchito mordnika (Ancistrodon halys) v srednei azii. Zool. Zhur. . 49: 1851-1856.

Bondy, G. 1908 Beitrage zur vergleichenden Anatomie des Gehororgans der Sauger., Anat. Hefte, Abt. 1, 106: 295-408.

Brosset, A. 1960 Les mammiteres du Maroc oriental. Leur repartition. Leur status actuel. Bull. Soc. Sci. Nat. Phys. Maroc, 40: 243-263.

Buxton, P. A. 1923 Animal life in deserts. E. Arnold and Co., London. 176 pp., 43 figs.

Cockerell, T. D. A., L. I. Miller and M. Printz $1914 \mathrm{a}$ The auditory ossicles of American rodents. Bull. Amer. Mus. Nat. Hist., 33: 347-380. $1914 \mathrm{~b}$ The auditory ossicles of some African rodents. Zool. Anz., 44: 433-440.

Coetzee, C. G. 1963 The prey of owls in the Kruger National Park as indicated by owl pellets collected during 1960-1961. Koedoe. 6: 115-125.

Darevsky. I. S. 1966 Ecology of rock-viper ( $\mathrm{Vi}$. pera xanthina raddei Boettger) in the natural surroundings of Armenia. Mem. Inst. Butantan. 33: 81-83.

Davis, D. H. S. 1958 Notes on small mammals in the Kalahari Gemsbok National Park, with special reference to those preyed upon by Barn Owls. Koedoe, 1: 184-188.

1962 Distribution patterns of Southern African Muridae with notes on some of their fossil antecedents. Ann. Cape Prov. Mus., 2: $56-76$.

Davis, H. 1954 The excitation of nerve impulses in the cochlea. Ann. Otol. Rhinol. Lar. yngol., 63: 469-480.

1959 Excitation of auditory receptors. pp. 565-584 in Field. Magoun and Hall. Handbook of physiology, Sec. 1. Neurophysiology, Am. Physiol. Soc., vol. 1

1961 Some principles of sensory receptor action. Physiol. Pev., 41: 381-418.

Dekeyser, P. L. 1955 Les mammiferes de l'Afrique Noire Francaise (Initiations Africaines 1). Grand imprem. Africaines. Dakar, $426 \mathrm{pp}$. (2nd ed.).

Dement'ev, G. P., and N. A. Gladkov 1951 Ptitsy Sovetskogo Coyuza. Vol, 1, 652 pp., Gos. lzd. "Sovetskaya Nauka." Moscow.

Dement'ev, G. P. N. N. Kartashev and A. N Soldatova 1953 Pitanie i prakticheskoe znachenie nekotorykh khshchnykh ptitz v yugozapadnoi Turkmenii. Zool. Zhur., 32: 361-375.

Dor, M. 1947 Observations sur les micromam. miferes trouves dans les pelotes de la chouette effraye (Tyto alba) en Palestine. Mammalia, 11: 49-54.

Doran, A. H. G. 1878 Morphology of the mam malian ossicla auditus. Trans. Linn. Soc. Lon don Ser. 2, 1: 371-498.

Dunaeva, T. H., and V. V. Kucheruk 1938 Osobennosti pitaniya domovogo sycha $v$ svyazi $s$ geograficheskimi i statzionarhymi ysloviyami i sezonami goda. Zool. Zhur., 17: 1080-1090. 
Ellerman, J. R. 1940 The families and genera of ljving rodents. 690 pp., Brit. Mus. (Nat. Hist.) Publ.. London.

1961 The fauna of India. Mammalia (2nd ed.). vol. 3. part 2, pp. 483-884.

Ellerman, J. R., and T. C. S. Morrison-Scott 1951 A checklist of palaearctic and Indian mammals. 810 pp, 1 fold out map, Brit. Mus. (Nat. Hist.) Publ., London.

Ellerman, J. R., T. C. S. Morrison-Scott and R. W. Hayman 1953 Southern African Mammals. 363 pp., 2 fold out maps. Brit. Mus. (Nat. Hist.) Publ., London.

Engstrom, H. and J. Wersall 1958 The ultrastructural organiation of the organ of Corti and of the vestibular sensory epithelia. Exp. Cell Res. Suppl. 5: 460-492.

Fay, G. S. 1965 Physical geography. 391 pp. Doubleday, New York.

Fernandez, C. 1952 Dimensions of the cochlea (Guinea pig). J. Acoust. Soc. America, 24: 519 523.

Field, J., H. W. Magoun, and V. E. Hall 1959 Handbook of Physiology. Sec. 1, Neurophysiology. Am. Physiol. Soc., Washington. D. C., vol. $1.779 \mathrm{pp}$.

Finck, A., and H. Goehl 1968 Vocal spectra and cochlear sensitivity in the Mongolian gerbil. J. Aud. Res., 8: 63-69.

Finck, A. and M. Sotouglu 1966 Auditory sensitivity of the Mongolian gerbil. J. Aud. Res., $6: 313-319$.

Golvan, Y. J., and J. A. Rioux 1961 Ecologie des Merions du Kuxdistan Iranien. Ann. Parasit. Hum. et Comp. 36: 449-588.

Griftin, D. R. 1958 Listening in the dark. Yale Univ. Press, New Haver. xviii +413 pp., 16 pls., 15 figs.

Gromov, I. M., A. A. Gureev, G. A. Novikov, I. I. Sokolov, P. P. Strelkov and K. K. Chapskii 1963 Mlekopitayushchie Fauny SSSR. Izd. Akad. Nauk SSSR. vol. 1, 638 pp., 295 figs.

Gromov, I. M., and N. M. Parfenova 1950 Novye materialy po pitaniyu filina (Bubo bubo L.) v polypustynyakh severnogo prikaspiya. Zool. Zhur., 29: 389-398.

Guild, S. R. 1927 The width of the basilar membrane. Science, 65: 67-69.

Gusev, V. M., and G. I. Chueva 1951 Materialy po pitaniyu nekotorykh ptitz del'ty reki Ili. Zool. Zhur., 30: 594-601.

Hanney, P. 1965 The Muridae of Malawi (Afri(ca:Nyasaland). J. Zool., 146: 577-633.

Happold, D. C. D. 1967 Biology of the jerboa. Jaculus jaculus butleri (Rodentia. Dipodidae), in the Sudan. J. Zool., 151: 257-275.

Harrison, D. L. 1964 . The mammals of Arabia. Vol. 1, Insectivora, Chiroptera, Primates. Ernest Ben Ltd., London. 192 pp., 1 fold out map.

Hatt. R. T. 1932 Vertebral columns of ricochetal rodents. Bull. Amer. Mus. Nat. Hist., 63: 599-738.

1940 Lagomorpha and rodentia other than Sciuridae, Anaomaluridae and Idiuridae. collected by the American Museum Congo Expedition. Bull. Amer. Mus. Nat. Hist., 76: 457604.

1959 The mammals of Iraq. Misc. Publ. Mus. Zool., Univ. Mich., No. 106, 113 pp., 6 pl.
Heim de Balsac, H. 1936 Biogeographie des Mammiferes et des Oiseaux de L'Afrique du Nord. Bull. Biol. de France et de Belgique. Suppl. 21, 446 pp., 16 figs., 17 maps, 7 pl.

1967 La distribution reelle de Desmo dilliscus (Gerbillinae). Mammalia, 31: 160-164.

Heim de Balsac, H., and M. LaMotte 1954 Les pelotes de rejection de la chouette effraye en Afrique Occídentale et leur interet pour les recherches faunistiques. Notes Africaines, $N$. 64: 124-125.

Heptner, V. G. 1940 Fauna peschanok (Mammalia, Glires) Irana. Nov. Mcm. Mosk. Obshch. Isp. Prirody., 29:5-72.73 figs.

1956 Fauna pozvonochnykh zhivotnykh Badkhyza (Yuzhnyi Turkmenistan). Izd. Akad. Nauk Turkmenskoi SSSR, (Inst. Biol.) Ashkhabad. $335 \mathrm{pp}, 22$ figs.

Holz, K. 1931 Vergleichende anatomische und topographische studien uber das Mittelohr der Saugetiere. Z. Anat. Entw. Gesch., 94: 757791,22 figs.

Hoogstraal, H. 1963 A brief review of the contemporary land mammals of Egypt (including Sinai). 2. Lagomorpha and Rodentia. J. Egyptian Publ. Health Assoc., 38: 1-35.

Hooper, E. T. 1968 Anatomy of middle-ear walls and cavities of microtine rodents. Occ. Pap. Mus. Zool., Univ. Mich., No. 657, 28 pp.

Howell, A. B. 1932 The saltatorial rodent $D i$ podomys: The functional and comparative anatomy of its muscular and osseous systems. Proc. Amer. Acad. Arts and Sci., 67:377-536.

Hyrtl, J. 1845 Vergleichend -- anatomische Untersuchungen uber das innere Gehororgen des Menschen und der Saugethiere. Prague, F. Ehrlich, 139 pp.. 9 pl.

Iurato, S. 1961 Submicroscopic structure of the membranous labyrinth. II. The epithelium of Corti's organ. Z. Zellforsch., 53: 250-298. 1962 Submicroscopic structure of the membranous labyrinth. III. The supporting structure of Corti's organ (Basilar membrane, limbus spiralis and spiral ligament). Z. Zellforsch., 56: 40-96.

_- 1967 Submicroscopic structure of the inner ear. Pergamon Press, New York, 367 pp., 196 figs.

Joleaud, L. 1938 Histoire de la formation d'un desert: paleogeographie du Sahara. Memoires de la Societe de biogeographie, Paris, 6: 21-47.

Keen, J. A.. and C. S. Grobbelaar 1941 The comparative anatomy of the tympanic bulla and auditory ossicles. with a note suggesting their function. Trans. Roy. Soc. S. Afr., 28: 307-329, 78 text figs.

Kim, T. A. 1960 Materialy po ekologii tamariskovii peschanki (Meriones tamariscinus Pall.) v pustyni kyzylkum. Zool. Zhur., 39: 759-765.

Knudsen, V. O. 1931 The effect of humidity upon the absorption of sound in a room, and a determination of the coefficients of absorption of sound in air. J. Acoust. Soc. America. 3: $126-138$.

- 1933 The absorption of sound in air. in oxygen. and in nitrogen - effects of humidity and temperature. J. Acoust. Soc. America, 5: 112-121.

1935 Atmospheric acoustics and the weather. Sci. Monthly, 40: 485-486. 
Kowalski, K. 1968 New data on the distribution of mammals in the Mongolian People's Republic. Acta Zool. Cracoviensia, 13: 1-11.

Lataste, F. 1882 Mammiferes nouveaux d'Algerie, Le Naturaliste, 1882: 107-109.

1888 Le Pachyuromys et ses Moeurs. Le Naturaliste, $1888: 181-182 ; 191-193$.

Lay, D. M. 1967 A study of the mammals of Iran. Fieldiana Zool., 54: 282 pp.

1968 The functional anatomy and evo. lution of the ear in rodents of the subfamily Gerbillinae. PhD Thesis Univ. of Chicago, $208 \mathrm{pp}$.

Legouix, J. P., F. Petter, and A. Wisner 1954 Etucle de l'audition chez des mammiferes a bulla tympaniques hypertrophiees. Mammalia, 18: $262-271,5$ figs.

Legouix, J. P., and A. Wisner 1955 Role fonctionnel des bulles tympaniques geantes de certains rongeurs (Meriones). Acoustica, 5: 208216.

Lewis, P. E., J. H. Lewis and S. I. Atallah 1967 A review of Lebanese mammals. Lagomorpha and Rodentia. J. Zool., 153: 45-70.

1968 A review of Lebanese mammals. Carnivora, Pinnipedia, Hyracoidea and Artiodactyla. J. Zool., 154: 517-531.

Mambetzhumaev, A. M., and M. Palvaniyazov 1968 Ekologiya, rasprostraneniei prakticheskoe znachenie nekotorykh koshek (Carnivora, Felidae) v Karakalpakskoi ASSR. Zool. Zhur., 47: 423-431.

Megard, R. O. 1967 Late-quaternary cladocera of Lake Zeribar, Western Iran. Ecology, 48: $179-189$

Meneses Cabral. J C. de 1966 Some new data on Angolian Muridae. Zool. Africana, 2: 193203.

Mironov, N. P. 1949 K voprosy o pitanii filina v usloviyakh polupostyni. Priroda, No. 9, 76-77.

Misonne, X. 1959 Analyse zoogeographique des mammiferes de l'Iran. Mem. Inst. Roy. Soc. Nat. Belgique, (ser 2), 59, 157pp., 3 pls., 8 pp. dist. maps.

Moreau, R. E. 1955 Ecological changes in the Palaearctic Region since the Pliocene. Proc. Zool. Soc. London, 125: 253-259.

1963 Vicissitudes of the African biomes in the late Pleistocene. Proc. Zool. Soc. London, 141: 395-421.

Niethammer, J. 1963 Nagetiere und Hasen aus der zentralen Sahara (Hoggar). Zeits. fur Saugetierk., 28: 350-369

1965 Die Saugetiere Afghanistans (Part 2): Insectivora, Lagomorpha, Rodentia. Science, Quart. J. Fac. Sci. Kabul Univ. (Afghanistan). August, 1965: 18-41.

1968 Gewolluntersuchungen aus Sudwestafrika. S.W.A. Wissensch. Gesellsch., 23: $5-34$.

Nel, J. A. J., and N. Holte 1965 Notes on the prey of owls in the Kalahari Gemsbok National Park, with special reference to the small mammals, Koedoe, pp. $75-81$.

Norris. K. S., J. H. Prescott, P. V. Asa-Dorian and P. Perkins 1961 An experimental demonstration of echolocation behavior in the porpoise, Tursiops trancatus (Montaga). Biol. Bull., 120: 163-176.

Nurgel'dyev, O. N. 1969 Ekologiya mlekopitayushchikh ravninnoi turkmenii. Akad. Nauk
Turkmen SSR Izd. "Ylym," Ashkhabad. 258 pp., 96 tab., 46 figs.

Oaks, E. C. 1967 Structure and function of inflated middle ears of rodents. Ph.D. Thesis, Yale Univ., 411 pp., 99 figs. 13 tables.

Odum, E. P. 1959 Fundamentals of ecology. xviii + 546 pp., 160 figs. W. B. Saunders Co., Philadelphia.

Ognev, S. I. 1948 Zveri SSSR i prilezhashchikh stran. vol. 6, pp. 559. Izd. Akad. Nauk SSSR, Moscow.

Onchi, Y. 1961 Mechanism of the middle ear. J. Acoust. Soc. America, 33: 794-805.

Orr, R, 1940 The rabbits of California. Occ. Pap. Calif. Acad. Sci., 19: 207 pp., 9 pl.

Pavlov, A. N. 1962 O khozyaistvennom znachenii domovogo sycha $\mathrm{v}$ polupustyne severozapadnogo prikaspiya. Zool. Zhur., 41: 1898 1901.

Petrovskaya, E. P. 1951 : Pitanie khishchnykh ptitz v svyzi s raspredeleniem gryzunov na poberezh'e Aral'skogo Morya. Bull. Mosk. Obshch. Isp. Prirody, 56: 25-30.

Petter, F. 1953 Remarques sur la signification des bulles tympaniques chez les mammiferes, C. R. Acad. Sci., 237: 848-849.

1961 Repartition geographique et eco logie des rongeurs desertiques de la region palaearctique. Mammalia supplement. 219 pp.

1968 Retour au gite et nomadisme chez un rongeur a bulles tympaniques hypertrophiees. Mammalia, 32: 537-549.

Powell, J. H. 1924 The sensibility of circular diaphragms for the reception of sounds in water. Proc. Phys. Soc. London, 37: 84-96.

Powell, J. H., and J. H. T. Roberts 1923 On the frequency of vibrations of circular diaphragms. Proc. Phys. Soc. London, 35: 170-182.

Pritchard, U. 1881 The cochlea of the Omithorhyncus platypus compared with that of ordinary mammals and of birds. Trans. Roy. Soc. London, vol. 172. Part 2: 267-282.

Pye, A. 1965 The auditory apparatus of the Heteromyidae (Rodentia, Sciuromorpha) J. Anat., 99: 161-174.

$1966 \mathrm{a}$ The structure of the cochlea in Chiroptera. I. Microchiroptera: Emballonuroidea and Rhinolophoidea. J. Morph., 118: 495510 .

- 1966b The structure of the cochlea in Chiroptera. II. The Megachiroptera and Vespertilionoidea of the Microchiroptera. J. Morph., 119: 101-119.

1967 The structure of the cochlea in Chiroptera. III. Microchiroptera: Phyllostomatoidea. J. Morph., 121:241-254.

Ranck, G. L. 1968 The rodents of Libya: Taxonomy, ecology and zoogeographical relation ships. Bull. U. S. Nat. Mus. 275: 1-264, 8 pl.

Reysenbach de Haan, F. W. 1956 De Ceti Au ditu. Schotanus and Jens, Utrecht. $160 \mathrm{pp}$.

Roche, J., and F. Petter 1968 Faits nouveaux concernant trois gerbillides mal connus de Somalie: Ammodillus imbellis (De Winton), Microdillus peeli (De Winton), Monodia juliani (Saint Leger). Monitore Zool. Ital. (N.S.) 2 (suppl.): 181-198.

St. Leger, J. 1931 A key to the families and genera of African rodents. Proc. Zool. Soc. London, 1931: 957-997. 
Sapozhenkov, Yu. F. 1961 a K rasprostraneniy i ekologii barkhannogo kota (Felis margarita) v vostochnoi Turkmenii. Zool. Zhur., 40: 10861089 .

1961b Ob ekologii stepnogo kota (Felis libyca Forst.) v vostochnykh karakumakh. Zool. Zhur., 40: 1585-1586.

1962 Ob ekologii karakala (Felis caracal Mull.) v karakumakh. Zool. Zhur., 41: 1111-1112.

Schaub, S. 1934 Uber einige fossile Simplicidentatten aus China und der Mongolei. Abh. Schw. Pal. Gesel, 54: 100-121.

Schmidt-Nielsen, K. 1964 Desert animals. Clarendon Press, London. 277 pp., 51 figs., 36 tabs.

Schuknecht, H. F. 1960 Neural mechanisms of the Auditory and Vestibular Systems. Chapt. VI. G. L. Rasmussen and W. F. Windle, eds. Thomas, Springfield, pp. 76-90.

Schwentker, V. 1963 The gerbil. A new laboratory animal. Inl. Vet., 6: 5-9.

Setzer, H. W. 1956 Mammals of the AngloEgyptian Sudan. Proc. U. S. Nat. Mus,, 106 : 447--587.

- 1969 A review of the African mice of the genus Desmodilliscus Wettstein, 1916. Univ. Kansas Mus. Nat. Hist., Misc. Publ., 51: 283-288.

Shortridge. G. C. 1934 The mammals of South West Africa. William Heinemann Ltd, London. Vol. 1, 437 pp., 1 fold out map.

Simkin, G. N. 1965 Tipy slukhovykh polostei mlekopitayushchikh v svyazi s osobennostyami ikh obraza zhizni. Zool. Zhur., 44: 1538-1545.

Stebbins, G. L., Jr. 1952 Aridity as a stimulus to plant evolution. Am. Nat., $87: 33-44$.

Tasaki, J., H. Davis and J. P. Legouix 1952 The space-time pattern of the cochlear microphonics (guinea pig), as recorded by differential electrodes. J. Acoust. Soc. America, 24: 502-519.

Tullberg. T. 1899 Ueber daz system der Nagetiere: eine phylogenetische Studie. Reg. Soc. Scí. Upsaliensis, Nova Acta, 18: 1514.

Turkerich, V. G. 1939 Kostnoe vnutrennee i srednee ykho gryzunov srednei azii. $\mathrm{K}$ anatomii organa slukha mlekopitayushchikh. Tr. Sred. Az. Univ., Ser. Biol., 12: 1-116.

Van der Klauw, C. J. 1931 The auditory bulla in some fossil mammals. Bull. Amer. Mus. Nat. Hist., 62: 1-352, 18 figs.

Van Kampen, P. N. 1905 Die Tympanalgegend des Saugetierschades. Morpholog. Jahrbuch., 34: 321-722.

Vial, J. L. 1962 The auditory bulla of Dipodomys deserti (Rodentia) and evidence of its adaptive significance. Rev. Trop., 10:11-17.
Vinogradov, B. S. 1937 Tushkanchiki (Jerboas). Fauna SSSR, Mlekopitayushchie, Zool. Inst. Acad. Nauk SSSR, N. S. 13, 3, 197 pp., 68 figs.

Wassif, K. 1946 Anterior process of the malleus in rodents. Nature, 157:630.

- 1948 Studies on the structure of the auditory ossicles and tympanic bone in Egyptian Insectivora, Chiroptera and Rodentia. Bull. Fouad I Univ. Fac. Sci., 27: 177-213.

1951 The anterior process and the ossification of the malleus in mammals. Science, 113: 486-487.

1957 The development of auditory os sicles and tympanic bone in mammals with special reference to the part played by the anterior process in the ossification of the malleus. Ain Shams Sci. Bull, 2: 259-281, 2 pl.

Webster, D. B. 1960 The morphology and functional significance of the ear of the kangaroo rat, Dipodomys. Ph.D. Thesis, Univ. Microfilms, Inc, Ann Arbor. 135 pp., 37 figs.

1961 The ear apparatus of the kanga roo rat, Dipodomys. Am. J. Anat, 108: 123-148.

1962 A function of the enlarged middie-ear cavities of the kangaroo rat, Dipodomys. Physiol. Zool., 35: 248-255.

Wever, E. G. 1938 The width of the basilar membrane in man. Ann. Otol. Rhinol. Laryngol., 47: 37-47.

1966 Electrical potentials of the cochlea. Physiol. Rev., 46: 102-127.

Wever. E. G., and M. Lawrence 1954 Physiological Acoustics. Princeton Univ. Press, Princeton, pp. 454.

Wisner, A., J. P. Legouix and F. Petter 1954 Etude histologique de loreille d'un rongeur a'bulles tympanique hypertrophies: Meriones crassus. Mammalia, 18: 371-374, 2 figs.

Wood, A. E. 1965 Grades and clades among rodents. Evol., 19: 115-130.

Wright, S. 1940 Breeding structure of popu lations in relation to speciation. Amer. Nat. 74 : $232-248$.

Zahavi, A., and J. Wahrman 1957 The cytotaxonomy, ecology and evolution of the gerbils and jirds of Israel, (Rodentia: Gerbillinae). Manmmalia, 21: 341-380.

Zakhidov, T. Z. 1958 Ecological survey of the vertebrate fauna in the Kyzylkum Desert. Proc. XV Int. Cong. Zool., Sec. 10 Ecology, pp. 773775 .

Zavattari, E. 1938a Significato e funzione delle bulle timpaniche ipertrofiche dei mammiferi sahariani. Rev, Biol. Colon. Rome, 1: 249-259. 1938 b Essai d'une interpretation physiologique de l'hypertrophie des bulles tympaniques des mammiferes sahariens. Mammalia, 2: $173-176$ 


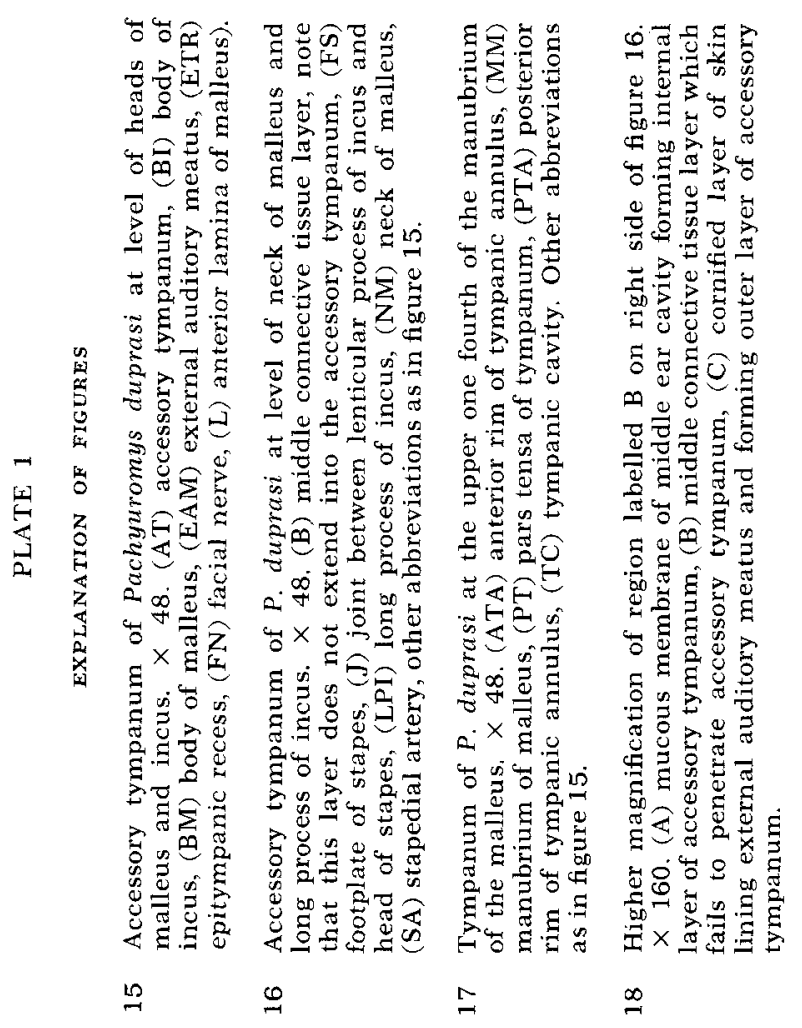



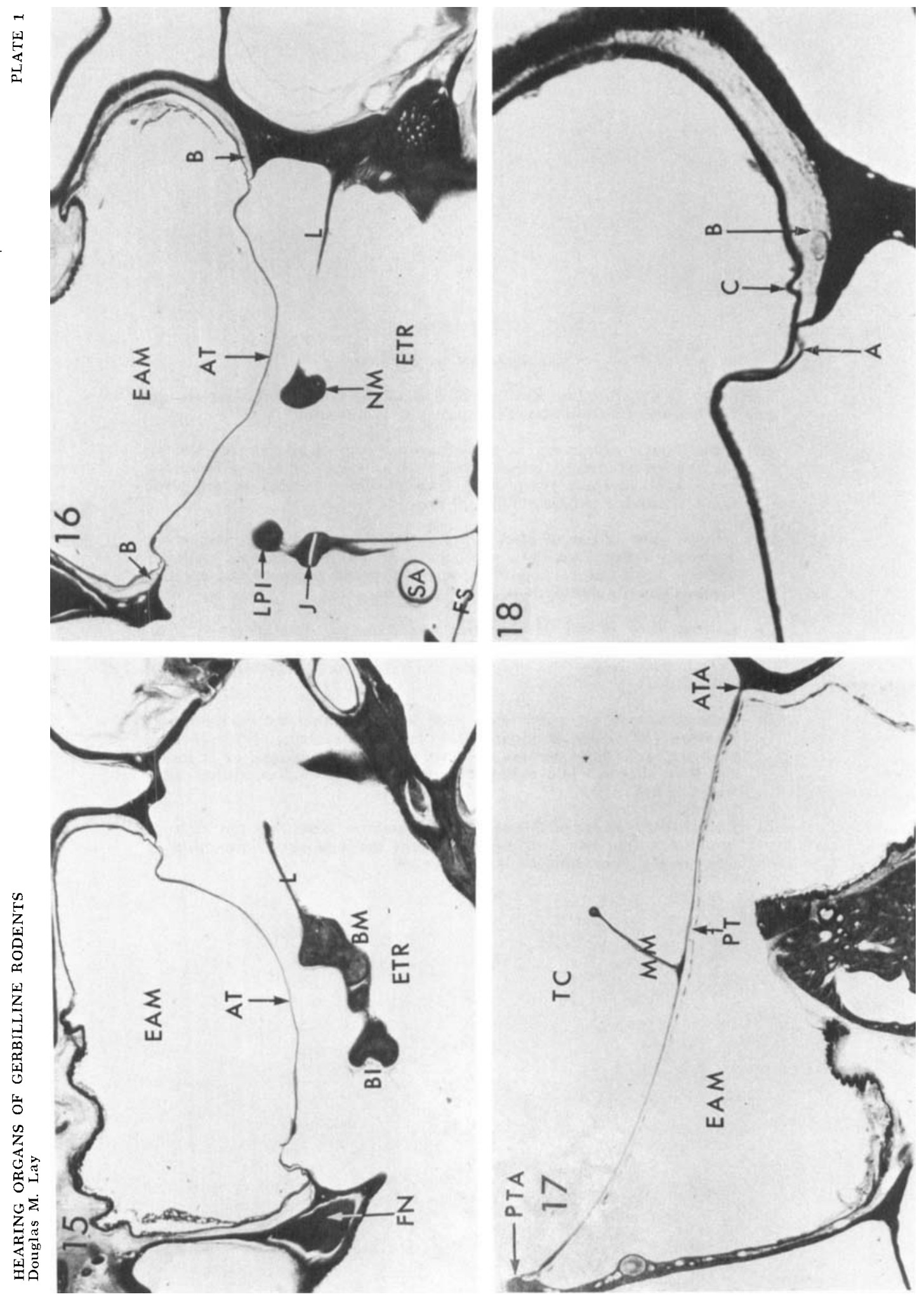


\section{PLATE 2}

\section{EXPLANATION OF FIGURES}

Figures 19-23 illustrate the lateral wall of the epitympanic recess and relative degrees of elaboration of the accessory tympanum.

19 Lateral view of ear region of Taterillus emini, a generalized species lacking an accessory tympanum. (AL) anterior lamina of tympanic bone, (IT) incisura tympanica, (PL) posterior lamina of tympanic bone. White bar at base of figure, $1 \mathrm{~mm}$.

20 Lateral view of ear of Meriones vinogradovi, a species in which the accessory tympanum does not constitute a unit character. (AT) accessory tympanum. Accessory tympanum is confined to anterior lamina. Other abbreviations as in figure 19.

21 Lateral view of ear of Meriones unguiculatus. The accessory tympanum is a unit character of this species. Note degree of enlargement of AT with respect to condition in figure 20. Abbreviations as in figure 19.

22 Lateral view of accessory tympanum in an anesthetized Pachyuromys duprasi. (BI) body of incus, (BM) body of malleus, (NM) neck of malleus, (LPI) long process of incus. Other abbreviations as in figure 19. Note that AT has enlarged considerably beyond condition illustrated in figure 21.

23 Lateral view of ear of Desmodillus auricularis. Note that the incisura tympanica (IT) has no connection with the accessory tympanum in this species. Abbreviations as in figure 19. 

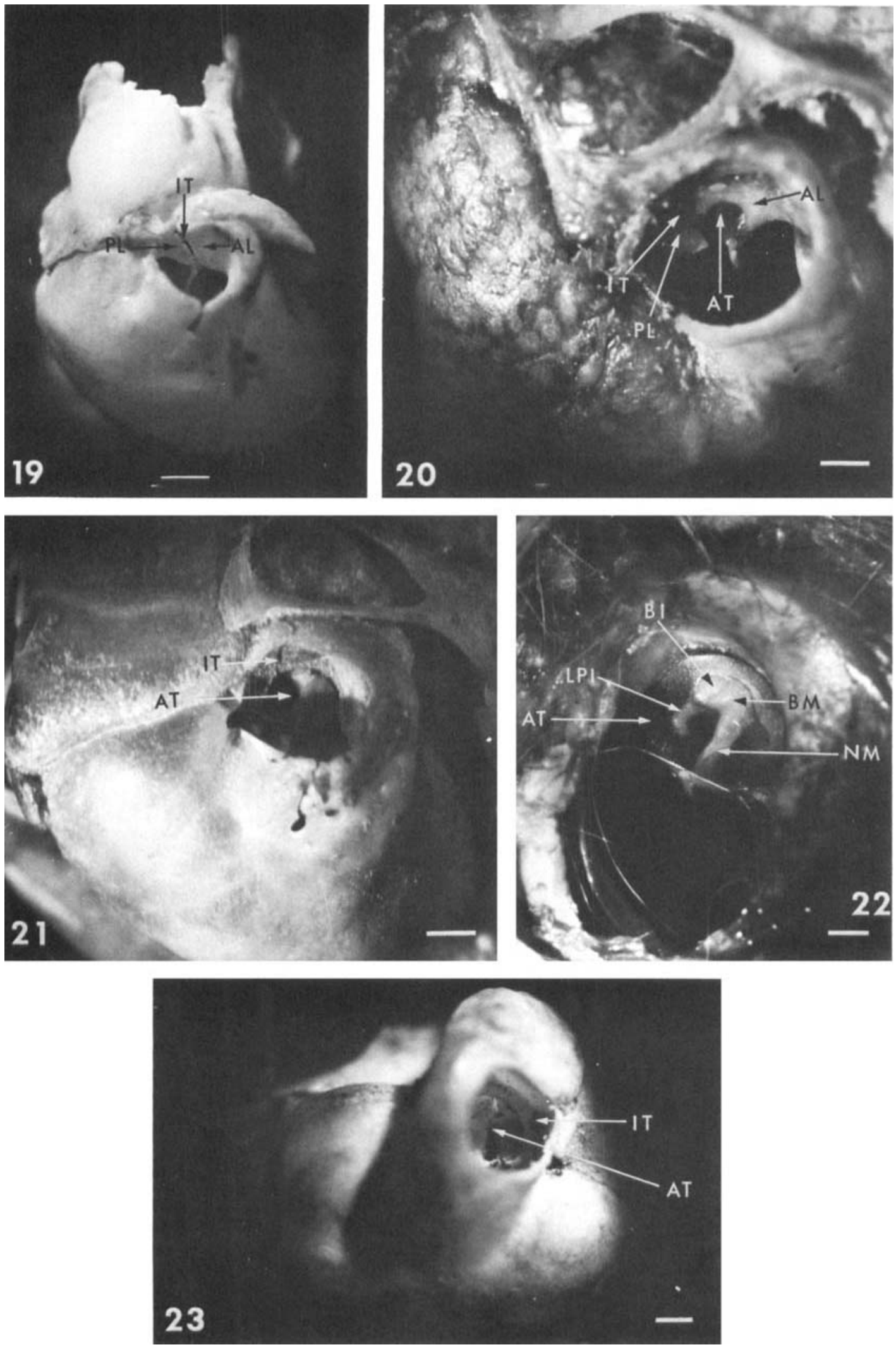
PLATE 3

EXPLANATION OF FIGURES

24 Lateral wall of the epitympanic recess of Allactaga elater (Dipodidae, Allactaginae). All species of this subfamily lack an accessory tympanum. Black arrow points mark the incisura tympanica. (AL) anterior lamina of tympanic bone, (PL) posterior lamina of tympanic bone. White bar lower right corner, $1 \mathrm{~mm}$.

25 Accessory tympanum of Jaculus blanfordi (Dipodidae, Dipodinae). Note the posterior position of the incisura tympanica (IT), the upper part of which remains patent. White dots demarcate suture line between anterior and posterior tympanic laminae. The accessory tympanum (AT) lies anterior to the incisura tympanica. Arrowheads indicate tympanic-mastoid suture line. White bar lower right corner, $1 \mathrm{~mm}$. 

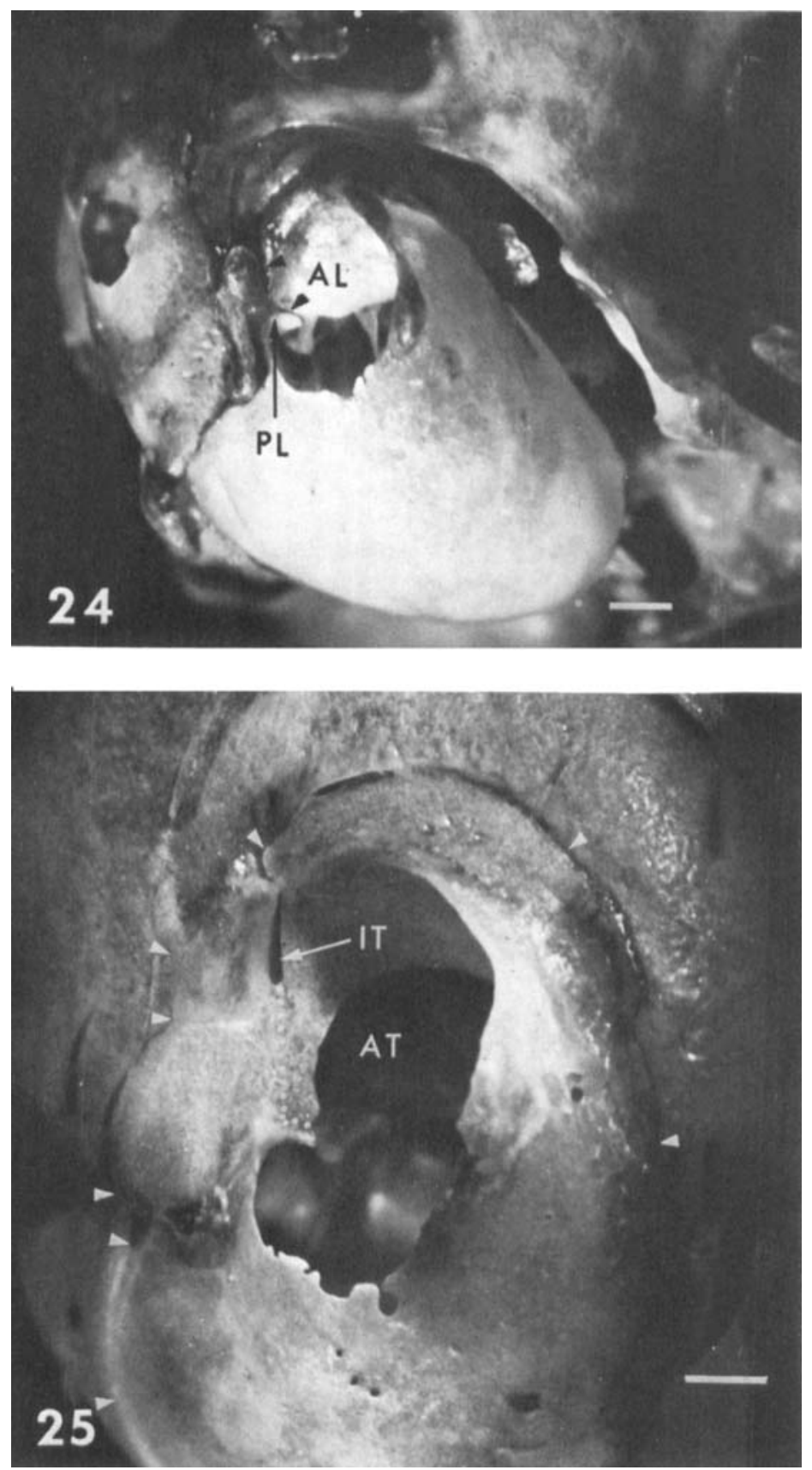


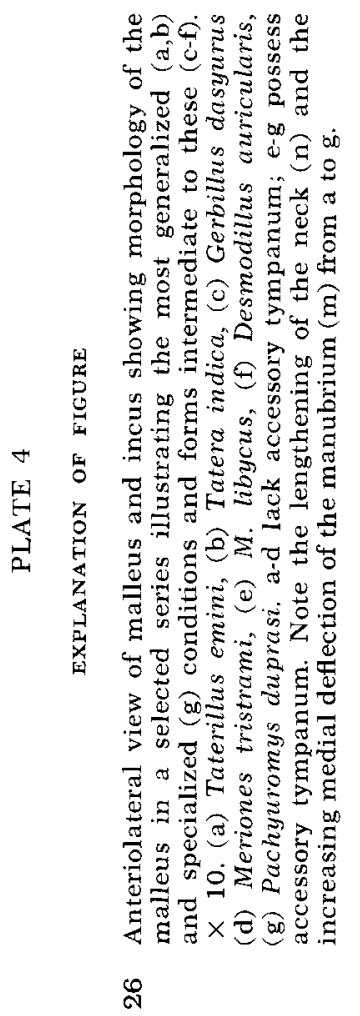

100 

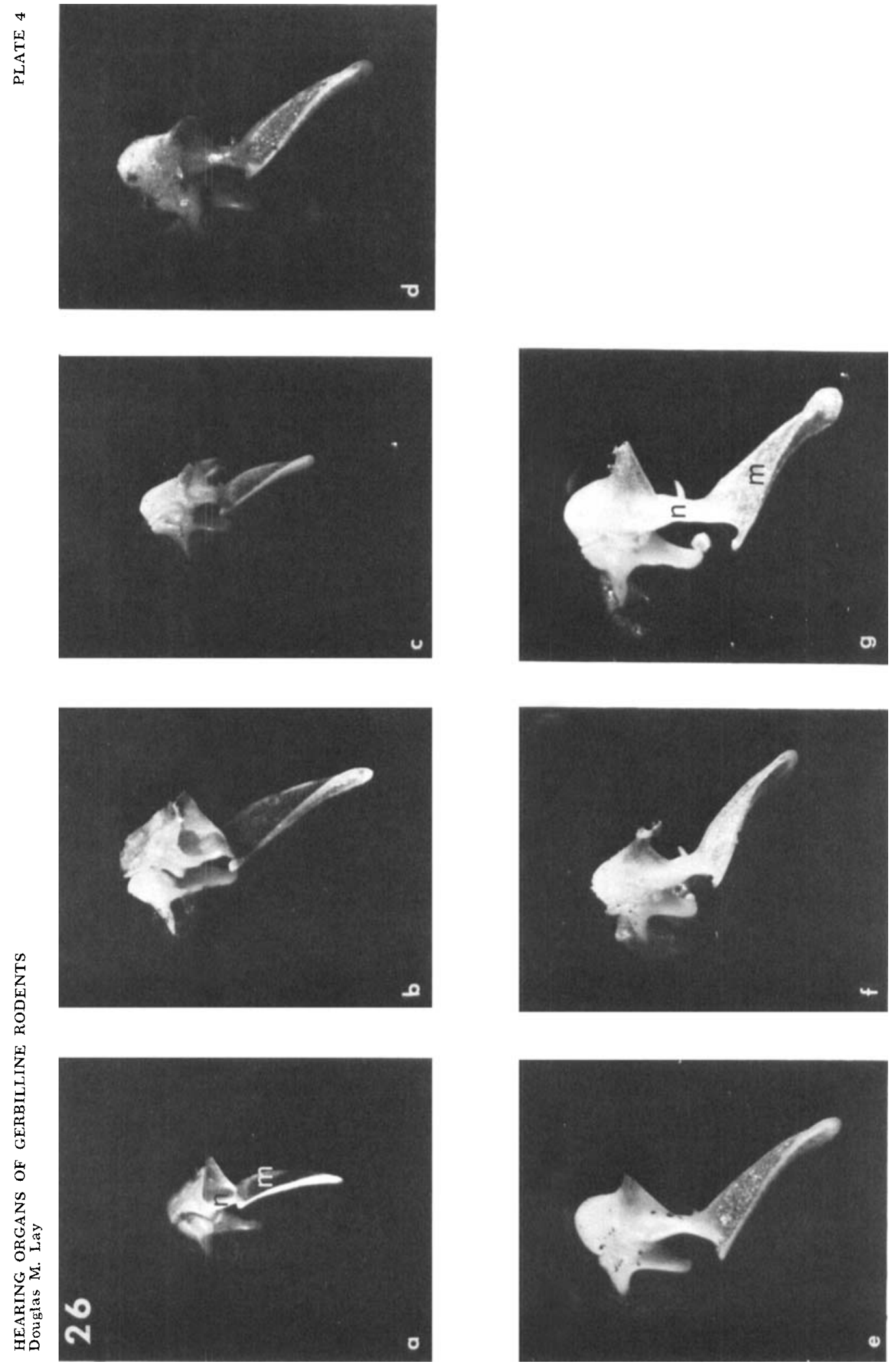
PLATE 5

EXPLANATION OF FIGURES

Morphology of the middle ear ossicles of Pachyuromys duprasi, $\times 10$.

27 Anterolateral view of malleus and incus. Malleus: (BR) processus brevis of manubrium; (L) lamina; (M) caput mallei; (MAN) manubrium; (MU) processus muscularis; (N) neck. Incus: (B) processus brevis; (I) caput inci; (L) processus longus; (LE) processus lenticularis.

28 Stapes: (AC) anterior crus; (F) footplate; (H) head; (PC) posterior crus.

Morphology of the mastoid air chambers of Sekeetamys calurus. The outer walls of the mastoid have been removed; the ventral tympanic bulla remains intact. White bar in lower right corner, $1 \mathrm{~mm}$.

29 Postero-dorsal view. (A) anterior semicircular canal; (AM) anterior mastoid chamber, (B) bony lamina within lateral extent of arc of lateral canal, (EAM) external auditory meatus, (i) head of incus, (IL) posterior inferior lateral chamber, (IM) posterior inferior medial chamber, (L) lateral semicircular canal, (m) head of malleus, (P) posterior semicircular canal, (SL) posterior superior lateral chamber.

30 Antero-medial view. (AMI) accessory inferior medial chamber, (SA) subarcuate fossa, (SM) posterior superior medial chamber. Other abbreviations as in figure 29.

31 Posterior view. Arrowheads mark course of the posterior auricular nerve between laminae of the mastoid and tympanic bones. 

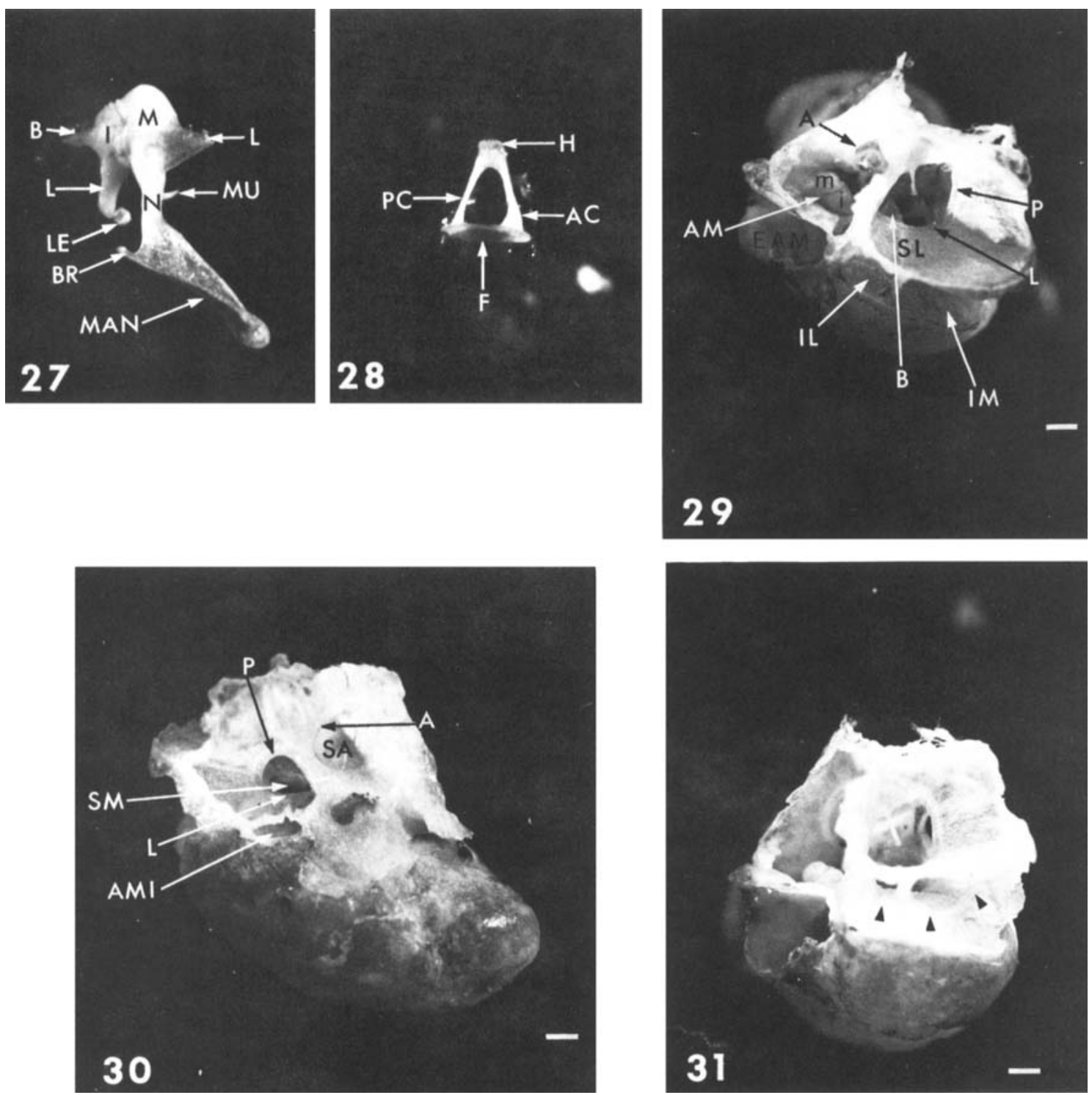


\section{PLATE 6}

EXPLANATION OF FIGURES

The two primary components of the auditory bulla in a specimen of Meriones unguiculatus.

32 Lateral view, (A) petromastoid, (B) tympanic.

33 Medial view. Abbreviations as in figure 32. 

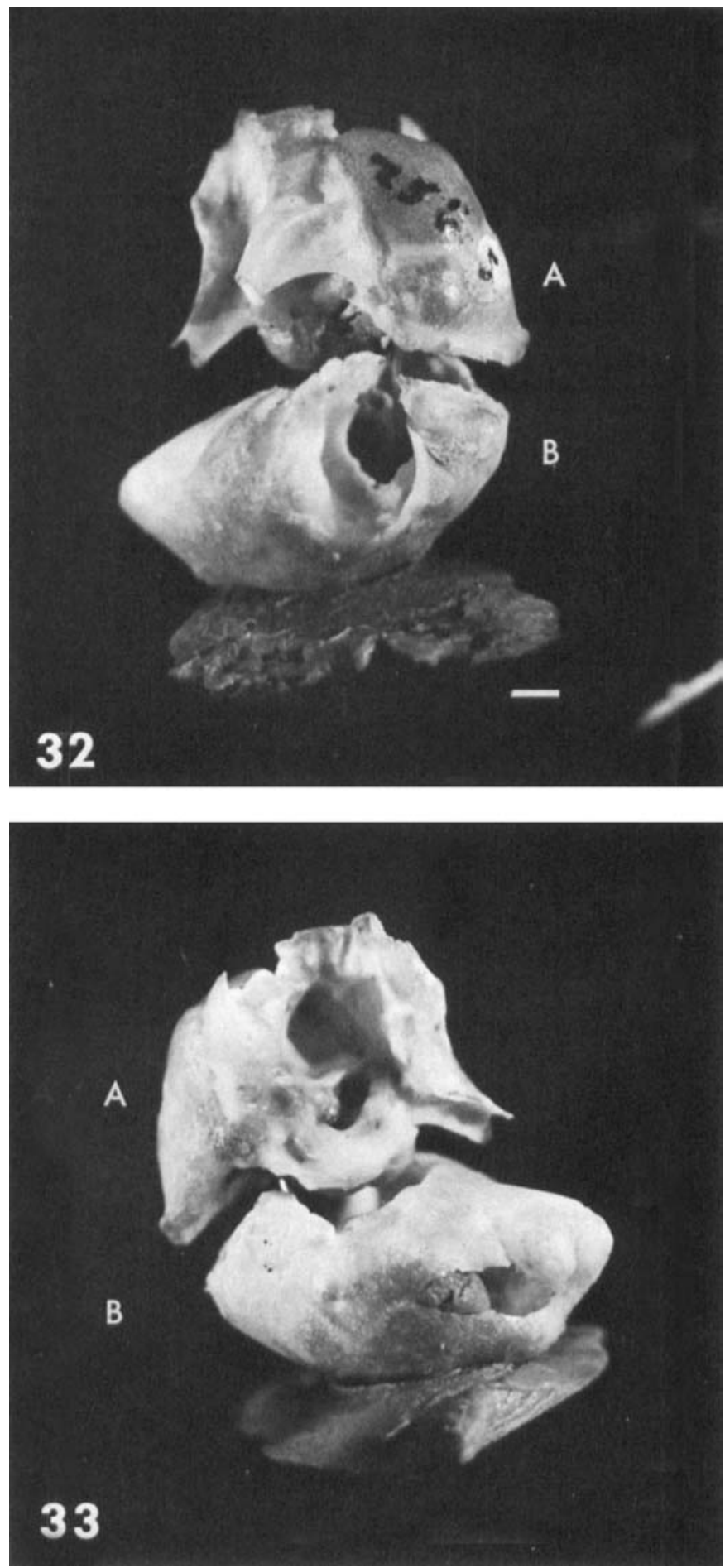
PLATE 7

EXPLANATION OF FIGURES

Internal mastoid morphology of Rattus rattus. White bar in lower right corner, $1 \mathrm{~mm}$.

34 Lateral view of bulla in which parts of lateral outer wall have been removed to display internal morphology of mastoid. Neither mastoid chamber opens into the tympanic chamber. Note that the large subarcuate fossa fills virtually all of the posterior mastoid. (AM) anterior mastoid chamber, (EAM) external auditory meatus, (PM) posterior mastoid chamber.

35 Postero-lateral view. All of the lateral wall and spongy bone have been removed. (AC) anterior canal, (LC) lateral canal, (PC) posterior canal, (SA) subarcuate fossa.

Internal morphology of the posterior mastoid of Gerbillurus paeba. White bar, $1 \mathrm{~mm}$.

36 Posterior view of mastoid with outer layer removed. An incipient posterior inferior chamber (PI) is present below the lateral canal but unconnected to the posterior superior chamber (PS). (SA) subarcuate fossa, (PC) posterior canal.

37 Postero-lateral view of same specimen. Note the medial extent of the posterior inferior chamber (PI). Anteriorly, the posterior superior chamber opens into the anterior chamber over the head of the incus (i). No septae separate these chambers.

38 Postero-superior view of anterior and posterior mastoid chambers of Desmodillus auricularis. Note the partial septum separating the two chambers. The superior part (S) is continuous with the anterior canal (A) and the inferior portion (I) lies upon the crista facialis (CF). (AM) anterior mastoid chamber, (L) lateral canal. 

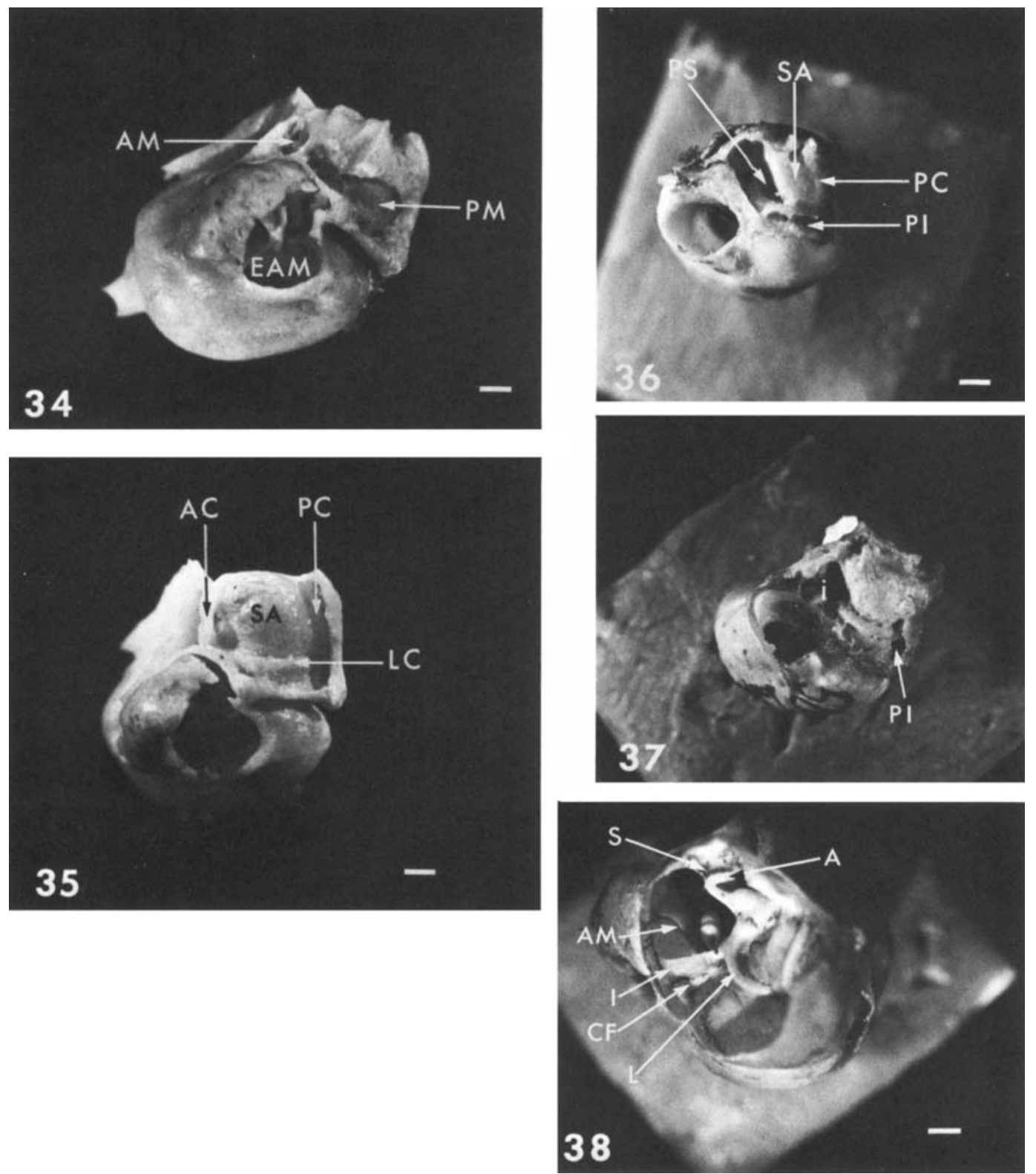
PLATE 8

EXPLANATION OF FIGURES

Fenestra between tympanic and common inferior chamber in Meriones crassus. The opening (horizontal white line) is of equal dimensions in populations from Iran and Egypt. Bulla volume of the Egyptian sample averages $2.1 \times$ that of the Iranian sample. White bar, $1 \mathrm{~mm}$.

39 Posterior view of Iranian specimen with outer wall removed. (PAN) posterior auriculax nerve, (RW) round window of cochlea, black arrowheads denote mastoid component overlying tympanic component (white arrowheads) at tympanic-mastoid juncture.

40 Posterior view of Egyptian specimen with outer wall removed. Compare the width of the tympanic-mastoid juncture shelf (black line) with that typical of the Iranian specimens. This larger structure probably serves as a strengthening beam for the greatly enlarged bulla. (CI) common inferior posterior chamber, (TA) posterior arm of tympanic annulus.

Examples of generalized species with large and specialized species with small subarcuate fossae. White bar, $1 \mathrm{~mm}$.

41 Antero-medial view of petrous temporal bone of Tatera indica. (IAM) internal auditory meatus, (SA) subarcuate fossa, (TC) tentorium cerebelli, black arrowheads mark anterior canal.

42 Antero-medial view of petrous temporal bone of Rhombomys opimus. Compare with figure 41 . 

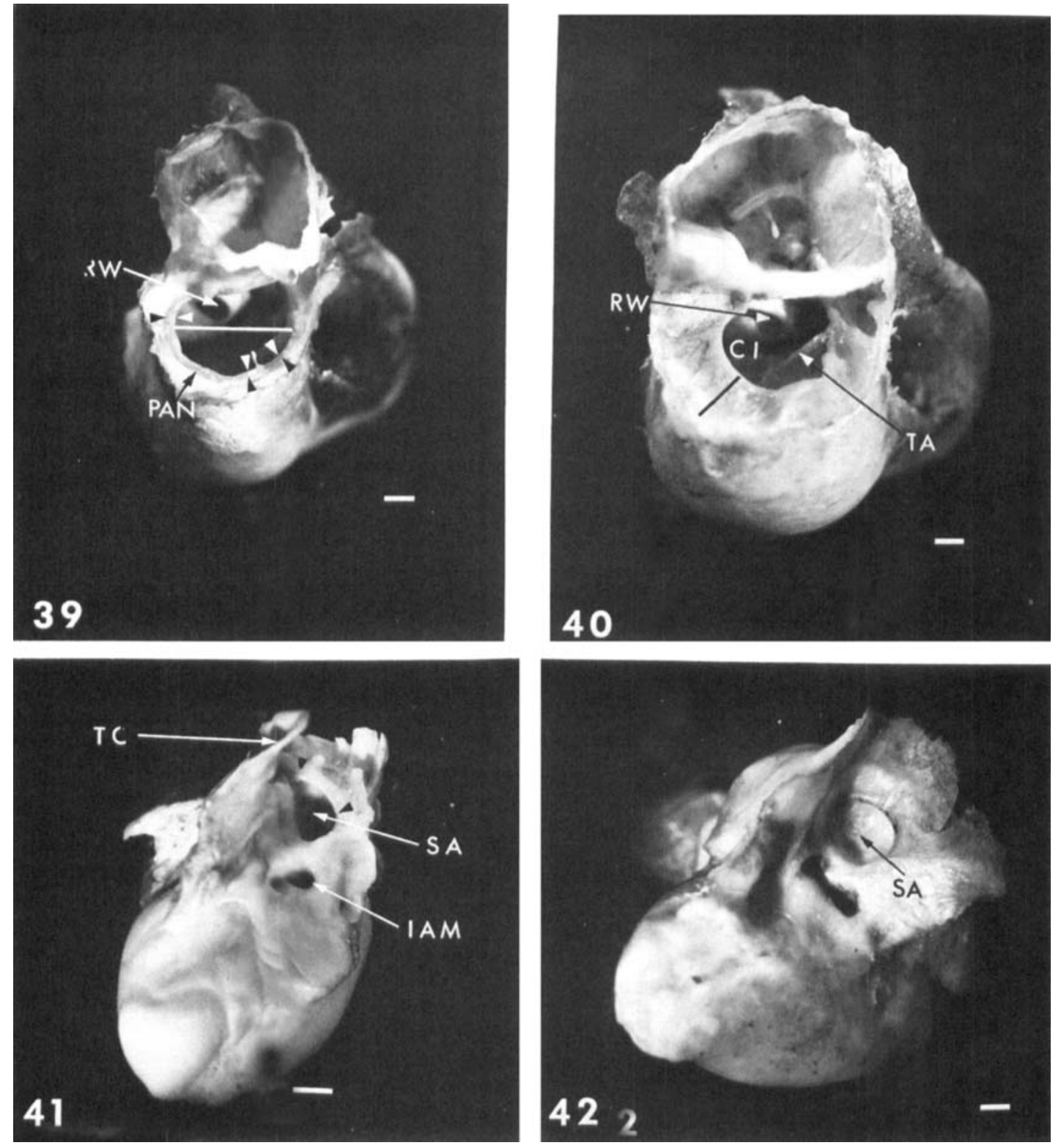


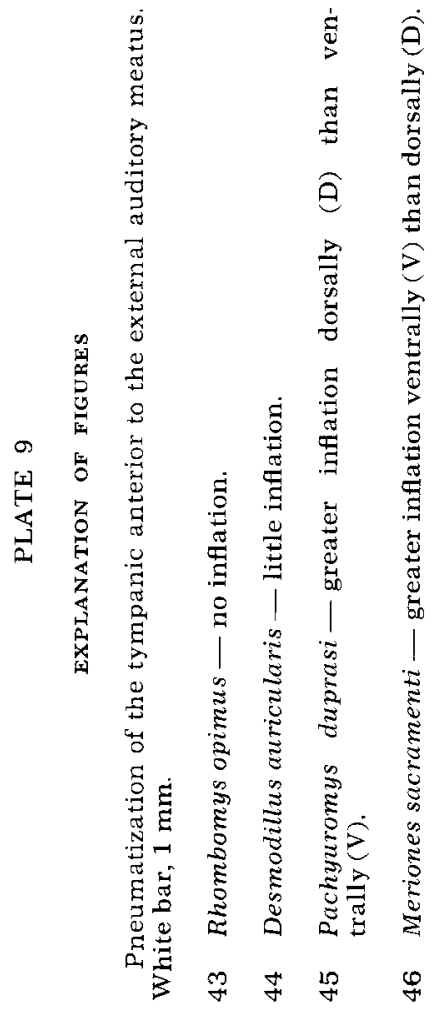


0
5
5
5
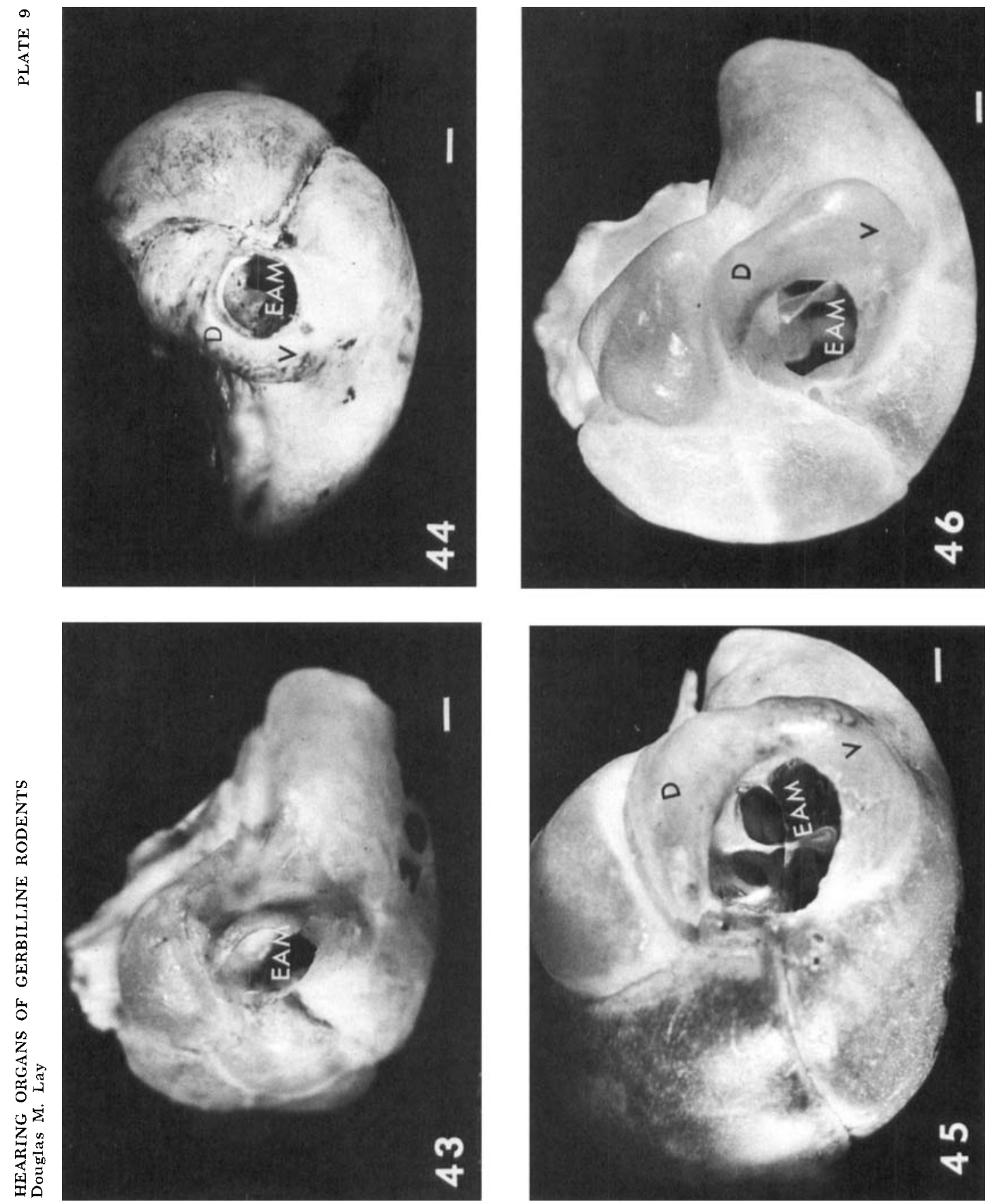
PLATE 10

EXPLANATION OF FIGURES

The brace of the tympanic annulus. White bar, $1 \mathrm{~mm}$.

47 Lateral view of tympanic annulus of Meriones crassus as seen with lateral wall of tympanic cut away. (A) anterior arm of modified $\mathrm{T}$ brace, (B) base of modified $\mathrm{T}$ brace, (F) V-shaped floor of external auditory meatus, $(P)$ posterior arm of modified $T$ brace, (X) lamina separating tympanic and posterior mastoid chambers, arrowheads mark the tympanic annulus.

48 Medial view of annulus of $M$. shawi in bisected bulla. Abbreviations as in figure 47 .

Second half-turn of organ of Corti of Pachyuromys duprasi. $\times 1720$.

49 (C) Claudius' cells, (D) Dieters' cells, (H) Hensen cells, (HM) hyaline mass within pars pectinata of basilar membrane, (P) pillar cells, $(R)$ Reisner's membrane, (RL) reticular lamina, (SL) spiral ligament, (SM) scala media, (ST) scala tympani, (SV, black) scala vestibuli, (SV, white) stria vascularis, circles indicate outer hair cells, arrowheads mark the basilar membrane. 

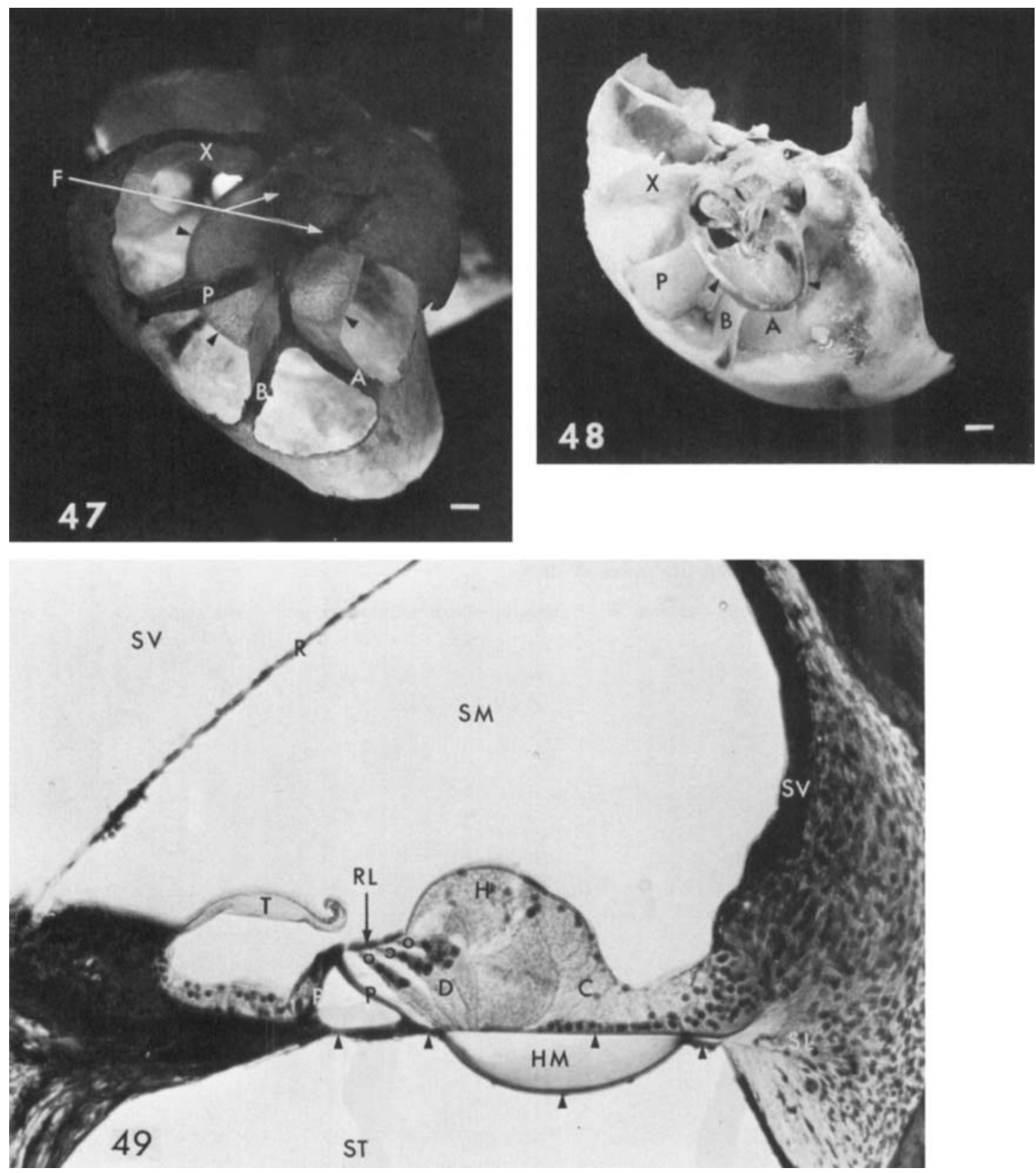
PLATE 11

EXPLANATION OF FIGURES

Cochlear half turns one to six. $\times 600$.

50 Tatera indica, hyaline mass absent.

51 Sekeetamys calurus, small hyaline mass present in half turns two to five. 
50
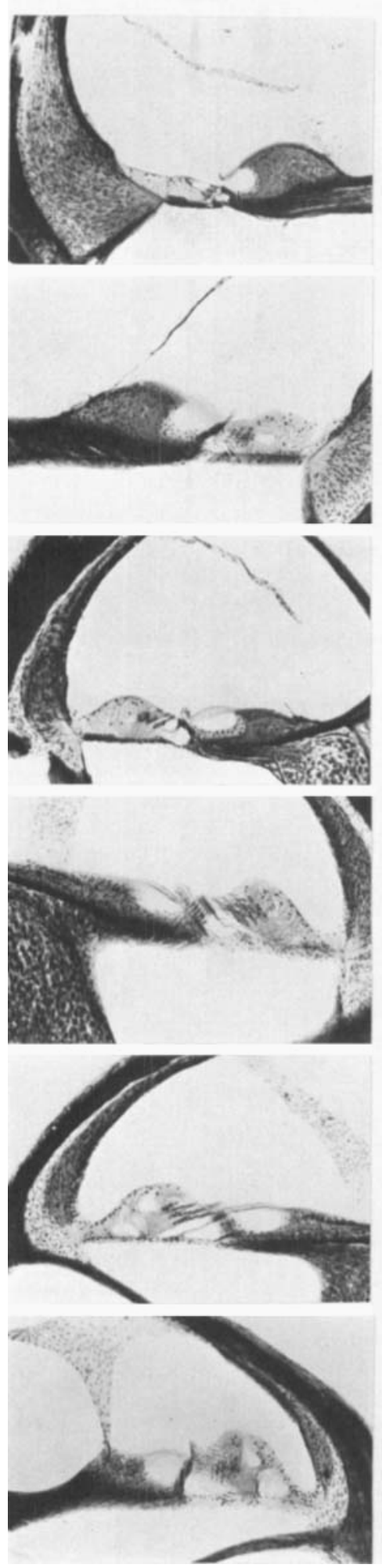

51

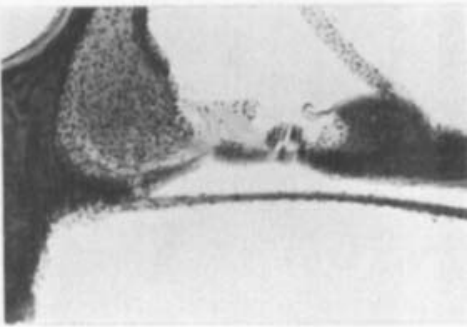

2

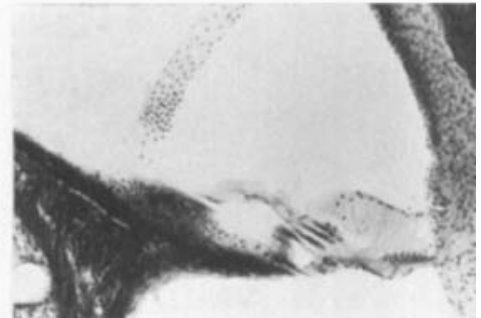

3

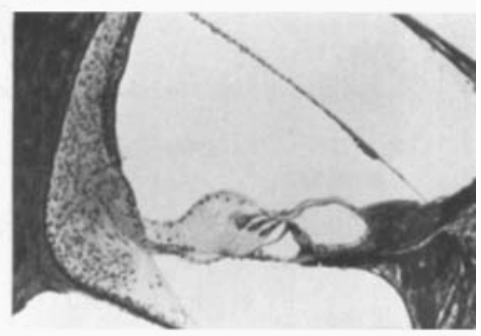

4

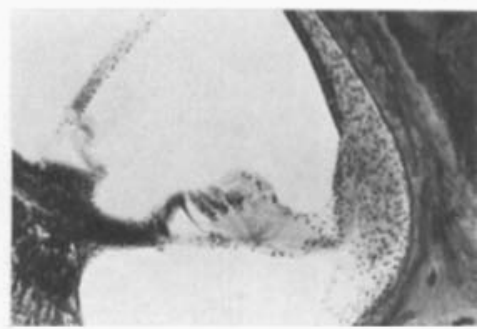

5

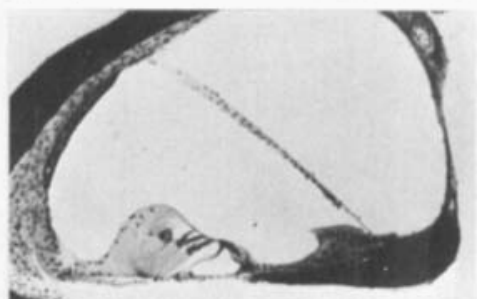

6

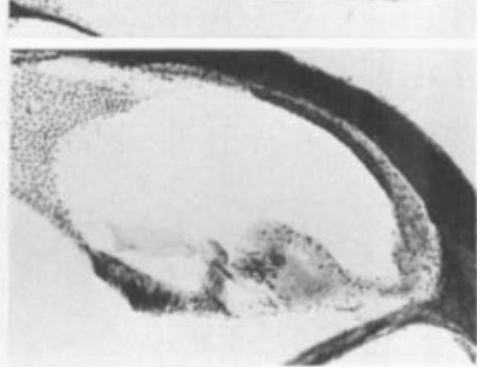


PLATE 12

EXPLANATION OF FIGURES

Cochlear half turns one to six. $\times 600$.

52 Gerbillus gerbillus, small hyaline mass present in half turns two to four.

53 Meriones persicus, moderate hyaline mass present in half turns two to six. 
52
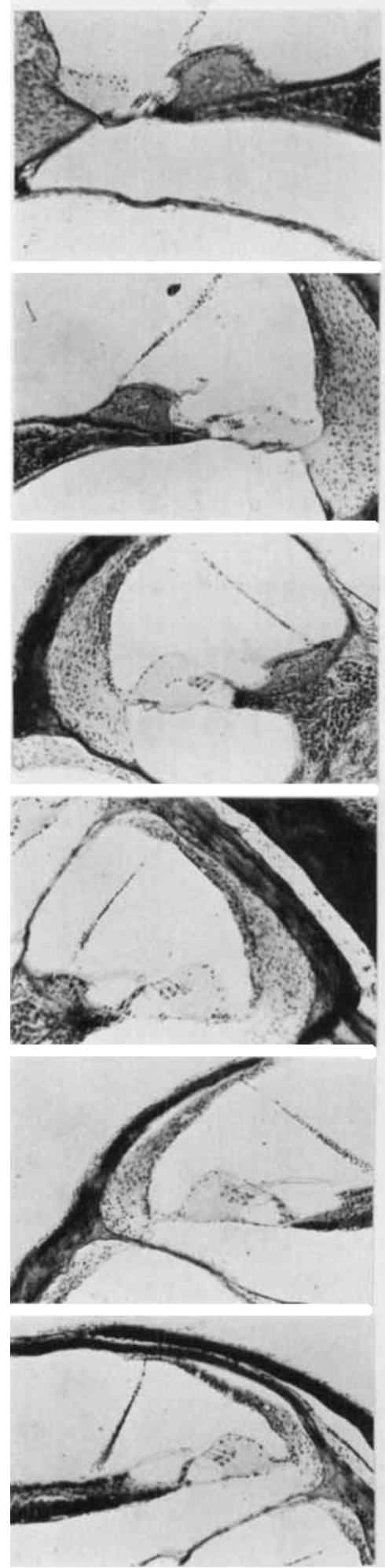

53

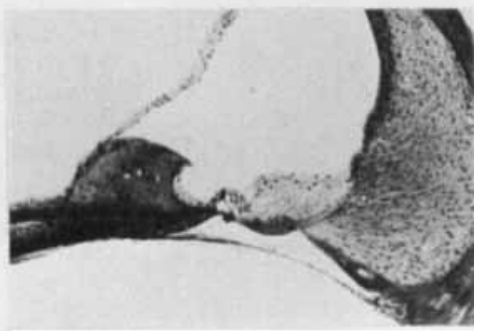

2

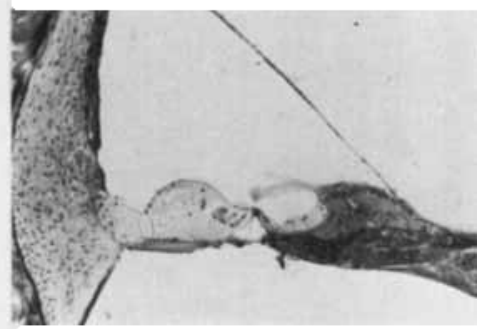

3

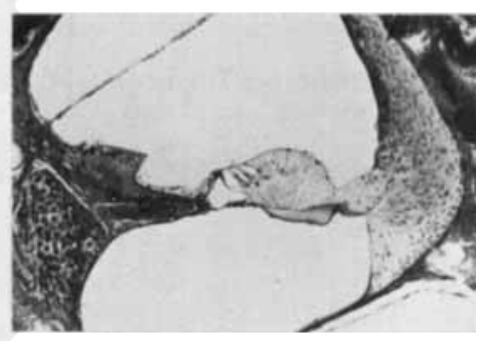

4

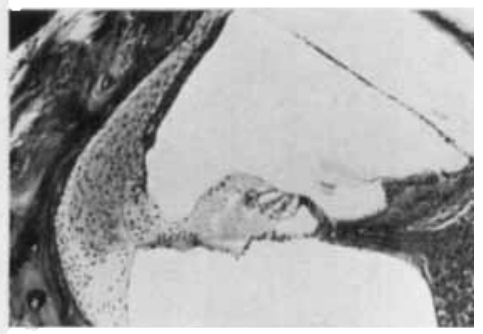

5

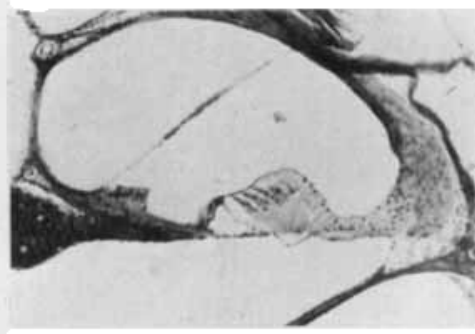

6

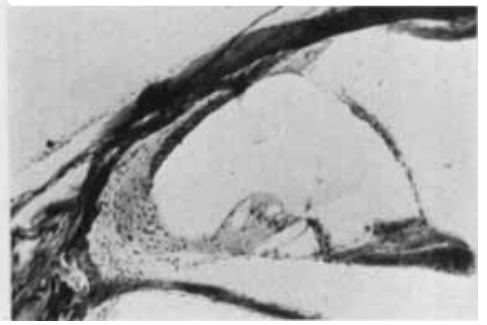


PLATE 13

\section{EXPLANATION OF FIGURES}

54 Meriones tristrami, well developed hyaline mass present in half turns two to five. $\times 600$.

55 Meriones crassus, well developed hyaline mass present in half turns two to six. $\times 600$. 
54
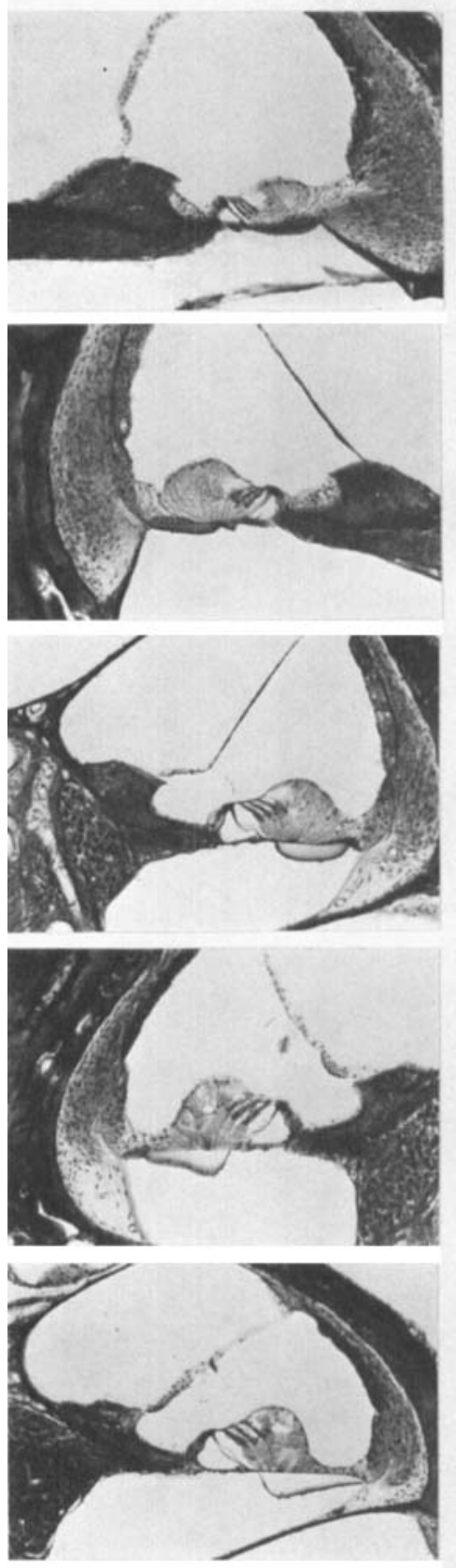

55
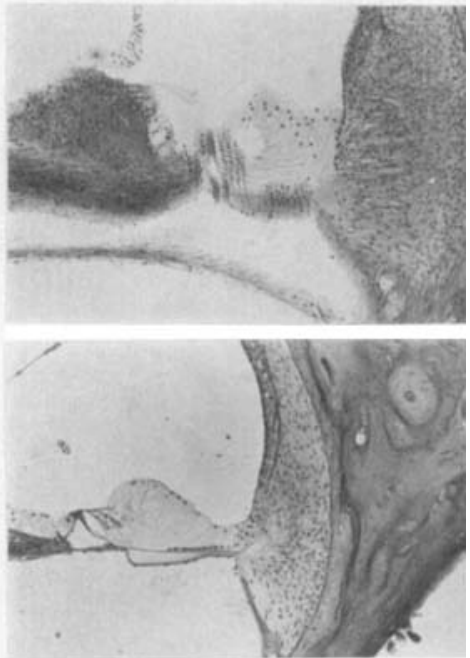

3
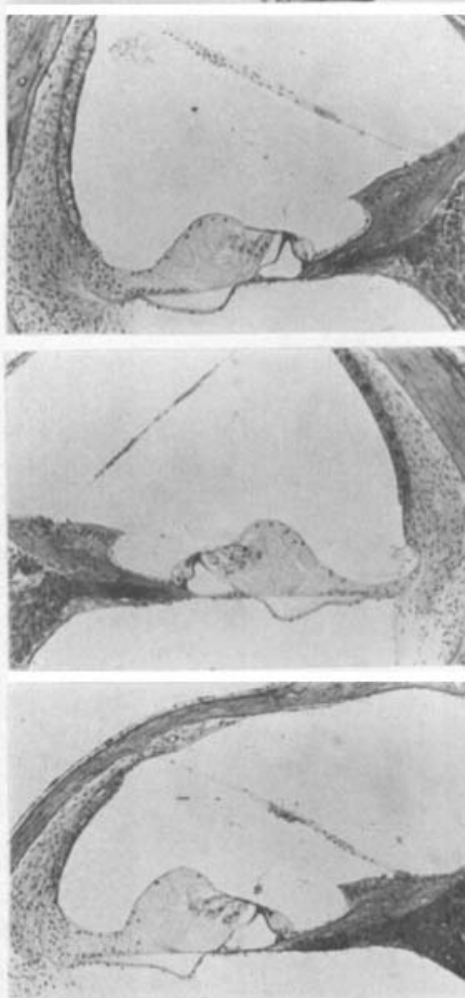

5

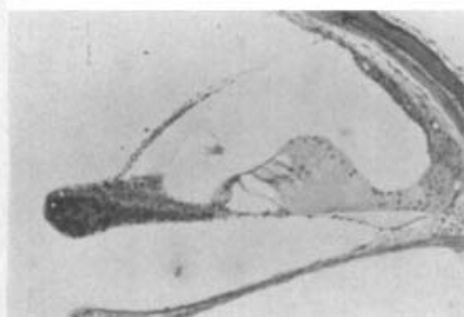




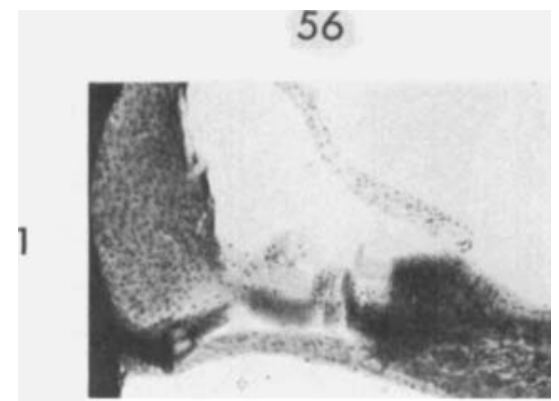

2

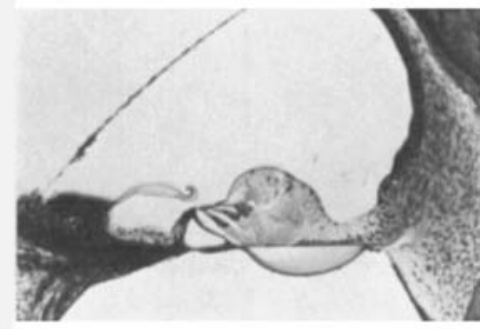

3
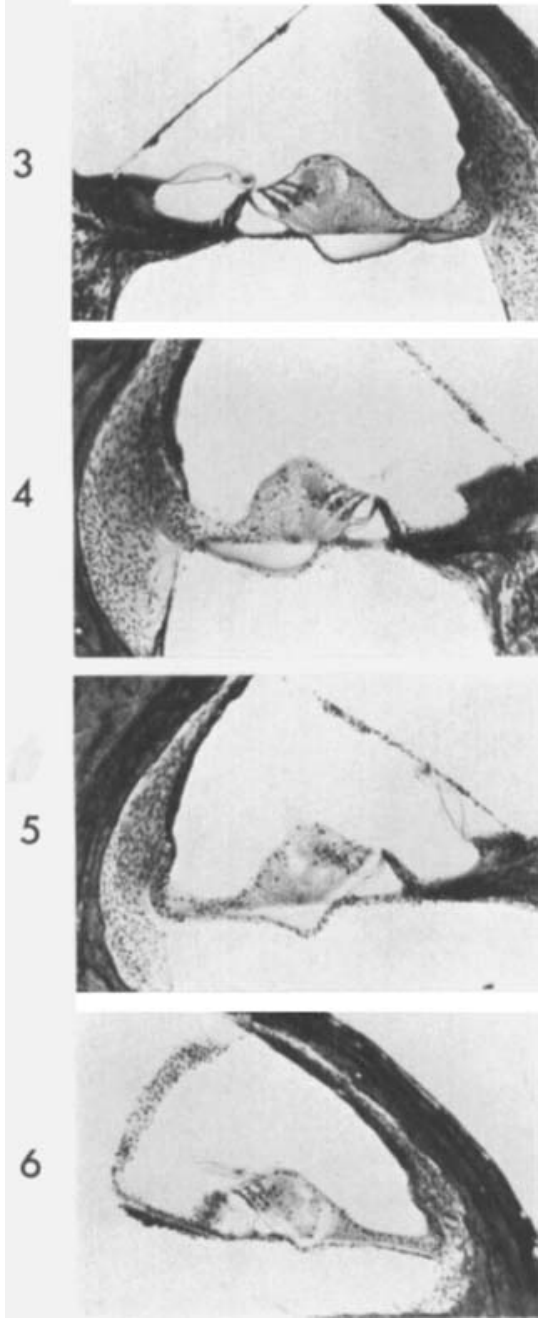

EXPLANATION OF FIGURE

56 Pachyuromys duprasi, well developed hyaline mass present in half turns two to six. $\times 600$. 